\title{
WestVirginiaUniversity
}

THE RESEARCH REPOSITORY @ WVU

Graduate Theses, Dissertations, and Problem Reports

2010

\section{Mercury removal from coal by leaching with sulfur dioxide}

\author{
Poornima Chateker \\ West Virginia University
}

Follow this and additional works at: https://researchrepository.wvu.edu/etd

\section{Recommended Citation}

Chateker, Poornima, "Mercury removal from coal by leaching with sulfur dioxide" (2010). Graduate Theses, Dissertations, and Problem Reports. 2171.

https://researchrepository.wvu.edu/etd/2171

This Thesis is protected by copyright and/or related rights. It has been brought to you by the The Research Repository @ WVU with permission from the rights-holder(s). You are free to use this Thesis in any way that is permitted by the copyright and related rights legislation that applies to your use. For other uses you must obtain permission from the rights-holder(s) directly, unless additional rights are indicated by a Creative Commons license in the record and/ or on the work itself. This Thesis has been accepted for inclusion in WVU Graduate Theses, Dissertations, and Problem Reports collection by an authorized administrator of The Research Repository @ WVU. For more information, please contact researchrepository@mail.wvu.edu. 


\title{
MERCURY REMOVAL FROM COAL BY LEACHING WITH SULFUR DIOXIDE
}

\section{POORNIMA CHATEKER}

\author{
Thesis Submitted to the \\ College of Engineering and Mineral Resources \\ at West Virginia University \\ in partial fulfillment of the requirements \\ for the degree of
}

Master of Science

in

\section{Chemical Engineering}

\section{Committee:}

Eung Ha Cho, Ph.D., Chair

Ray Y.K. Yang, Ph.D.

John W Zondlo, Ph.D.

\section{Department of Chemical Engineering \\ Morgantown, West Virginia 2010}

Keywords: Leaching, Mercury removal, Pyrite dissolution, Electrode potential, Oxidizing agents, Sulfur Dioxide, Solubility. 


\section{ABSTRACT \\ MERCURY REMOVAL FROM COAL BY LEACHING WITH SULFUR DIOXIDE}

\section{$\underline{\text { Poornima Chateker }}$}

Mercury from coal-fired utilities has been identified as one of the most hazardous air pollutants and the greatest potential public health concern. Furthermore, it has a tendency to bio-accumulate in the food chain. Mercury is present in coal in concentration well below 1 ppm; however, the large tonnages of coal consumed for electric power generation represent a significant source of mercury vapor entering the environment. There are various technologies available to control the emission of mercury from coal-fired power plants. Among them activated carbon injection into the flue gas stream has been studied for many years and is considered to be the "standard technology" at this time to control the mercury emissions from flue gas. In this research, it is proposed to develop a diverse technology beyond the "standard technology" of activated carbon injection. This technology is based on pre-combustion treatment of solid coal to remove its mercury content by a unique leaching method using $\mathrm{SO}_{2}$ and $\mathrm{O}_{2}$. The overall objective of this study is to explore this new technology and determine its technical feasibility to be used for a commercial process. The minute amounts of mercury in Pittsburgh No.8 Coal (0.177 ppm) and Illinoi No.6 Coal (0.216 ppm) was removed by flowing a gas stream containing 10\% oxygen and $1000 \mathrm{ppm}$ sulfur dioxide into a coal slurry at $30 \mathrm{ml} / \mathrm{s}$. A total of $50 \mathrm{~g}$ of $35 \times 65$ mesh coal was leached every time in $500 \mathrm{ml}$ solution for 3 hours. The variables were temperature $\left(50\right.$ to $\left.80^{\circ} \mathrm{C}\right)$, initial solution $\mathrm{pH}(1.5-5.7)$, Sulfur dioxide and oxygen gas concentrations. It was found that the mercury removal percentages increased with increase in temperature and decrease in $\mathrm{pH}$. Removal percentages of as high as 92.09 were achieved in Pittsburgh No.8 coal where as percentage removals of about 99.98\% were achieved in Illinoi No.6 Coal. The pyrite removal percentages were much lower than those of mercury. Mercury removal was high enough to consider the application of this technology to a commercial process. 
To my Father Ashok Rao Chateker and my Brother Kuldeep Chateker 


\section{ACKNOWLEDGEMENTS}

This Research study was possible with the help of many people who shared their valuable time, expertise and opinions. I would like to express my sincere appreciation and gratitude to them.

It is difficult to overstate my gratitude to my supervisor, Dr. Eung Ha Cho. With his enthusiasm, his inspiration, and his great efforts to explain things clearly and simply, he helped to make this research a great success. Throughout my thesis-writing period, he provided encouragement, sound advice, good teaching, good company, and lots of good ideas. I would have been lost without him.

I acknowledge and express my gratitude to my committee members Dr.Ray Y.K. Yang and Dr.John W. Zondlo, for their enthusiastic supervision and great assistance during this project. The patience and support provided by them is also highly appreciated.

I also take this opportunity to thank all the Faculty and staff members of the Chemical Engineering Department at West Virginia University.

Above all, I would like to thank my mother, Kalpana Chateker. She bore me, raised me, taught me, supported me, and loved me. I cannot ask for more from my mother.

I'm also very much grateful to my best friend Naveen K Bogum for helping me get through the difficult times, and for all the emotional and moral support, entertainment, and caring he provided.

Finally, I would like thank the Center for Advanced Separation Technologies (CAST), NETL/DOE for financial support under grant CR-19147-A-4929231, which made this project possible. 


\section{Table of Contents}

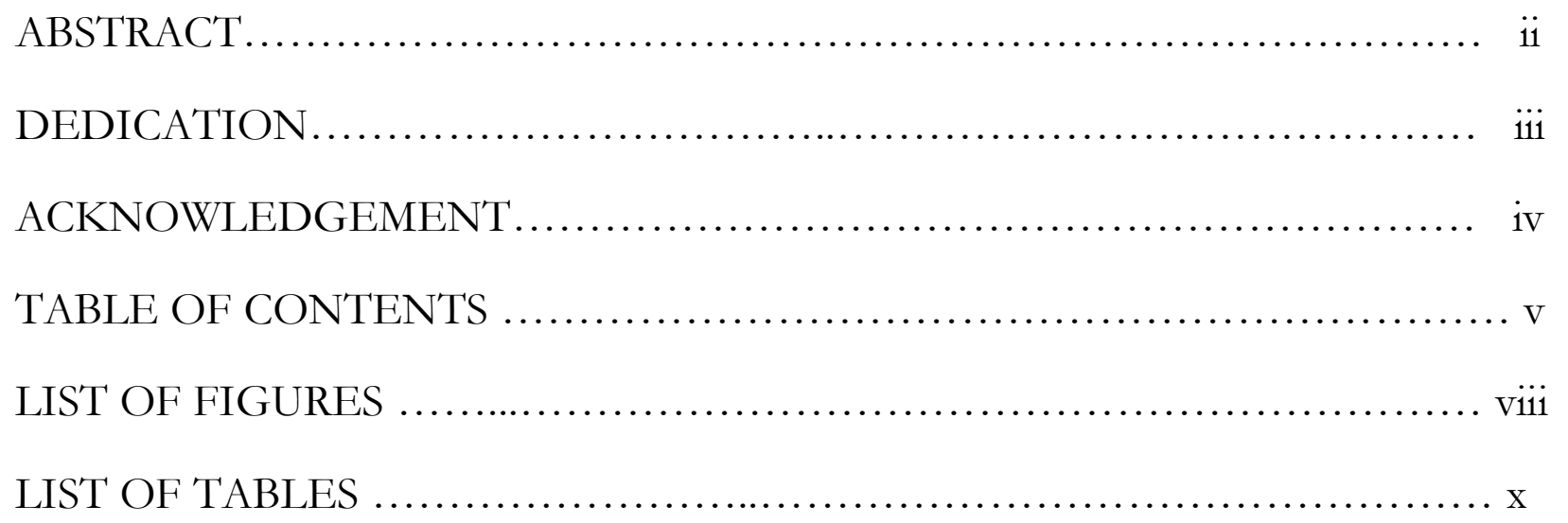

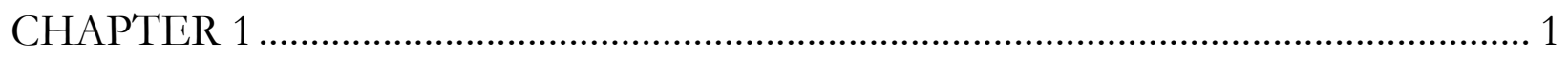

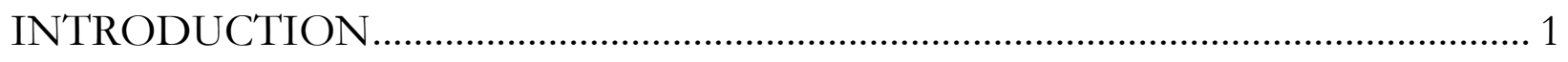

1.1 Background ................................................................................................... 1

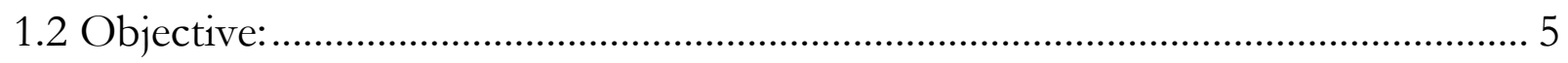

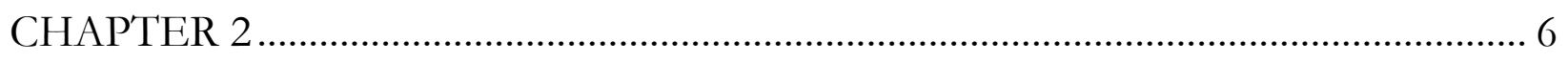

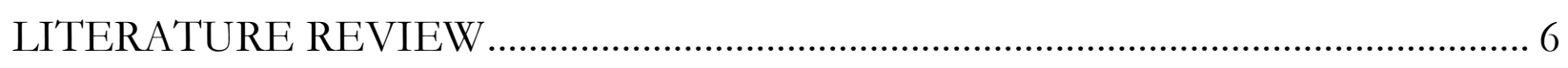

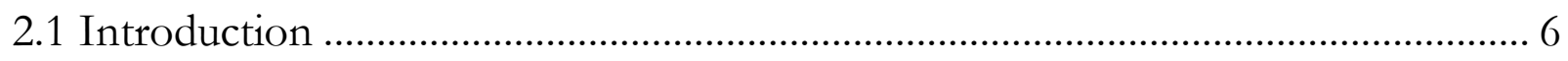

2.1.1 Mercury from Coal-Fired Power Plants and its Impacts ............................. 7

2.1.2 Technologies available to Control Mercury Emissions ................................ 8

2.2 Sulfur dioxide and its solubility: ................................................................... 10

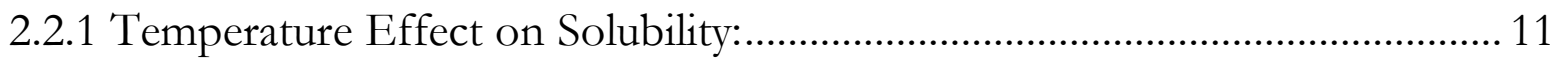

2.2.2 pH Effect on Solubility: .......................................................................... 13

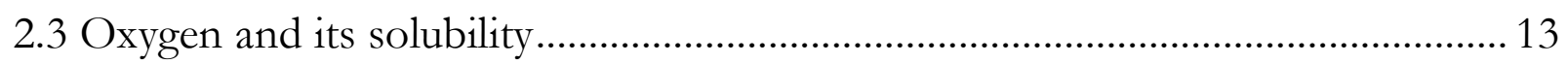

2.3.1 Temperature Effect on Solubility:............................................................. 14 


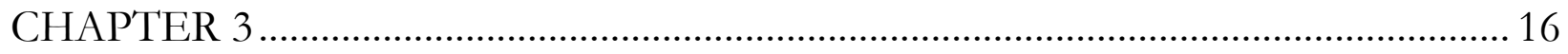

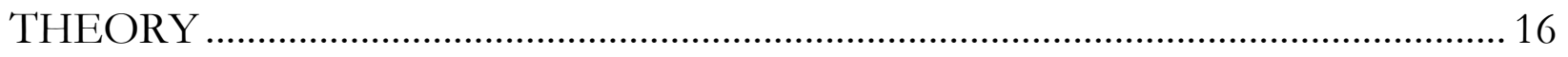

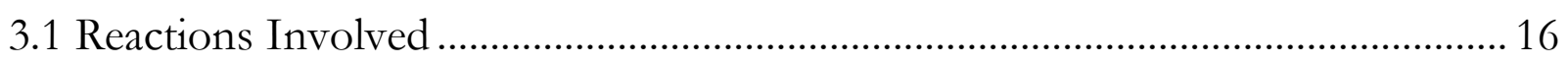

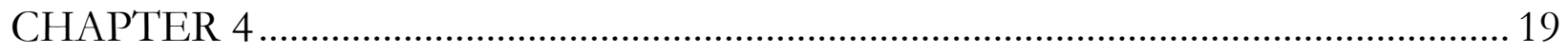

SAMPLE PREPARATION AND ANALYSIS …………….................................... 19

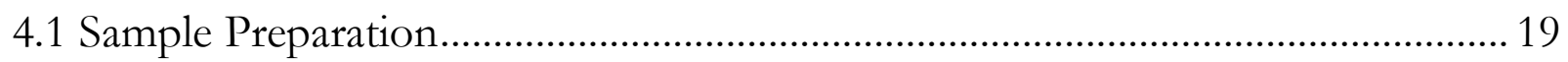

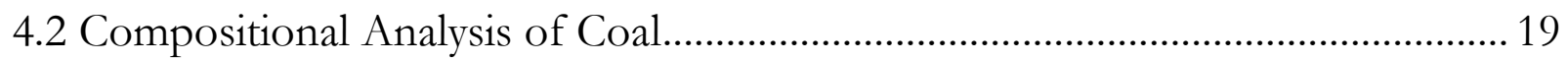

4.2.1 Analysis of Pyritic and Non Pyritic Iron: ........................................................ 19

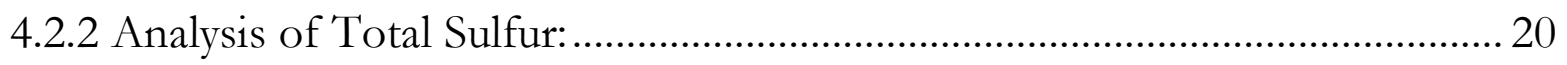

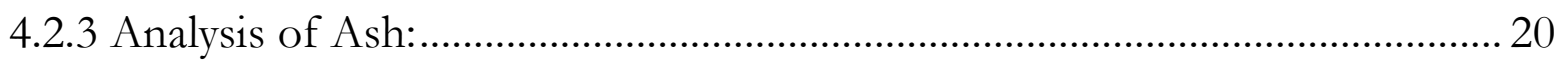

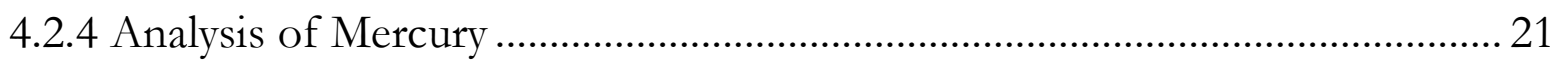

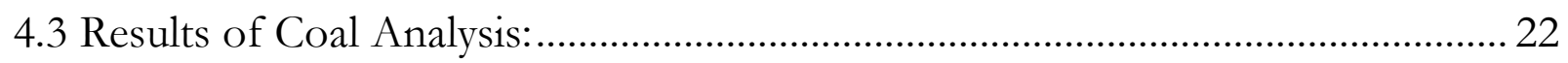

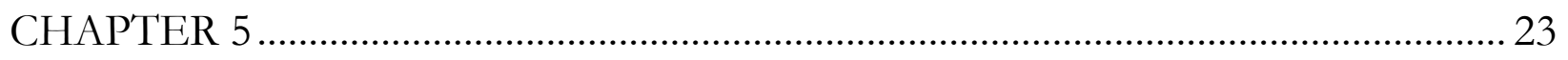

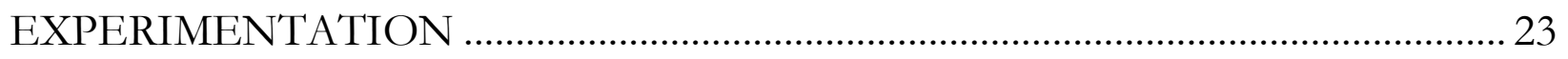

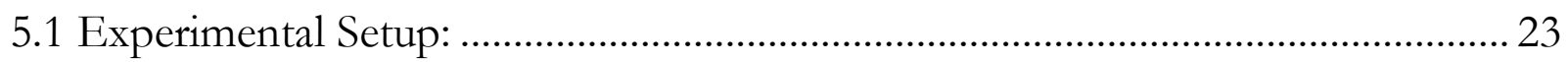

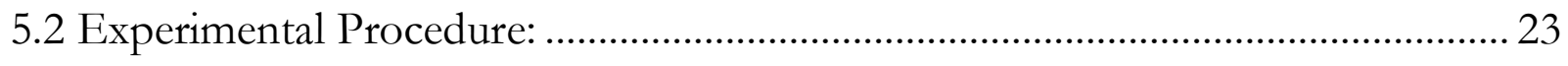

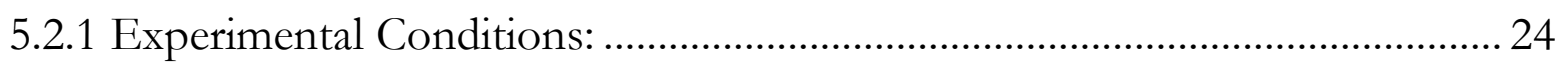

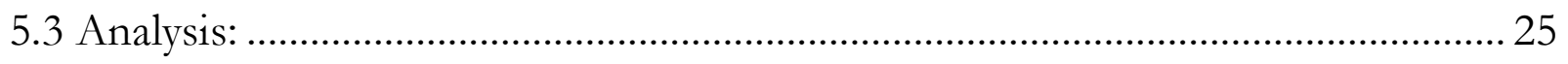

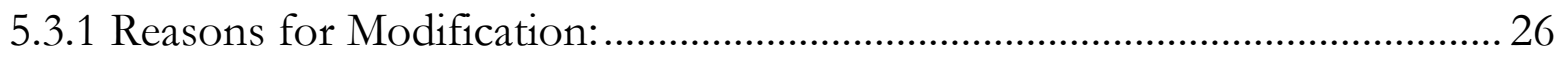

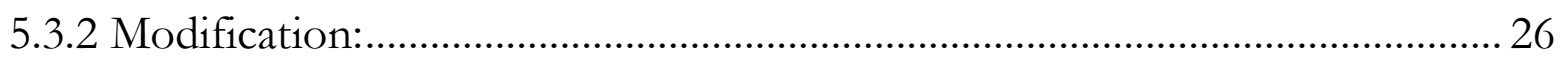

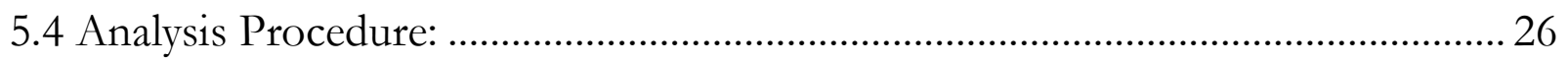

5.5 Material balance for mercury: ............................................................................ 27

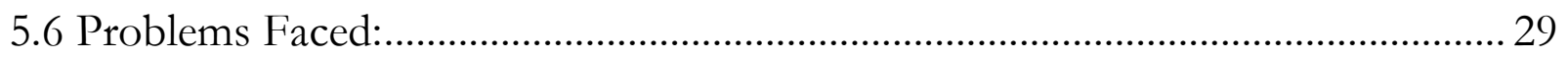




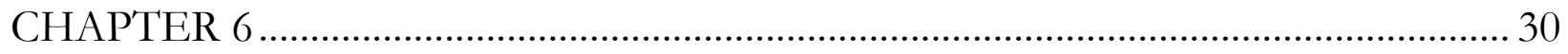

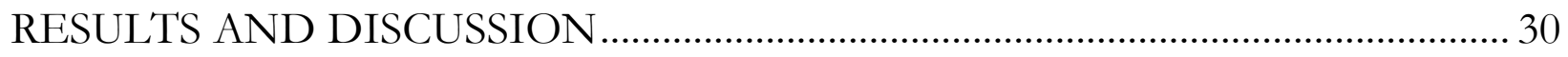

6.1 Temperature Effect for Pittsburgh No.8 Coal:......................................................... 30

6.2 pH Effect on Pittsburgh No.8 Coal: ...................................................................... 32

$6.3 \mathrm{SO}_{2}$ Concentration Effect for Pittsburgh No.8 Coal: ............................................. 34

6.4 $\mathrm{O}_{2}$ Effect Results for Pittsburgh No.8 Coal: ....................................................... 35

6.5 Leaching without Gas for Pittsburgh No.8 Coal:................................................... 36

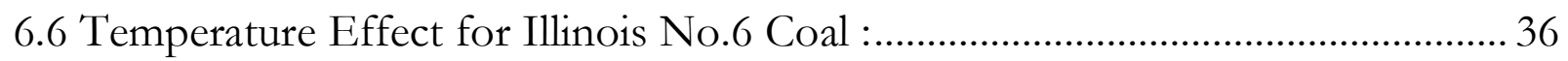

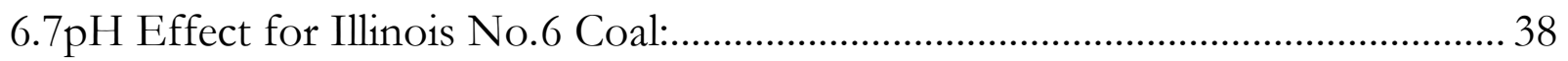

6.8 No Gas Leaching for Illinois No.6 Coal.............................................................. 40

6.8.1 No Gas Temperature Effect for Illinois No.6 Coal : ....................................... 40

6.8.2 No Gas pH Effect for Illinois No.6 Coal: ........................................................ 41

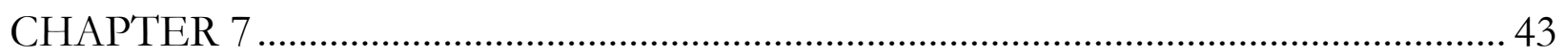

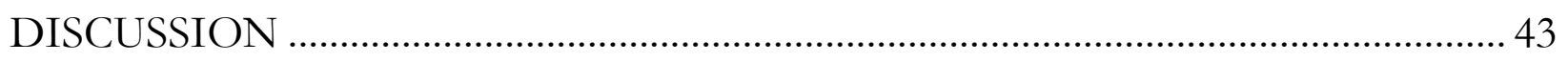

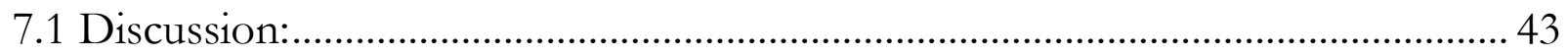

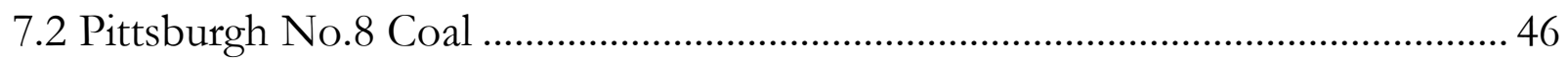

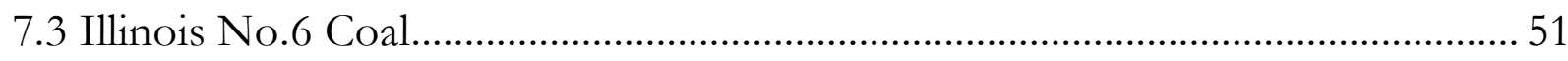

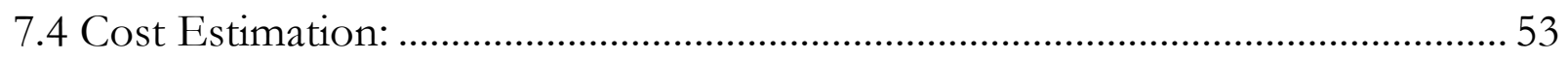

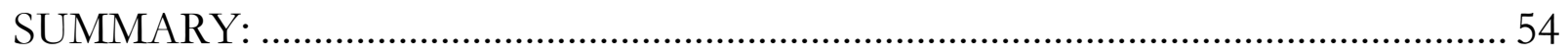

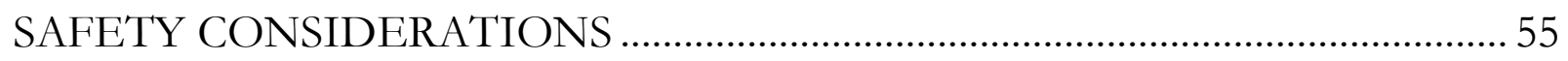

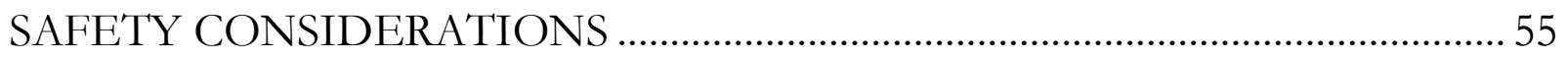

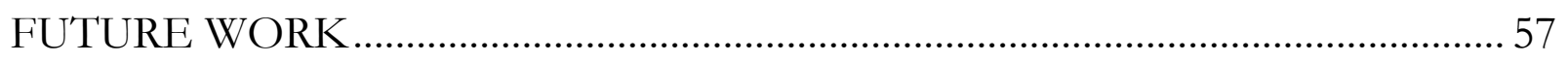

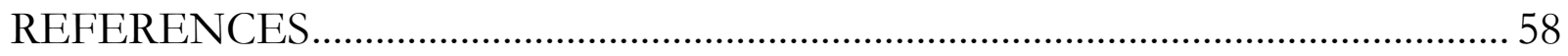




\section{List of Figures}

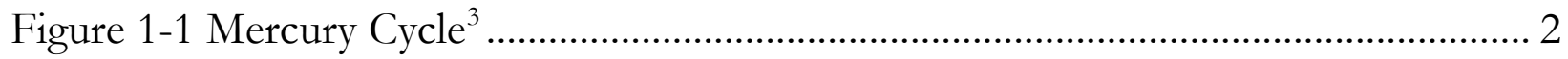

Figure 2-1 Sources of Human Made Mercury in United States ${ }^{8}$...................................... 6

Figure 2-2 Mercury from Power Plants to Human Beings ${ }^{9}$ ……...................................... 8

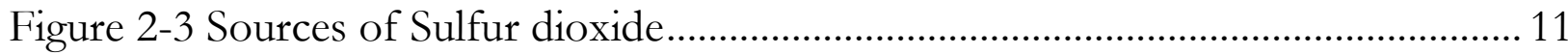

Figure 2-4 Henry's law solubility curve for $\mathrm{SO}_{2}-\mathrm{H}_{2} \mathrm{O}^{27}$................................................. 12

Figure 2-5 Solubility curve for oxygen showing that the solubility decreases with

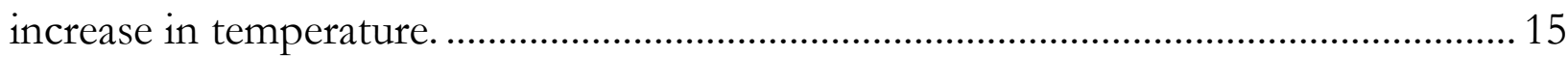

Figure 5-1 Experimental Setup for the leaching of Mercury from coal using $\mathrm{SO}_{2}$ and

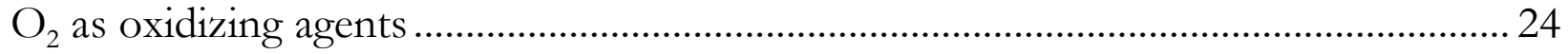

Figure 5-2 Atomic Absorption Unit (Perkin Elmer Model \#2380) ................................ 25

Figure 5-3 Calibration curve of Absorbance VS Concentration for mercury standards

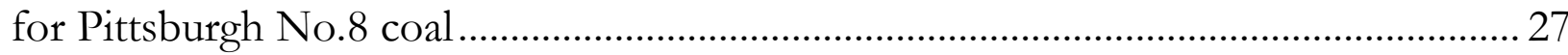

Figure 6-1 Percentage removals of pyrite at $\mathrm{pH} 5.7$ and varying temperatures for

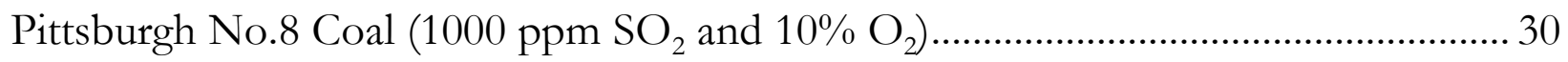

Figure 6-2 Percentage removals of Mercury at $\mathrm{pH} 5.7$ and varying temperatures for Pittsburgh No.8 Coal (1000 ppm SO $\mathrm{SO}_{2}$ and $\left.10 \% \mathrm{O}_{2}\right)$ )................................................. 31

Figure 6-3 Percentage removals of Pyrite at $70.5^{\circ} \mathrm{C}$ and at varying $\mathrm{pH}$ values for Pittsburgh No.8 Coal (1000 ppm SO $\mathrm{S}_{2}$ and 10\% $\left.\mathrm{O}_{2}\right)$ ).................................................... 32

Figure 6-4 Percentage removals of Mercury at $70.5^{\circ} \mathrm{C}$ and at varying $\mathrm{pH}$ values for Pittsburgh No.8 Coal $\left(1000\right.$ ppm SO$~_{2}$ and 10\% $\left.\mathrm{O}_{2}\right)$ )................................................. 33

Figure 6-5 Percentage removals of Mercury at $70.5^{\circ} \mathrm{C}, \mathrm{pH} 5.7$ and varying

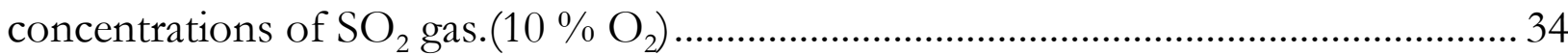

Figure 6-6 Percentage removals of Mercury at $70.5^{\circ} \mathrm{C}$, pH 5.7 and varying concentrations of $\mathrm{O}_{2}$ gas.(1000 $\mathrm{ppm} \mathrm{SO}_{2}$ ) 35 
Figure 6-7 Percentage removals of Pyrite at $\mathrm{pH} 5.7$ and varying temperatures for

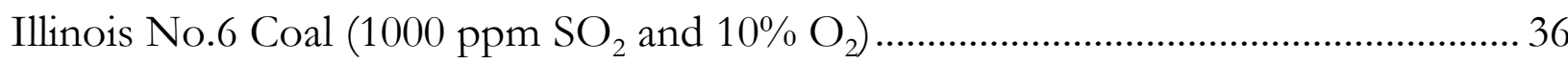

Figure 6-8 Percentage removals of Mercury at $\mathrm{pH} 5.7$ and varying temperatures for Illinois No.6 Coal (1000 ppm SO $\mathrm{S}_{2}$ and 10\% $\left.\mathrm{O}_{2}\right)$.......................................................... 37

Figure 6-9 Percentage removals of Pyrite at $70.5^{\circ} \mathrm{C}$ and at varying $\mathrm{pH}$ values for

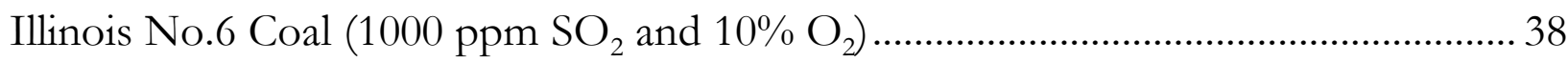

Figure 6-10 Percentage removals of Mercury at $70.5^{\circ} \mathrm{C}$ and at varying $\mathrm{pH}$ values for Illinois No.6 Coal (1000 ppm $\mathrm{SO}_{2}$ and $10 \% \mathrm{O}_{2}$ ).......... 39

Figure 6-11 Percentage removals of Mercury at $\mathrm{pH} 1.25$ and at varying temperatures and no gas for Illinois No.6 Coal

Figure 6-12 Percentage removals of Mercury at $70.5^{\circ} \mathrm{C}$ and at different $\mathrm{pH}$ values and

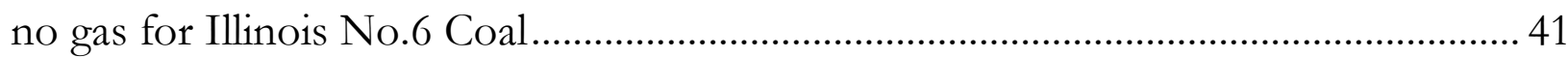

Figure 7-1 Coal particle of radius $\mathrm{r}_{0}$ showing Reaction Zone ${ }^{14}$..................................... 43

Figure 7-2 Plot of [1-(1-F) 1/3] VS time at various temperatures for pyrite removal for

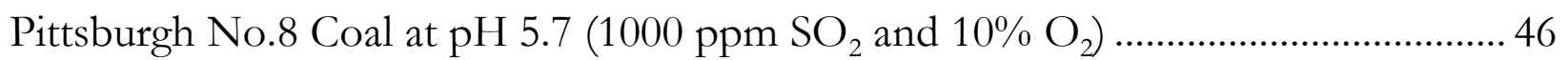

Figure 7-3 Arrhenius Plot for Leaching of Pyrite for Pittsburgh No.8 Coal at pH 5.7 (1000 $\mathrm{ppm} \mathrm{SO}, 10 \% \mathrm{O}_{2}$ )

Figure 7-4 Plot of [1-(1-F) 1/3] versus time at various temperatures, $\mathrm{pH} 5.7$ for mercury removal for Pittsburgh No.8 Coal (1000 $\left.\mathrm{ppm} \mathrm{SO}_{2}, 10 \% \mathrm{O}_{2}\right)$

Figure 7-5 Arrhenius Plot for leaching of Mercury for Pittsburgh No.8 Coal at pH 5.7 (1000 $\mathrm{ppm} \mathrm{SO}, 10 \% \mathrm{O}_{2}$ ) 50

Figure 7-6 Plot of [1-(1-F) 1/3] VS time at various temperatures for Mercury removal for Illinoi No.6 Coal at pH $5.7\left(1000\right.$ ppm SO $\left.2,10 \% \mathrm{O}_{2}\right)$........................................... 51

Figure 7-7 Arrhenius Plot for Leaching of Mercury for Illinois No.6 Coal at pH 5.7 (1000 $\mathrm{ppm} \mathrm{SO}, 10 \% \mathrm{O}_{2}$ ) 52 


\section{List of Tables}

Table 1-1 Typical composition of flue gas from a coal fired power plant ....................... 4

Table 2-1 Henry's law constants for $\mathrm{SO}_{2}$ and $\mathrm{O}_{2}$ in water: ............................................ 13

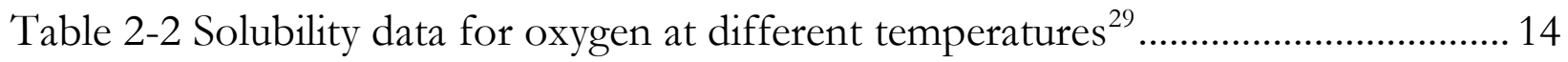

Table 4-1 Pyritic Iron Analysis .......................................................................................... 19

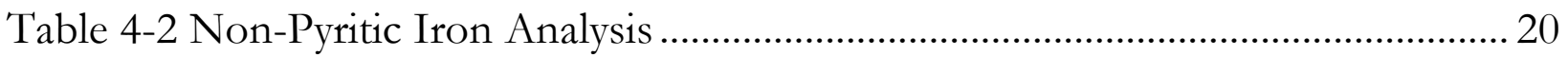

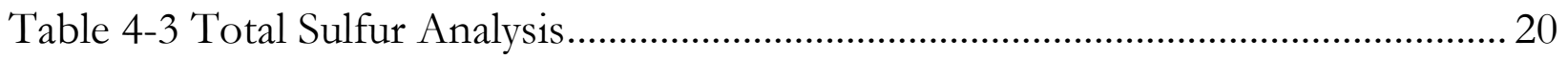

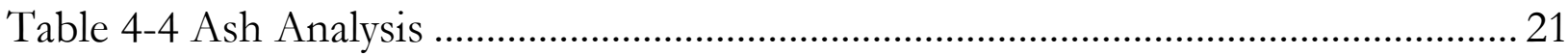

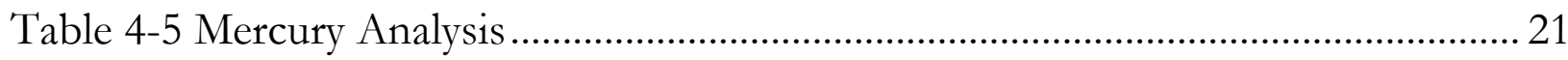

Table 4-6 Composition of Pittsburgh No.8 Coal and Illinois No.6 Coal ...................... 22

Table 7-1 Rate Constant Values for Pyrite Leaching ....................................................... 47

Table 7-2 Rate Constant Values for Mercury Leaching.................................................... 49

Table 7-3 Rate Constant Values for Mercury Leaching................................................... 52 


\section{CHAPTER 1}

\section{INTRODUCTION}

\section{$\underline{1.1 \text { Background }}$}

Mercury from coal-fired utilities has been identified as one of the most hazardous air pollutants and the greatest potential public health concern. Furthermore, it has a tendency to bio-accumulate in the food chain. Mercury is present in coal in concentration well below 1 ppm; however, the large tonnages of coal consumed for electric power generation represent a significant source of mercury vapor entering the environment. It is estimated that about 50 tons of mercury is accumulated in the environment annually in U.S.A. alone from the coal-fired power plants. ${ }^{1}$ Under Title III of the 1990 Clean Air Act Amendments, the Environmental Protection Agency (EPA) is empowered to set emission standards for 189 pollutants, including mercury. ${ }^{2}$

Mercury cycles in the environment as a result of natural (ex: geothermal activity) and anthropogenic (human) activities. The primary anthropogenic sources are: fossil fuel combustion and smelting activities. Both these natural and human activities release elemental mercury vapor $\left(\mathrm{Hg}^{\mathrm{g}}\right)$ into the atmosphere. Once in the atmosphere, the mercury vapor can circulate for up to a year, and hence become widely dispersed. The elemental mercury vapor can then undergo a photochemical oxidation to become oxidized that can combine with water vapor and travel back to the Earth's surface as rain. This 'mercury-water' is deposited in soils and bodies of water'.

Mercury in the environment is constantly cycled and recycled through a biogeochemical cycle which is a pathway by which a chemical element or molecule moves through both biotic (biosphere) and abiotic (lithosphere, atmosphere, and hydrosphere) compartments of Earth. The cycle has six major steps:

1. Degassing of mercury from rock, soils, and surface waters, or emissions from volcanoes and from human activities.

2. Movement in gaseous form through the atmosphere.

3. Deposition of mercury on land and surface waters.

4. Conversion of the element into insoluble mercury sulfide.

5. Precipitation or bioconversion into more volatile or soluble forms such as methyl mercury. 
6. Reentry into the atmosphere or bioaccumulation in food chains ${ }^{3}$.

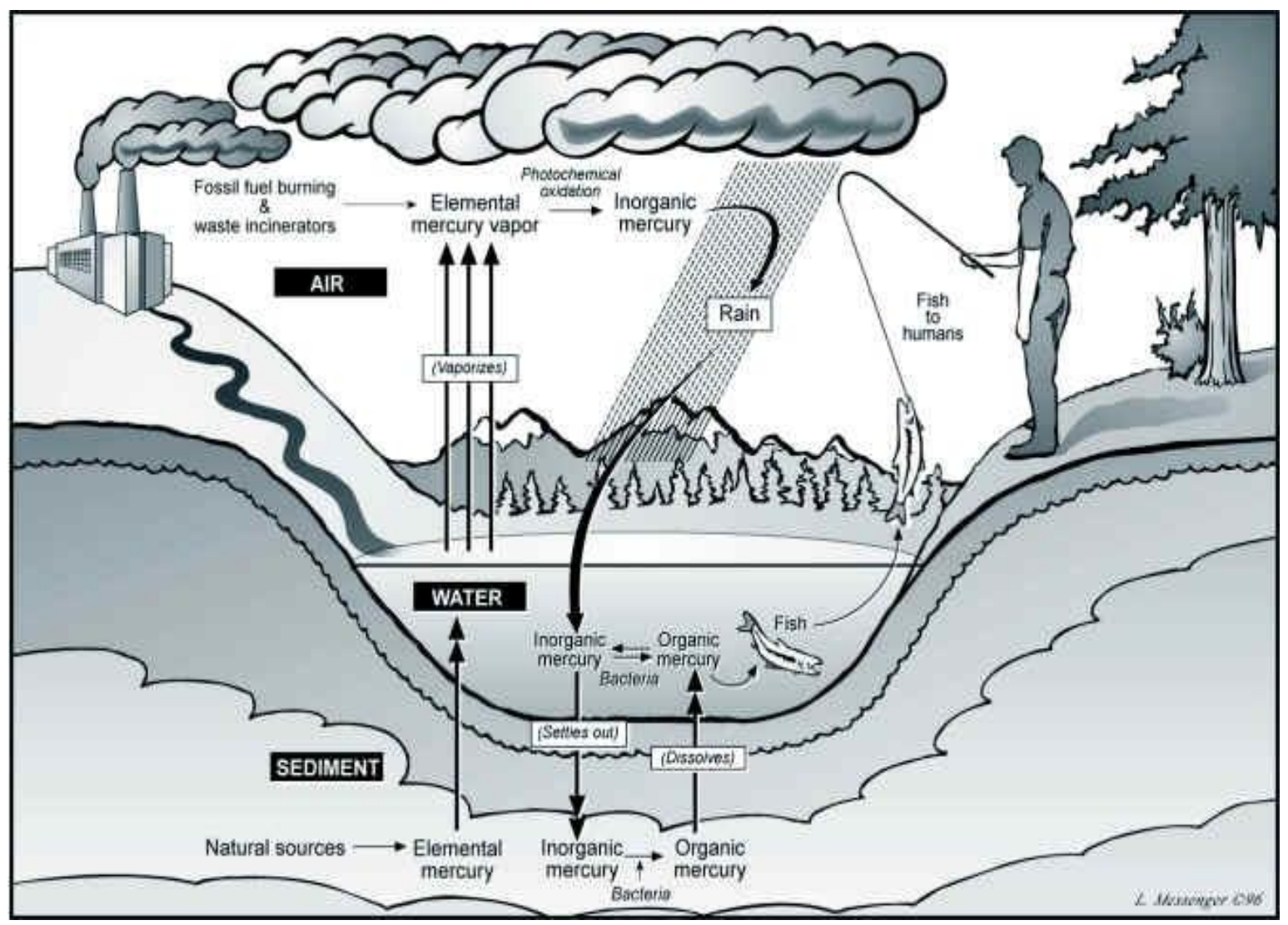

Figure 1-1 Mercury Cycle ${ }^{3}$

Mercury is released into the atmosphere in three forms: elemental mercury $\left(\mathrm{Hg}^{0}\right)$, divalent mercury (Hg (II)) and particulate phase mercury $\left(\mathrm{Hg}_{\mathrm{p}}\right)$. These three $\mathrm{Hg}$ species have different atmospheric behavior and residence times. During coal combustion, the mercury is released into the exhaust gas as mercury vapor, $\mathrm{Hg}^{0}$. This vapor may then be oxidized to $\mathrm{Hg}^{2+}$ via homogeneous (gas gas) and heterogeneous (gas-solid, surface catalyzed) reactions. Elemental mercury, once emitted, generally remains aloft in the atmosphere for much longer periods and over greater distances and thus tends to travel regional or global distances before depositing to the earth's surface. Both elemental and oxidized mercury, once emitted to the atmosphere, may deposit to the earth's surface through physical and chemical processes even in the absence of precipitation. Mercury in the air eventually settles into rivers, lakes, streams and oceans or onto land where it washes into water bodies. It is important to know that mercury can have a local impact or be carried across continents by the wind. In water bodies, mercury can be transformed by natural processes into a more toxic form of mercury called methyl mercury, a type of organic mercury ${ }^{3}$. 
There are various technologies available to control the emission of mercury from coal-fired power plants. Among them activated carbon injection into the flue gas stream has been studied for many years and is considered to be the "standard technology" at this time to control the mercury emissions from flue gas. It can achieve as high as $90 \%$ of mercury removal if activated carbon as much as 4000 times of its stoichiometric amount is injected. This makes the technology very expensive. For example, it is reported that the cost of mercury control is estimated to range from $\$ 33,000 / \mathrm{lb}$ mercury removed to $\$ 131,000 /$ lb mercury removed for the bituminous-fired unit. ${ }^{4}$

Very small amounts of mercury are contained in coal. Its typical concentration in coal is in the vicinity of $0.1 \sim 0.2 \mathrm{ppm}$. It is reported that $58 \%$ of the mercury in coal exists in association with coal pyrite, $16 \%$ as oxides, and $26 \%$ organic mercury which may be associated with the coal structure. ${ }^{5}$

Coal contains toxic trace elements such as arsenic, cadmium, chromium, mercury, lead and selenium in ppm ranges. The average value for arsenic in raw Pittsburgh No. 8 coal is 22 ppm; lead, 19 ppm; selenium, $1.9 \mathrm{ppm}$; cadmium, $0.15 \mathrm{ppm}$; mercury, $0.13 \mathrm{ppm}^{6}$. These trace elements are subject to removal by conventional coal cleaning processes. In general, the removal of mercury is poor with a value less than 30\% while those of the other elements except for selenium reach approximately $50 \%{ }^{5}$.This poor removal of mercury from coal by conventional coal cleaning processes necessitates exploration of an alternative method to remove mercury more effectively.

This current situation may allow researchers to explore technologies which are more economically feasible and at the same time technically-sound. This is diversification of the effort to develop feasible technologies to control mercury emissions.

It has been found that coal pyrite could be leached effectively by the combination of $\mathrm{SO}_{2}$ and $\mathrm{O}_{2}$ and that this coal scrubbing can capture incoming $\mathrm{SO}_{2}$ effectively ${ }^{7}$. Because the largest fraction of mercury exists in association with coal pyrite, this gas mixture of $\mathrm{SO}_{2}$ and $\mathrm{O}_{2}$ can liberate mercury sulfide from the pyrite matrix, which can be subsequently leached by the gas mixture. One advantage of this method is that the leaching agents are waste gas mixtures of the flue gas stream containing a few hundred parts per million of $\mathrm{SO}_{2}, \mathrm{~N}_{2}, \mathrm{O}_{2}$, and $\mathrm{CO}_{2}$, thus making this method economically competitive. The other advantage is that this method serves two purposes of removing mercury from coal and, at the same time, capturing $\mathrm{SO}_{2}$ from the stack gas stream. 
Flue gas is gas that exits to the atmosphere via a flue, which is a pipe or channel for conveying exhaust gases from a fireplace, oven, furnace, boiler or steam generator. Quite often, it refers to the combustion exhaust gas produced at power plants. Its composition depends on the fuel being burned, but it will usually consist of mostly nitrogen (typically more than two-thirds) derived from the combustion air, carbon dioxide $\left(\mathrm{CO}_{2}\right)$ and water vapor as well as excess oxygen (also derived from the combustion air). Typical composition of flue gas stream from a coal fired power plant is shown in Table 1-1. It further contains a small percentage of pollutants such as particulate matter, carbon monoxide, nitrogen oxides and sulfur oxides. When fuels are burned there remains, besides ash, a certain number of gas components. If these still contain combustion heat, they are called heating gases. As soon as they have conveyed their energy to the absorbing surfaces of a heat exchanger, they are called flue or stack gases ${ }^{18}$.

Table 1-1 Typical composition of flue gas from a coal fired power plant

\begin{tabular}{|c|c|}
\hline$\underline{\text { GAS }}$ & $\underline{\text { CONCENTRATION }}$ \\
\hline Nitrogen & 78 to $80 \%$ (approx) \\
\hline Carbon Dioxide & $10-12 \%$ (approx) \\
\hline Oxygen & 2 to $6 \%$ (approx) \\
\hline Sulfur Dioxide & $180-2000 *$ ppm \\
\hline
\end{tabular}

*When poor quality coal is being fired, the $\mathrm{SO}_{2}$ concentration can sometimes exceed $2000 \mathrm{ppm}^{19}$.

At power plants, flue gas is often treated with a series of chemical processes and scrubbers, which remove pollutants. Electrostatic precipitators or fabric filters remove particulate matter and flue gas desulphurization captures the sulfur dioxide produced by burning fossil fuels, particularly coal. Nitrogen oxides are treated either by modifications to the combustion process to prevent their formation, or by high temperature or catalytic reaction with ammonia or urea. In either case, the aim is to produce nitrogen gas, rather than nitrogen oxides ${ }^{18}$. 


\subsection{Objective:}

In this research, it is proposed to develop a diverse technology beyond the "standard technology" of activated carbon injection. This technology is based on pre-combustion treatment of solid coal to remove its mercury content by a unique leaching method using $\mathrm{SO}_{2}$ and $\mathrm{O}_{2}$.

The overall objective of this study is to explore this new technology and determine its technical feasibility to be used for a commercial process.

The main objectives of this research are to study the effects of varying temperatures and $\mathrm{pH}$ values during leaching experiments and establish the standard condition for which the mercury removal is highest.

The specific goals of this research work are:

- To study the effect of temperature on mercury removal

- To study the effect of $\mathrm{pH}$ on mercury removal

- To study the effect of $\mathrm{SO}_{2}$ gas concentration on mercury removal

- To study the effect of $\mathrm{O}_{2}$ gas concentration on mercury removal.

Various leaching experiments are conducted by varying the temperature and $\mathrm{pH}$ values and the amount of mercury leached for every experiment is calculated using the standard value obtained from commercial analysis done by Standard Laboratories Inc at South Charleston, WV. 


\section{CHAPTER 2}

\section{LITERATURE REVIEW}

In this chapter, a brief literature overview is given on mercury emissions from coal-fired power plants, impacts of mercury emission on the environment and various technologies available to control mercury emissions from coal-fired power plants.

\subsection{Introduction}

More than half of the electricity generated in the United States comes from coal. The producers of the largest share of our nation's energy, coal-fired power plants, are also one of the dirtiest sources of electricity. Coal-fired power plants are the largest single man-made source of mercury pollution in the U.S, and are the largest contributors of hazardous air pollutants ${ }^{8}$. In smokestack tests, coal-fired power plants were found to release 67 air toxics, many of which are known or suspected carcinogens and neurotoxins that can cause developmental problems, respiratory problems, and aggravation of asthma.

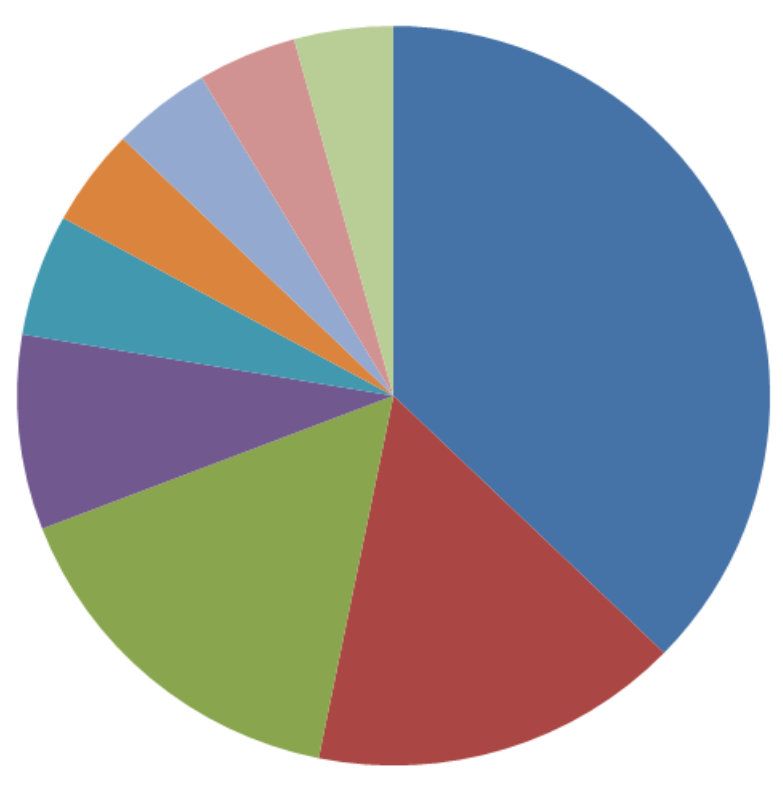

- Power Plants

Muncipal Incinerators

- Commercial Boilers

- Medical Incinerators

other

Chlor-Alkali Plants

Hazardous Waste

cement

Residential Boilers

Figure 2-1 Sources of Human Made Mercury in United States ${ }^{8}$ 


\section{$\underline{\text { 2.1.1 Mercury from Coal-Fired Power Plants and its Impacts }}$}

Of the air toxics produced by power plants, one of the most dangerous is mercury. The form of mercury emitted from point sources is a critical variable in modeling the patterns and amount of mercury deposition from the atmosphere. Both elemental and oxidized mercury are emitted to the air from combustion point sources. Elemental mercury has a lifetime in the atmosphere of up to a year, while oxidized forms of mercury have lifetimes of a few days or less as a result of the higher solubility of $\mathrm{Hg}^{+2}$ in atmospheric moisture. Elemental mercury can thus be transported over long distances, whereas oxidized and particulate mercury deposit near the point of emission. Once mercury has deposited on land or water, it can transform into methyl-mercury, an organic form, and thereby enter the food chain. Humans are most likely to be exposed to methyl-mercury through consumption of fish (See Figure 2-1). Mercury from coal-fired power plants is released into the air through the exhaust system when coal is burned ${ }^{21}$. During combustion the mercury is released into the exhaust gas as mercury vapor, $\mathrm{Hg}^{0}$. This vapor is further oxidized to $\mathrm{Hg}^{2+}$ via homogeneous (gas-gas) and heterogeneous (gas-solid, surface catalyzed) reactions. Although the major reaction pathways for mercury in coal combustion flue gas can be identified with some degree of confidence, quantitative predictions of the emissions of specific mercury species from coal-fired power plants cannot yet be made.

The primary exposure for humans occurs when this mercury falls to the earth and runs into lakes, rivers, and streams and contaminates the fish. Humans can be contaminated when they eat these fish and shellfish ${ }^{8}$. Mercury is a developmental toxin, primarily affecting fetal development. In unborn children, it can cause brain damage, mental retardation, blindness, and many other problems. Infants are also exposed to these dangers through contaminated breast milk. While the dangers of mercury are most often associated with women and children, eating fish high in mercury has also been found to put middle-aged men at a greater risk for coronary heart disease ${ }^{22}$. 


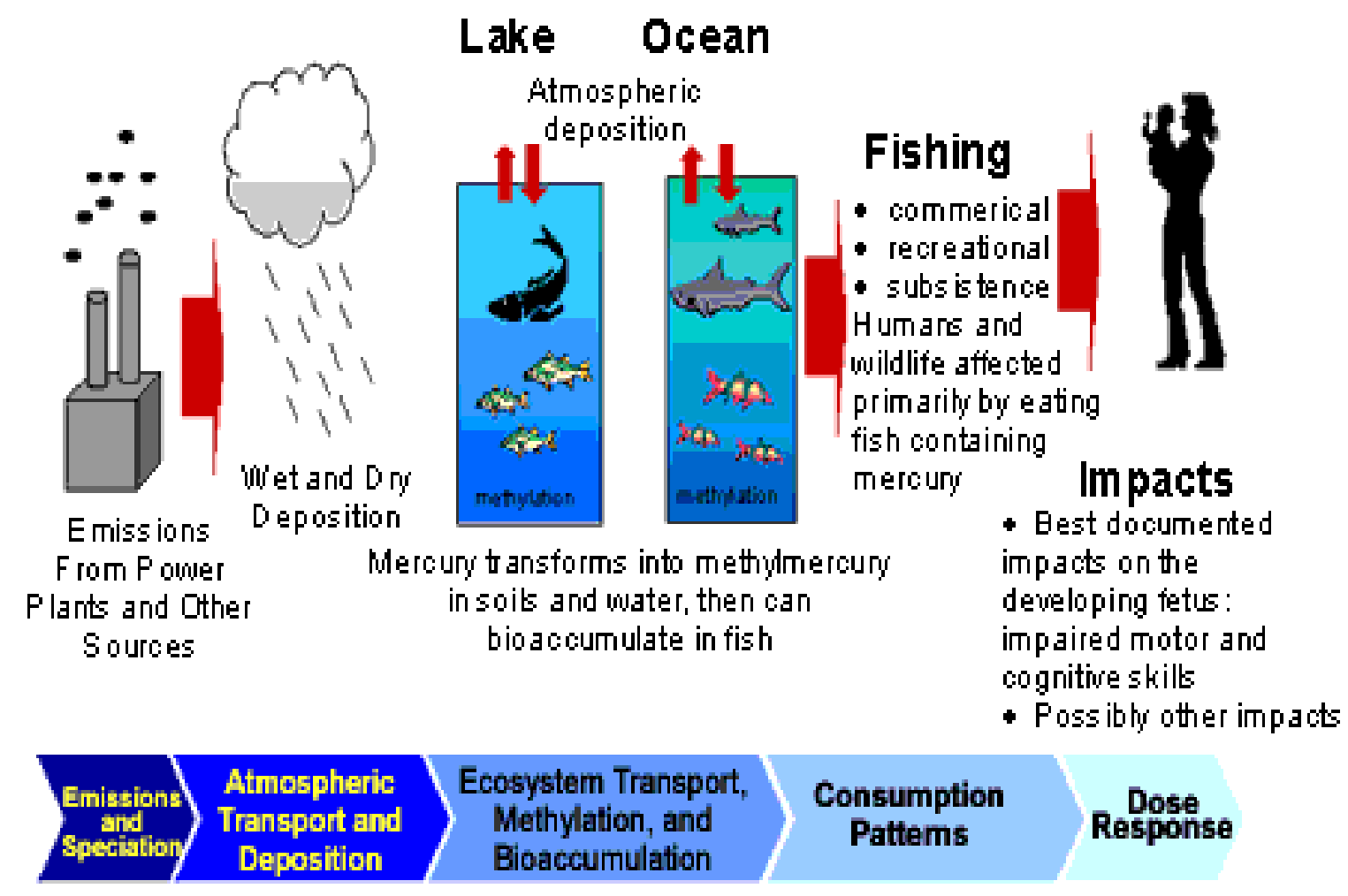

Figure 2-2 Mercury from Power Plants to Human Beings ${ }^{9}$

\subsubsection{Technologies available to Control Mercury Emissions}

Currently, no single technology can provide cost-effective mercury control for all generating configurations or all fuel types. Early estimates of the cost of mercury control were as high as $\$ 70,000$ per pound of mercury captured. Activated Carbon Injection (ACI) as a sorbent to capture flue gas mercury, has shown the most promise as a near-term mercury control technology. Even so, the application of ACI for mercury capture at coal-fired utility boilers is still in its early stages, and the effectiveness of ACI for mercury capture under varied conditions (e.g., fuel properties, flue-gas temperature, and trace-gas constituents such as chlorine, sulfur, NOx, and calcium) is still being investigated. Furthermore, the effect of long-term use of ACI (or any other injected sorbent or additive) on plant operations has yet to be determined, and it is likely that some degradation in the performance of downstream equipment, primarily particulate collection devices, may occur ${ }^{15}$. 
There are various technologies in practice for the control of mercury emissions from coal-fired power plants. These include:

\section{- Capture of Mercury with Existing Controls:}

Many power plants have existing mercury reduction as a co-benefit of air pollution control technologies for $\mathrm{NOx}, \mathrm{SO}_{2}$, and particulate matter (PM). These existing controls offer a significant opportunity for mercury capture ${ }^{16}$.

\section{- Sorbent Injection Technologies:}

This includes Activated Carbon Injection for the capture of mercury from power plants. This technology, though very expensive, can remove as much as $90 \%$ of mercury. The cost of mercury control with this techniques is estimated to range from $\$ 33,000 / 1 b$ mercury removed to $\$ 131,000 / \mathrm{lb}$ mercury removed for the bituminous-fired unit. .

\section{- Enhanced Conventional Technologies:}

Air pollution control systems like scrubbers, designed to capture sulfur dioxide $\left(\mathrm{SO}_{2}\right)$ and particulate matter (PM) generally capture some mercury as well. Conventional air pollution control technologies capture about one-third of the potential mercury emissions from coalfired power plants. In general, these systems seek to increase the oxidized fraction of mercury present in the power plant's flue gas, and decrease the fraction of elemental mercury, which is more difficult to capture. Research is being done to enhance the performance of such systems on mercury capture ${ }^{17}$.

\section{- Multi-pollutant Capture Technologies:}

Multi-pollutant approaches have potential synergies which could increase pollution reduction and lower control costs. Calcium based sorbents and oxidizing agents are being evaluated. These systems could remove both $\mathrm{SO}_{2}$ and mercury. 


\section{- Leaching of Coal with Sulfur Dioxide:}

A gas mixture of $\mathrm{SO}_{2}$ and $\mathrm{O}_{2}$ can liberate mercury sulfide from the pyrite matrix which can be subsequently leached by the gas mixture. It is also possible to leach organically-associated mercury with this gas mixture. The advantage of this method is that the leaching reagents are contained in the waste gas mixture of the flue gas stream, thus making this method economically competitive. If a process is developed using this technology, it could simultaneously function as stack gas desulfurization. In other words, the process will serve the double purposes of removal of mercury from coal and $\mathrm{SO}_{2}$ from flue gas. This latter mechanism has been studied by Cho in " $\mathrm{SO}_{2}$ Removal by Leaching Coal Pyrite" in which coal is used as scrubbing medium in place of lime to remove $\mathrm{SO}_{2}$ by scrubbing flue gas ${ }^{7}$.

\subsection{Sulfur dioxide and its solubility:}

As shown in Figure 2-3, Sulfur dioxide gas is released primarily from the electricity generation and combustion of fossil fuels ( $75 \%$ to $85 \%$ of the industrial sources), the smelting of sulfide ores, volcanic emissions, and several other natural sources. Sulfur dioxide has a wide range of industrial applications, the most notable being as an intermediate in producing sulfuric acid and is used in removing oxygen in petroleum recovery processes to prevent corrosion in piping and storage systems. Also, it is applied in water treatment to reduce residual chlorine. In clay processing it reduces iron compounds and other color-forming impurities. Other uses are extracting sulfide ores; casting magnesium; catalyst modifier in certain organic oxidation reactions; and colorimetric analysis of sulfite ion in aqueous samples. In the chemical industry, sulfur dioxide is used as a reducing agent in a number of preparative and analytical reactions. Liquid sulfur dioxide is used as a solvent for sulfur trioxide in sulfonation.

$\mathrm{SO}_{2}$ is a U.S. Environmental Protection Agency (EPA) priority air pollutant, but it has many industrial and agricultural uses as well. Approximately 300,000 tons are used each year to manufacture hydrosulfites and other sulfur-containing chemicals (40\%); to bleach wood pulp and paper $(20 \%)$; to process, disinfect, and bleach food (16\%); for waste and water treatment (10\%); in metal and ore refining (6\%); and in oil refining (4\%). Toxic amounts of sulfur dioxide can be released from the preservative chemical meta-bisulfite in the presence of water and $\mathrm{acid}^{25}$. The main human sources of sulfur dioxide are burning fossil fuels, smelting, paper manufacture and the 
production of sulfuric acid via the Contact Process. Since coal and petroleum often contain sulfur compounds, their combustion generates sulfur dioxide. Sulfur dioxide is an acidic gas and this can easily be demonstrated by adding water and a few drops of universal indicator to a container of the gas. The resulting acid is the weakly dibasic acid sulfurous acid $\left(\mathrm{H}_{2} \mathrm{SO}_{3}\right)$.

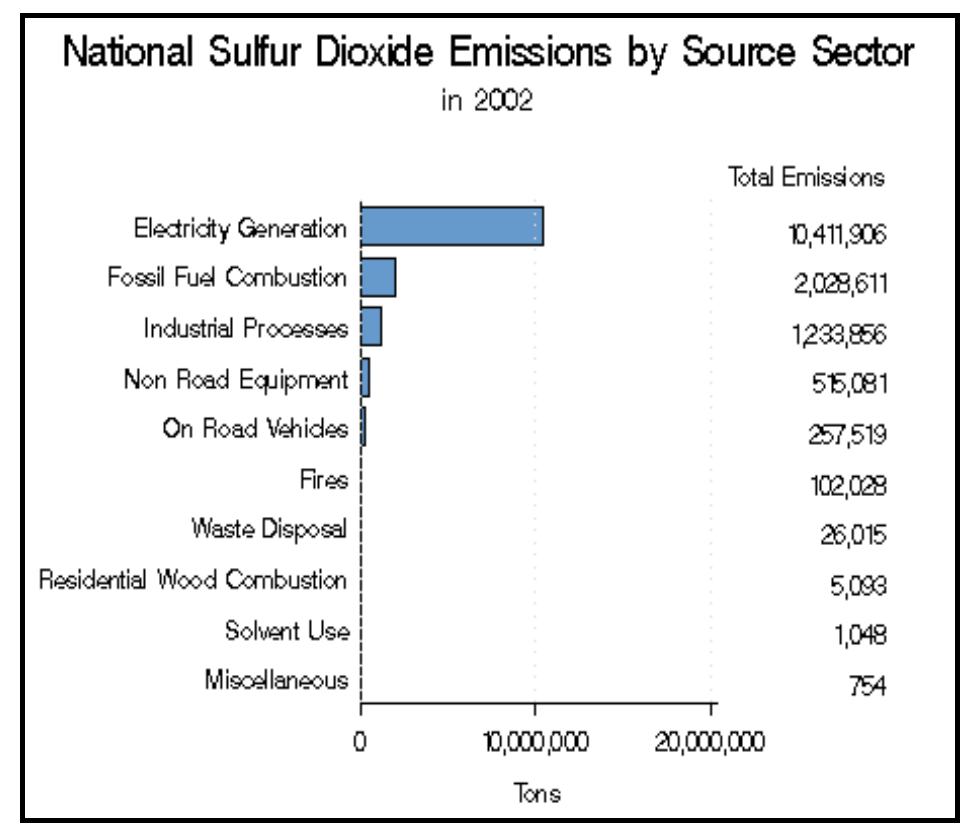

Figure 2-3 Sources of Sulfur dioxide

\subsubsection{Temperature Effect on Solubility:}

Solubility of gas in a liquid depends on the gas partial pressure according to Henry's law. Compounds with relatively high Henry's law constants indicate that they are not substantially removed by absorption. Lower Henry's law constants indicate greater solubility of the compound. As the temperature increases, the solubility of a gas decreases. More gas is present in a solution with a lower temperature compared to a solution with a higher temperature. The reason for this gas solubility relationship with temperature is very similar to the reason that vapor pressure increases with temperature. Increased temperature causes an increase in kinetic energy. The higher kinetic energy causes more motion in molecules which break intermolecular bonds and escape from solution. The solubility of $\mathrm{SO}_{2}$ in neutral (or alkaline) water is generally going to be higher because of the $\mathrm{pH}$-dependent speciation of $\mathrm{SO}_{2}$ in the solution with the production of bisulfite and some 
sulfite ions ${ }^{26}$. As the temperature increases the solubility of a gas in a liquid decreases and the partial pressure of the gas increases. As the temperature rises from $50^{\circ} \mathrm{C}$ to $70^{\circ} \mathrm{C}$, there is a net transfer of $\mathrm{SO}_{2}$ from the liquid phase to the gas phase. Therefore the concentration of $\mathrm{SO}_{2}$ in the liquid decreases and the concentration in the gas phase increases.

The Henry's law solubility curve ${ }^{26}$ for the sulfur dioxide gas in water at $101.3 \mathrm{k}$ Pa is shown in Figure 2-4. In most air pollution applications the pollutant concentrations are relatively low. The slope of the solubility curve for these applications is a straight line and is equivalent to Henry's law constant, $H$. As the temperature increases, the slope of the solubility graph becomes steeper or increases (from $H_{1}$ to $H_{2}$ ). This is due to the fact that, as the temperature rises, gases become less soluble in liquids and a higher proportion of the pollutant gas resides in the gas phase than the liquid phase.

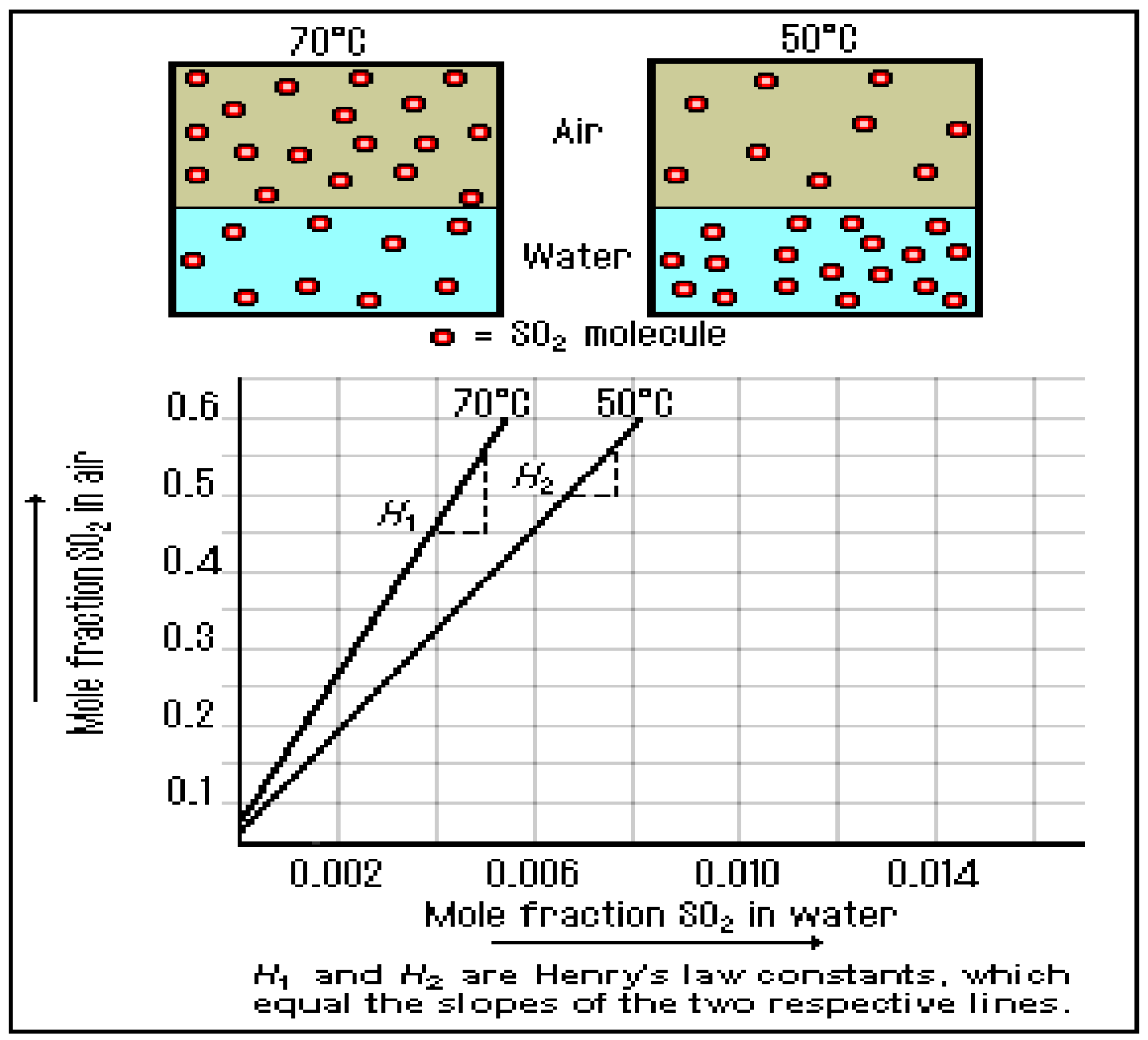

Figure 2-4 Henry's law solubility curve for $\mathrm{SO}_{2}-\mathrm{H}_{2} \mathrm{O}^{27}$ 
Table 2-1 Henry's law constants for $\mathrm{SO}_{2}$ and $\mathrm{O}_{2}$ in water:

\begin{tabular}{|c|c|c|}
\hline Gas & \multicolumn{2}{|c|}{ Henry's law constants $\left(\mathrm{H} \times 10^{5}\right.$ atm/mole fraction) } \\
& $\underline{20} \mathrm{C}$ & $\underline{30^{\circ} \mathrm{C}}$ \\
\hline Oxygen $\left(\mathrm{O}_{2}\right)$ & 40.1 & 47.5 \\
\hline Sulfur-dioxide $\left(\mathrm{SO}_{2}\right)$ & 0.014 & 0.016 \\
\hline
\end{tabular}

\subsection{2 pH Effect on Solubility:}

The effect of changing the $\mathrm{pH}$ is that as the $\mathrm{pH}$ is decreased (solution becomes more acidic), the $\mathrm{OH}$-concentration decreases, thus the $\mathrm{HSO}_{3}{ }^{-}$concentration increases in order to maintain the constant ion product. In order to increase the concentration of $\mathrm{HSO}_{3}^{-}$, (which is aqueous $\mathrm{SO}_{2}$ ) solubility of sulfur dioxide in water increases with a decrease in $\mathrm{pH}$.

\subsection{Oxygen and its solubility}

Oxygen takes its name from the two words 'ox' meaning 'sharp (taste)' and 'gen', which means 'to form'. Oxygen is the most abundant and most widely distributed element on earth. More than 50\% of the earth's mass constitutes oxygen. Oxygen is a component of the earth's crust, mantle, rocks, minerals, hydrosphere and the atmosphere. It occurs in all oxides and in a large number of minerals containing phosphates, sulfates, carbonates, nitrates and hydroxides. The oxygen content of the earth's oceans is about $88.7 \%$ by mass. Oxygen is a component of innumerable inorganic and organic compounds that include water, carbon dioxide, nitrogen oxides, sulfur oxides, oxo acids, most bases, alcohols, aldehydes, ketones, esters, carboxylic acids, lactones, sugars and carbohydrates. Oxygen is a major constituent of air, being the second most abundant gas of the earth's atmosphere constituting $20.8 \%$ of atmosphere. While the oxygen in the lower atmosphere essentially is diatomic $\mathrm{O} 2$ molecule, at about 30 to $45 \mathrm{~km}$ height, a triatomic form of oxygen, ozone (O3), coexists with O2 at varying but significant concentrations. Atomic oxygen, $\mathrm{O}$, is found with molecular oxygen in the upper atmosphere ${ }^{27}$.

Oxygen exists as $\mathrm{O}_{2}$ and $\mathrm{O}_{3}$ (ozone), and is present in a number of compounds including water molecules. Dissolved oxygen is an important determinant for stability of waters and survival of water organisms. Micro organisms may decompose organic substances in water by means of oxygen. 
Oxygen application per unit of time is indicated by BOD (Biochemical Oxygen Demand). Organic pollutants may negatively influence water organisms, because they decrease BOD.

Thermal pollution causes the same problem, because oxygen solubility is lower in warmer water. This may be a consequence of cooling water discharge on surface waters. In eutrophic lakes and relatively enclosed sea areas, oxygen concentrations decrease strongly with depth. In some cases conditions may even be anaerobic. Natural examples of influences of temperature on oxygen concentrations in water and environmental impact are seasonal temperature changes in lakes. Oxygen can be found dissolved in water as $\mathrm{O}_{2}$ molecules. Consequently, the oxygen content of seawater is $85.7 \%{ }^{28}$. Gaseous oxygen does not react with water. It is water soluble and functions as an oxidator:

$$
\mathrm{O}_{2}+2 \mathrm{H}_{2} \mathrm{O}+4 \mathrm{e}^{-}->4 \mathrm{OH}^{-}
$$

\subsubsection{Temperature Effect on Solubility:}

Water solubility of oxygen at $25^{\circ} \mathrm{C}$ and pressure $=1 \mathrm{bar}$ is at $40 \mathrm{mg} / \mathrm{L}$ water. In air with a normal composition the oxygen partial pressure is $0.2 \mathrm{~atm}$. This results in dissolution of $8 \mathrm{mg} \mathrm{O} / \mathrm{L}$ in water that comes in contact with air. Oxygen solubility is strongly temperature dependent and decreases at higher temperatures. Oxygen solubility is negatively correlated with the amount of dissolved solids ${ }^{28}$. The solubility data for oxygen can be shown as:

Table 2-2 Solubility data for oxygen at different temperatures ${ }^{29}$

\begin{tabular}{|c|c|}
\hline Temperature (Degrees C) & Oxygen Solubility (mg/l) \\
\hline 0 & 14.6 \\
\hline 5 & 12.8 \\
\hline 10 & 11.3 \\
\hline 15 & 10.2 \\
\hline 20 & 9.2 \\
\hline 25 & 8.6 \\
\hline 30 & 7.5 \\
\hline 35 & 6.9 \\
\hline 40 & 6.4 \\
\hline $100(b o i l i n g)$ & 0 \\
\hline
\end{tabular}


The solubility curve corresponding to above data is:

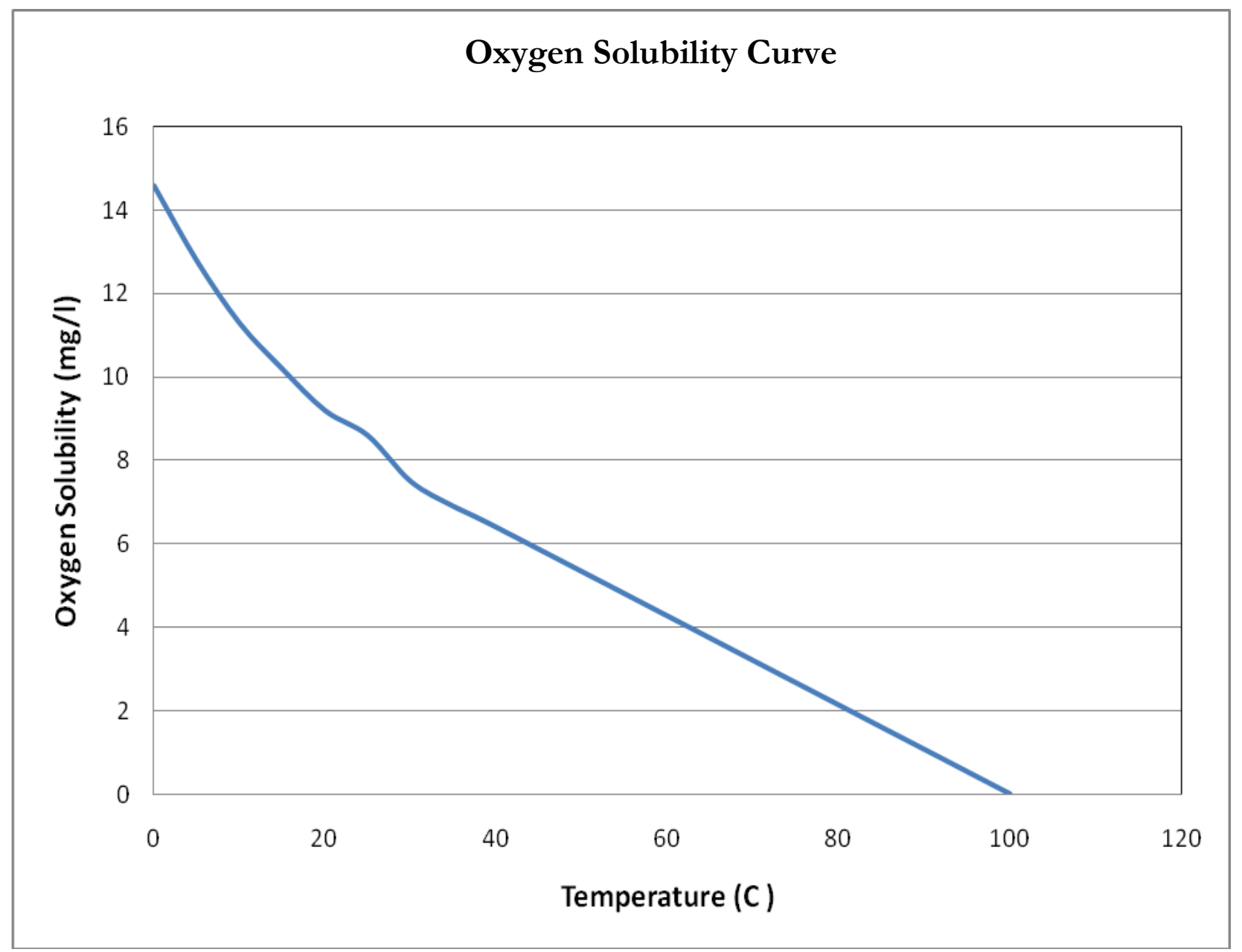

Figure 2-5 Solubility curve for oxygen showing that the solubility decreases with increase in temperature. 


\section{CHAPTER 3}

\section{THEORY}

This chapter gives a brief overview of the theory involved in the oxidation and removal of mercury from solid coal by flue gas.

\section{$\underline{\text { 3.1 Reactions Involved }}$}

The standard electrode potentials are customarily determined at the concentrations of 1 Molar, gas pressures of 1 atmosphere, and a standard temperature which is usually $25^{\circ} \mathrm{C}$. The standard cell potential is denoted by a degree sign as a superscript.

1. Measured against standard hydrogen electrode.

$\begin{array}{ll}\mathrm{E}^{\circ} & \text { 2. } \\ & \text { 3. } \text { Concentration } 1 \text { Molar } \\ & \text { 4. } \text { Temperature } 1 \text { atmosphere } \\ & \end{array}$

The removal of mercury from coal is based on the oxidation of mercury by a strong oxidation reagent, which here is a combination of $\mathrm{SO}_{2}$ and oxygen, both self-supplied from the flue gas. $\mathrm{SO}_{2}$ is a reducing reagent, but when it combines with oxygen in an acid solution, it becomes a strong oxidizing reagent. The cathode reaction for the oxidizing reagent can be written as:

$$
\mathrm{H}_{2} \mathrm{SO}_{3}+\mathrm{O}_{2}+2 \mathrm{e}=\mathrm{SO}_{4}{ }^{2-}+\mathrm{H}_{2} \mathrm{O} \quad \mathrm{E}^{0}=2.29 \mathrm{eV}
$$

Where- $\mathrm{H}_{2} \mathrm{SO}_{3}$ represents the aqueous $\mathrm{SO}_{2}$ which is predominant at low $\mathrm{pH}$ values.

It can be seen that the magnitude of $\mathrm{E}^{0}$ value of reaction 3-1 is very high. This value is much higher than those of strong oxidizing reagents such as permanganate $(1.51 \mathrm{eV})$ and dichromate $(1.33 \mathrm{eV})$.

When $\mathrm{SO}_{2}$ is dissolved in an aqueous medium, it forms $\mathrm{H}_{2} \mathrm{SO}_{3}$ in an acid solution, which is then dissociated into $\mathrm{HSO}_{3}^{-}$as the $\mathrm{pH}$ increases. It can be shown as: 


$$
\begin{array}{ll}
\mathrm{SO}_{2}+\mathrm{H}_{2} \mathrm{O}=\mathrm{H}_{2} \mathrm{SO}_{3} & \mathrm{~K}=1.204 \\
\mathrm{H}_{2} \mathrm{SO}_{3}=\mathrm{H}^{+}+\mathrm{HSO}_{3}^{-} & \mathrm{K}=1.32 * 10^{-2}
\end{array}
$$

The equilibrium constants of reactions 3-2 and 3-3 are those at room temperature. In an acid solution, dissolved $\mathrm{SO}_{2}$ forms $\mathrm{H}_{2} \mathrm{SO}_{3}$. When the $\mathrm{pH}$ is increased, $\mathrm{H}_{2} \mathrm{SO}_{3}$ turns to $\mathrm{HSO}_{3}{ }^{-}$. The concentrations of $\mathrm{H}_{2} \mathrm{SO}_{3}$ and $\mathrm{HSO}_{3}{ }^{-}$are the same at $\mathrm{pH}$ 1.88. Thus, in order to increase the $\mathrm{H}_{2} \mathrm{SO}_{3}$ concentration in the dissolved $\mathrm{SO}_{2}$, the solution $\mathrm{pH}$ should be below 1.88 .

The dissolution of coal pyrite in the presence of $\mathrm{SO}_{2}$ and oxygen is based on an electrochemical reaction. The anode reaction for the overall reaction may be given as:

$\mathrm{FeS}_{2}+8 \mathrm{H}_{2} \mathrm{O}=\mathrm{Fe}^{2+}+2 \mathrm{SO}_{4}^{2-}+16 \mathrm{H}^{+}+14 \mathrm{e} \quad \mathrm{E}^{0}($ for anode reaction $)=0.355 \mathrm{eV}$

The cathode reaction is reaction 3-1. The difference in $\mathrm{E}^{0}$ values between the cathode and anode reactions is large, suggesting that the leaching reaction of pyrite is thermodynamically very much spontaneous under normal conditions. The overall leaching reaction can then be written as

$\mathrm{FeS}_{2}+\mathrm{H}_{2} \mathrm{O}+7 \mathrm{H}_{2} \mathrm{SO}_{3}+7 \mathrm{O}_{2}=\mathrm{Fe}^{2+}+9 \mathrm{SO}_{4}^{2-}+16 \mathrm{H}^{+} \quad \Delta \mathrm{G}^{0}=-624.7 \mathrm{kcal} / \mathrm{mol}$

The magnitude of the standard Gibbs free energy suggests that the leaching reaction is thermodynamically spontaneous under normal conditions.

Mercury sulfide $(\mathrm{HgS})$, upon liberation from coal may be leached on the basis of an electrochemical reaction. The anodic reaction may be written as:

$\mathrm{HgS}+4 \mathrm{H}_{2} \mathrm{O}=\mathrm{Hg}^{2+}+\mathrm{SO}_{4}^{2-}+8 \mathrm{H}^{+}+8 \mathrm{e} \quad \mathrm{E}^{0}($ for anode reaction $)=0.54 \mathrm{eV}$ 3-6

It is seen that the difference in $\mathrm{E}^{0}$ between the cathode and anode reactions is large, suggesting that the leaching of $\mathrm{HgS}$ is thermodynamically spontaneous under normal conditions. 
The overall leaching reaction can be written as:

$\mathrm{HgS}+4 \mathrm{H}_{2} \mathrm{SO}_{3}+4 \mathrm{O}_{2} \rightarrow \mathrm{Hg}^{2+}+5 \mathrm{SO}_{4}{ }^{2-}+8 \mathrm{H}^{+} \quad \Delta \mathrm{G}^{0}=-242.13 \mathrm{kcal} / \mathrm{mol}$

The magnitude of the standard Gibbs free energy suggests that the leaching reaction is thermodynamically spontaneous under normal conditions.

In the case of organic mercury, it may be seen as un-oxidized or elemental mercury. The anodic reaction of elemental mercury is given as

$\mathrm{Hg}=\mathrm{Hg}^{2+}+2 \mathrm{e} \quad \mathrm{E}^{0}($ for cathode reaction $)=0.85 \mathrm{eV}$

The high $\mathrm{E}^{0}$ values of reactions 3-6 and 3-8 necessitate a strong oxidizing reagent such as the mixture of $\mathrm{SO}_{2}$ and oxygen used in this study. 


\section{CHAPTER 4}

\section{SAMPLE PREPARATION AND ANALYSIS}

This chapter gives a brief description about the sample preparation and the composition analysis of coal using ASTM standards. The results of composition analysis of the coal sample are also presented in this chapter.

\subsection{Sample Preparation}

Coal samples of Pittsburgh No. 8 Coal were collected from the Blacksville Mine \#2 (Consol), Wadestown, West Virginia and Illinois No.6 coal samples were collected from Peabody Energy. Both coal samples were crushed and screened to give a fraction of $-35 /+65$ mesh which is used in this study. The raw coal sample is selected because pre-cleaning with froth flotation would decrease the pyrite content and would result in difficulty particularly in analyzing for leaching of a smaller amount of pyrite.

\subsection{Compositional Analysis of Coal}

\subsubsection{Analysis of Pyritic and Non Pyritic Iron:}

Three different samples of Pittsburgh No.8 coal and Illinois No.6 coal of approximately 3 grams each are weighed and analyzed for Pyritic and Non Pyritic Iron using ASTM standard D2492. The average of these three samples is used as the Pyritic Iron content in Coal samples.

Table 4-1 Pyritic Iron Analysis

\begin{tabular}{|c|c|c|}
\hline Pyritic Iron & Pittsburgh No.8 Coal & Illinois No.6 Coal \\
\hline Sample 1 & 0.955 & 1.18 \\
\hline Sample 2 & 0.964 & 1.01 \\
\hline Sample 3 & 0.981 & 1.18 \\
\hline Average & $\underline{\mathbf{0 . 9 6 7}}$ & $\underline{\mathbf{1 . 1 2 0}}$ \\
\hline
\end{tabular}


Table 4-2 Non-Pyritic Iron Analysis

\begin{tabular}{|c|c|c|}
\hline Non-Pyritic Iron & Pittsburgh No.8 Coal & Illinois No.6 Coal \\
\hline Sample 1 & 0.095 & 0.145 \\
\hline Sample 2 & 0.116 & 0.119 \\
\hline Sample 3 & 0.110 & 0.130 \\
\hline Average & $\underline{\mathbf{0 . 1 0 7}}$ & $\underline{\mathbf{0 . 1 3 2}}$ \\
\hline
\end{tabular}

\subsubsection{Analysis of Total Sulfur:}

Three different samples of Pittsburgh No.8 coal and Illinois No.6 coal of approximately 1 gram each are weighed and analyzed for Total Sulfur content using ASTM standard D3177(Eschka Method). The average of these three samples is used as the Total Sulfur content in Coal samples.

Table 4-3 Total Sulfur Analysis

\begin{tabular}{|c|c|c|}
\hline Total Sulfur & Pittsburgh No.8 Coal & Illinois No.6 Coal \\
\hline Sample 1 & 2.451 & 2.455 \\
\hline Sample 2 & 2.785 & 2.959 \\
\hline Sample 3 & 3.436 & 2.693 \\
\hline$\underline{\text { Average }}$ & $\underline{\mathbf{2 . 8 9 2}}$ & $\underline{\mathbf{2 . 7 1 0}}$ \\
\hline
\end{tabular}

\subsubsection{Analysis of Ash:}

Three different samples of Pittsburgh No.8 coal and Illinois No.6 coal of approximately 5 grams each are weighed and analyzed for Ash content using ASTM standard D 3174. The average of these three samples is used as the actual ash content of coal samples. 
Table 4-4 Ash Analysis

\begin{tabular}{|c|c|c|}
\hline$\underline{\text { Ash }}$ & $\underline{\text { Pittsburgh No.8 Coal }}$ & Illinois No.6 Coal \\
\hline Sample 1 & 13.686 & 17.467 \\
\hline Sample 2 & 12.183 & 14.226 \\
\hline Sample 3 & 11.021 & 15.725 \\
\hline$\underline{\text { Average }}$ & $\underline{\mathbf{1 2 . 2 9 0}}$ & $\underline{\mathbf{1 5 . 8 0 0}}$ \\
\hline
\end{tabular}

\subsubsection{Analysis of Mercury}

About six samples of each coal type were sent to commercial analyzer for mercury analysis. The average value of the entire samples was taken as the standard mercury content in doing calculations. The average mercury content of Pittsburgh No.8 coal sample as obtained from commercial analyzer by Standard Laboratories Inc., was $\underline{0.177 p p m}$ with those of six samples while that of Illinois No.6

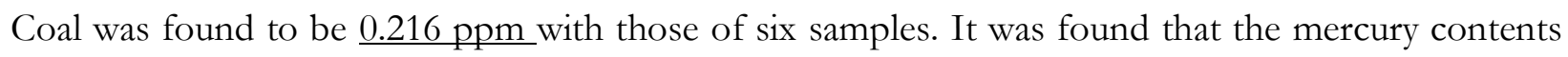
of the Pittsburgh No.8 coal were in between $\underline{180.77}$ and 174.81 ppb respectively and not much varied. On the other hand, the mercury contents of the Illinois No.6 Coal were much scattered from $\underline{70.28} \mathrm{ppb}$ to $\underline{729.37} \mathrm{ppb}$.

Table 4-5 Mercury Analysis

\begin{tabular}{|c|c|c|}
\hline Mercury & Pittsburgh No.8 Coal & Illinois No.6 Coal \\
\hline Sample 1 & $177.895 \mathrm{ppb}$ & $100.567 \mathrm{ppb}$ \\
\hline Sample 2 & $176.365 \mathrm{ppb}$ & $70.286 \mathrm{ppb}$ \\
\hline Sample 3 & $180.776 \mathrm{ppb}$ & $98.435 \mathrm{ppb}$ \\
\hline Sample 4 & $178.982 \mathrm{ppb}$ & $729.373 \mathrm{ppb}$ \\
\hline Sample 5 & $174.812 \mathrm{ppb}$ & $150.869 \mathrm{ppb}$ \\
\hline Sample 6 & $176.456 \mathrm{ppb}$ & $148.657 \mathrm{ppb}$ \\
\hline Average & $177 \mathrm{ppb}$ & $216 \mathrm{ppb}$ \\
\hline
\end{tabular}




\subsection{Results of Coal Analysis:}

Table 4-6 shows the results of the analysis of the 35x65 mesh Pittsburgh No.8 coal and Illinois No.6 coal samples, to be used in this study.

Table 4-6 Composition of Pittsburgh No.8 Coal and Illinois No.6 Coal

\begin{tabular}{|c|c|c|}
\hline Element & $\begin{array}{c}\text { Pittsburgh No.8 Coal } \\
\text { (\% Content) }\end{array}$ & $\begin{array}{c}\text { Illinois No.6 Coal } \\
\text { (\%Content) }\end{array}$ \\
\hline Pyritic Iron & 0.967 & 1.120 \\
\hline Non Pyritic Iron & 0.107 & 0.132 \\
\hline Pyritic Sulfur & 1.110 & 1.120 \\
\hline Organic Sulfur & 1.765 & 0.101 \\
\hline Sulfate Sulfur & 0.016 & 2.710 \\
\hline Total Sulfur & 2.892 & 15.800 \\
\hline Ash & 12.290 & $0.216 \mathrm{ppm}$ \\
\hline Total Mercury & $0.177 \mathrm{ppm}$ & \\
\hline
\end{tabular}

In sample preparation, the coal samples were thoroughly mixed with a riffler for at least 15-20 times to make sure the contents of the coal are homogeneous. 


\section{CHAPTER 5}

\section{EXPERIMENTATION}

A detailed description of the experimental setup is given in this chapter along with different types of experimentation carried out for this study and the analysis procedures. The analysis equipment used is briefly discussed.

\subsection{Experimental Setup:}

The apparatus in which the mercury removal experiments were conducted, consists of three gas cylinders (nitrogen, oxygen and $1 \% \mathrm{SO}_{2}$ in $\mathrm{N}_{2}$ ), a glass reactor (with a volumetric capacity of one liter), and a gas bubbler as shown in Figure 5-1. The reactor is immersed in a constant-temperature oil bath which held the temperature of about $5-8^{0} \mathrm{C}$ above the desired reaction temperature. The reactor has four necks: the central neck is equipped with a stirrer connected to a motor operating at a speed of 470- $500 \mathrm{rpm}$. One of the three side necks is fitted with a condenser for the gas outlet, the next with a bubbler, and the last with a sampling device.

\subsection{Experimental Procedure:}

Leaching experiments are conducted by adding 50 -g coal into $500 \mathrm{ml}$ de-ionized water in the reactor and is continuously mixed with a stirrer attached to a motor operating at around $500 \mathrm{rpm}$. The stirrer operated at $500 \mathrm{rpm}$ for all the experiments carried out during this research. The reactor with the coal water slurry is immersed in oil bath. The oil bath along with reactor is heated until the desired temperature is obtained. The gases, after being metered for their flow rates through flow meters, which were pre calibrated for 100\% accuracy, are combined in a gas mixer. The gases are then introduced into the reactor and bubbled through the coal water slurry added to the reactor. During the leaching process, the $\mathrm{SO}_{2}$ and $\mathrm{O}_{2}$ are dissolved in the water and then oxidize the mercury and coal pyrite. The un-dissolved fraction of $\mathrm{SO}_{2}$ exits the reactor and flows through the condenser to knock out some of its moisture content. This un-dissolved or un-reacted $\mathrm{SO}_{2}$ concentration is expected to be very low ${ }^{7}$ (e.g., $<20$ ppm) and the gas stream is emitted into the atmosphere under a ventilation hood. The gas flow rate is maintained at $30 \mathrm{ml} / \mathrm{s}$ for all the experiments which contains $1000 \mathrm{ppm}$ of $\mathrm{SO}_{2}, 3 \mathrm{ml} / \mathrm{s}$ of $\mathrm{O}_{2}\left(10 \% \mathrm{O}_{2}\right)$ and the rest $\mathrm{N}_{2}$. 


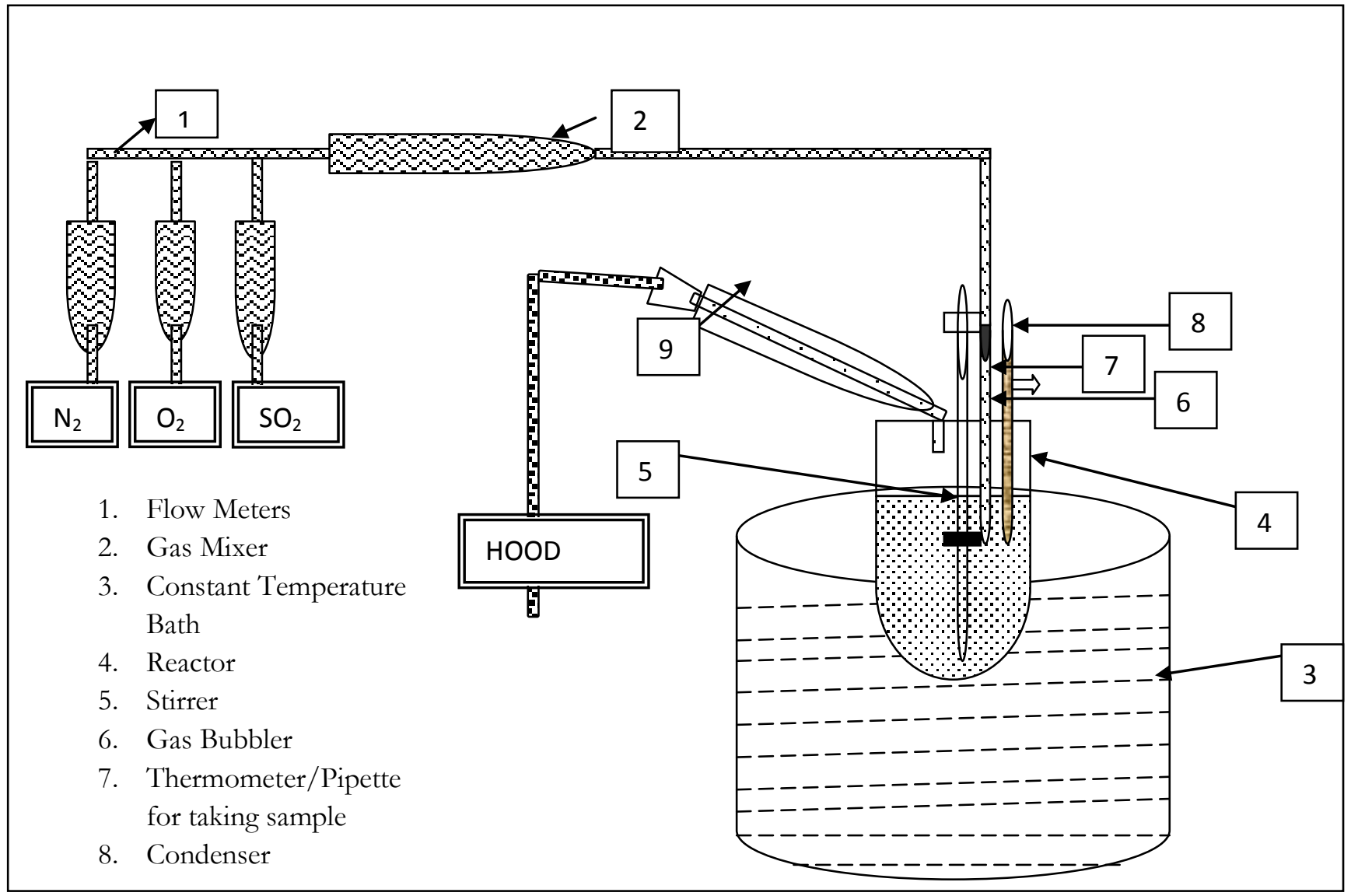

Figure 5-1 Experimental Setup for the leaching of Mercury from coal using $\mathrm{SO}_{2}$ and $\mathrm{O}_{2}$ as oxidizing agents

\subsubsection{Experimental Conditions:}

The gas flow rate of $30 \mathrm{ml} / \mathrm{s}$ is held constant for all the experiments which contained $1000 \mathrm{ppm}$ $\mathrm{SO}_{2}, 10 \% \mathrm{O}_{2}$ and the rest being $\mathrm{N}_{2}$. The experiments are carried out in order to determine the effects of various parametric conditions on the mercury removal. The temperature is varied from 50 to $80^{\circ} \mathrm{C}$. The solution $\mathrm{pH}$ values are maintained at $5.7,1.8,1.5,1.25$ and 1.08 . The $\mathrm{pH} 5.7$ is the $\mathrm{pH}$ of the distilled water and the other $\mathrm{pH}$ values were obtained by adding 17.5, 35, 70 and $100 \mathrm{ml}$ of 1 $\mathrm{N}$ sulfuric acid solution, respectively. It was observed that the sulfur-dioxide gas dissolves in the water during the reaction time and caused change in the $\mathrm{pH}$ of the solution. But this change in $\mathrm{pH}$ was very small. The reaction time is three hours for all the experiments with Pittsburgh No.8 Coal. In the case of Illinois No.6 Coal, the reaction time was two hours for all the experiments. 
Liquid samples of $20 \mathrm{ml}$ are withdrawn from the reactor every hour, filtered and analyzed for soluble iron and mercuric ion. The analysis results were used to determine the leaching conversions of pyrite and mercury content. After some selective runs, the coal slurry is filtered, dried, and analyzed for non-pyritic iron and mercury (Commercial Analysis) to determine how much of its original amount is leached. As the leaching reactions of both pyrite and mercury (equations 3-5 and 3-6) are acid producing, the $\mathrm{pH}$ of the final solution in the reactor went down by a very small number (1-3) by the end of reaction time.

\subsection{Analysis:}

Soluble iron is analyzed with an atomic absorption unit from Perkin Elmer (Model \#2380) as shown in Figure 5-2. Mercuric ion is analyzed by modifying an existing method. The existing method is based on the reduction of mercuric ion to elemental mercury in the presence of sodium tetra hydro borate before being analyzed as the vapor in a mercury hydride system connected to an atomic absorption unit.

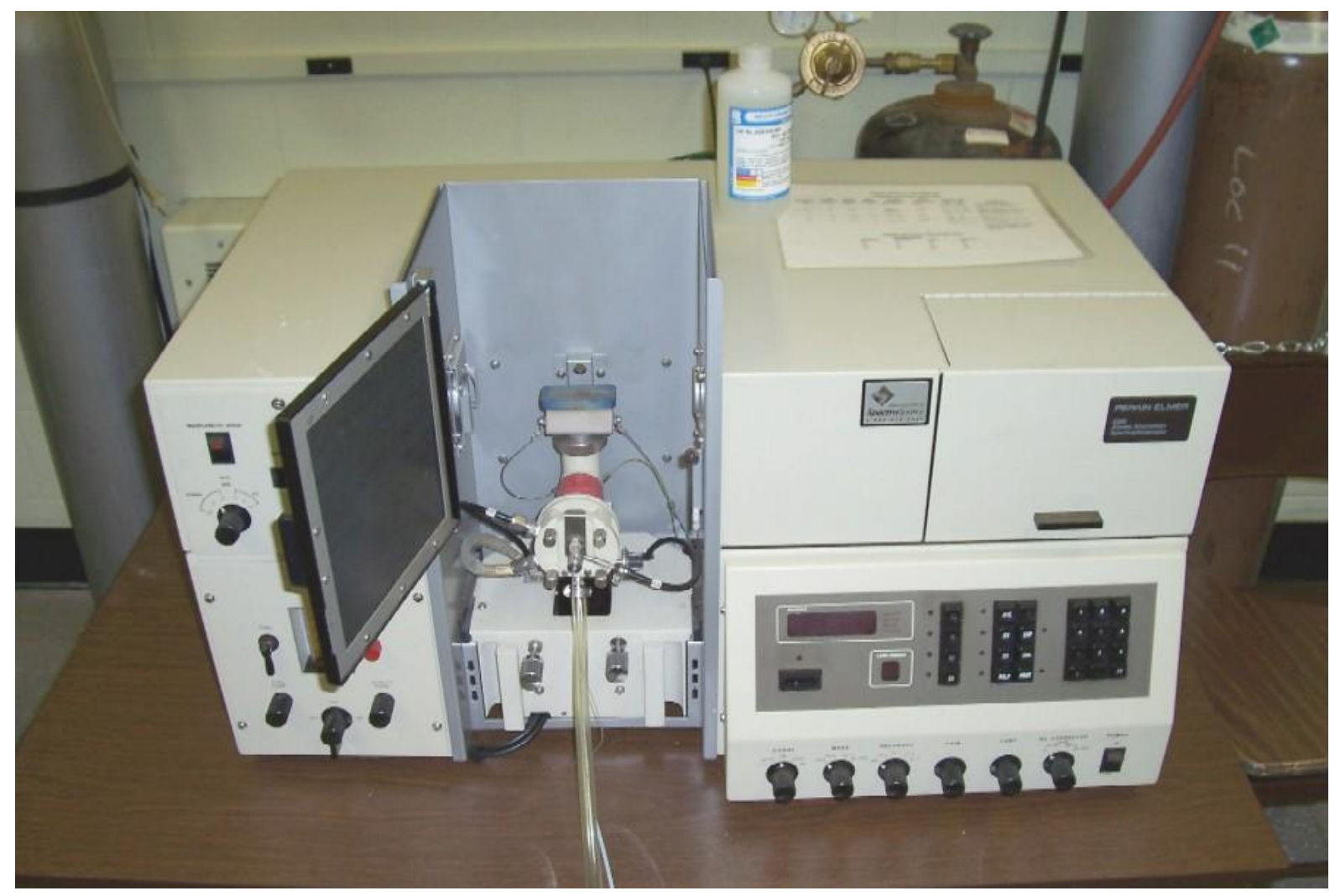

Figure 5-2 Atomic Absorption Unit (Perkin Elmer Model \#2380) 


\subsubsection{Reasons for Modification:}

The problem with the existing method for the analysis of mercury is that it suffered from interference with soluble iron. During the reduction of mercuric ion, the soluble iron is also reduced to elemental iron and precipitated. Mercuric ion seems to be co-precipitated with the iron, which reduced the absorbance to little or no value. The soluble iron came from the dissolution of coal pyrite and non-pyritic iron. The concentration of soluble iron reached levels as high as $183 \mathrm{ppm}$ during three hours of leaching.

\subsubsection{Modification:}

The modification to the existing method for mercury analysis is done by adding citrate. This solved the interference from iron as it forms strong complexes with soluble iron but not with mercuric ion ${ }^{8}$; thus, eliminating the possibility of the reduction of soluble iron during analysis ${ }^{10}$.

\subsection{Analysis Procedure:}

The equipment used for analysis was an Atomic Absorption Unit from Perkin Elmer (model \#2380) as shown in Figure 5-2. The samples for analysis were prepared everyday by adding 9 milliliters of the filtrate ( from the reactor) with $3 \mathrm{ml}$ of a $7.5 \%$ nitric acid solution, $3 \mathrm{ml}$ of a 0.4 molar citrate solution and $100 \mu \mathrm{L}$ of a 1 ppm mercury stock solution. After thorough mixing, $10 \mathrm{ml}$ of this solution is used for the analysis. $100 \mu \mathrm{L}$ of stock solution was added to facilitate the analysis of very small amount of mercury from the leached solution. Standard solutions were prepared everyday by adding $9 \mathrm{ml}$ of de-ionized water with $3 \mathrm{ml}$ of a $7.5 \%$ nitric acid solution and $3 \mathrm{ml}$ of a 0.4 molar citrate solution after which 100, 200 and $300 \mu \mathrm{L}$ of a 1 ppm mercury stock solution were added to prepare standard solutions containing 6.62, 13.16 and 19.61 ppb mercury, respectively. The $1 \mathrm{ppm}$ mercury stock solution was also prepared fresh every day. 10 milliliters of sample from each of these standards was used for analysis.

The maximum absorbance value was taken from a data acquisition module-computer system for each analysis run. The concentration of mercury was determined from a calibration curve of absorbance versus concentration for the standard solutions as shown in Figure 5-3 below. 


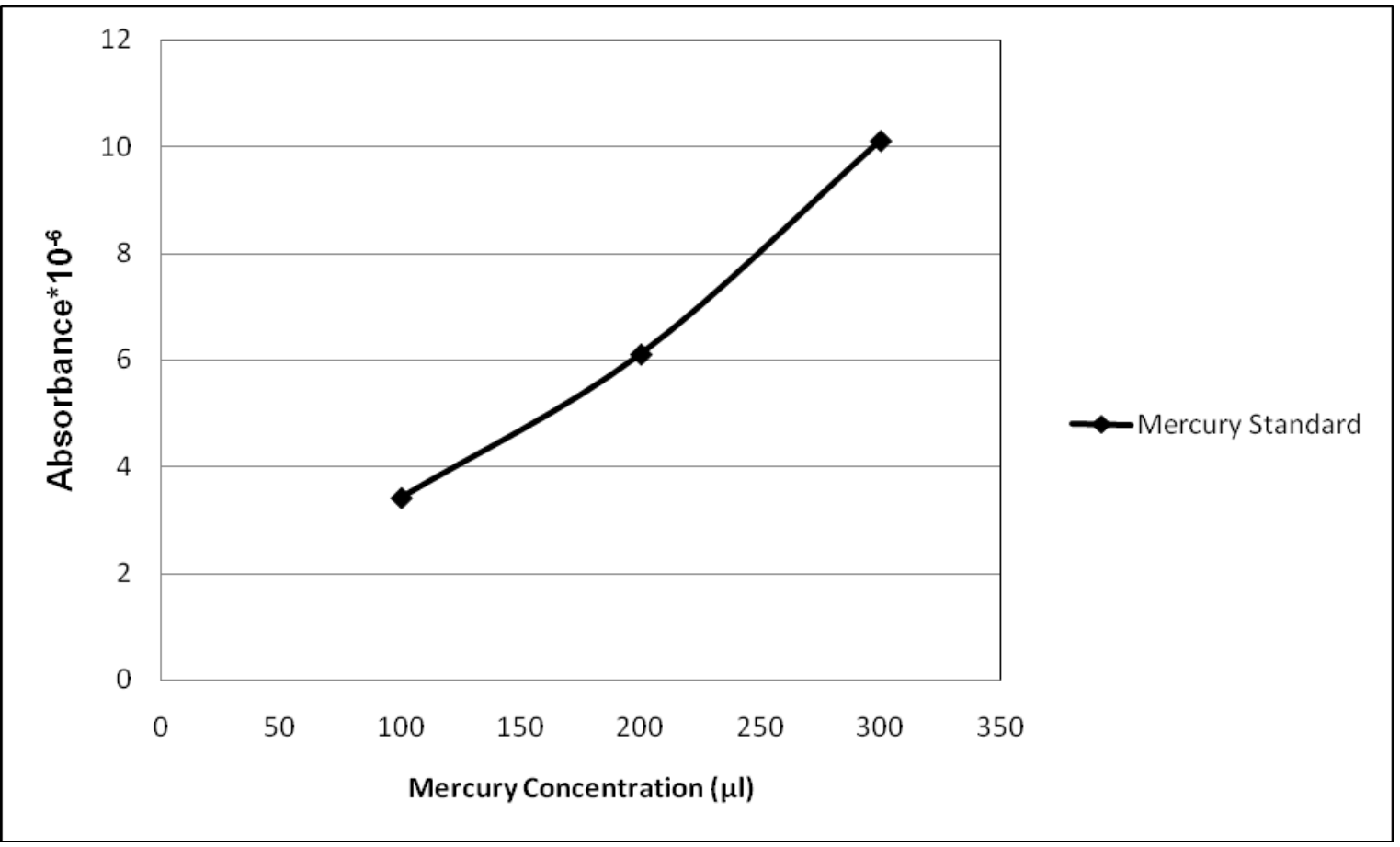

Figure 5-3 Calibration curve of Absorbance VS Concentration for mercury standards for Pittsburgh No.8 coal

The concentration of mercury in the liquid sample was converted to leaching conversion (fraction of mercury reacted) using the original mercury content $(0.177 \mathrm{ppm})$ in the coal sample used.

\subsection{Material balance for mercury:}

Amount of mercury in the reactor (before leaching)

$$
=50 * 0.177 / 10^{6}=8.85^{*} 10^{-6} \mathrm{gm}
$$

Cumulative amount leached by the end of the leaching process $=92.09 \%$

$$
\begin{aligned}
& =0.9209 * 8.85^{*} 10^{-6} \mathrm{gm} \\
& =8.15^{*} 10^{-6} \mathrm{gm}
\end{aligned}
$$

Leached coal was dried thoroughly and was sent to commercial analyzer (standard laboratories Inc.) for mercury analysis. The mercury content in the leached coal sample was found to be $\underline{0.0125 \mathrm{ppm}}$.

Mercury content in the leached coal $\quad=50 * 0.0125 / 10^{6}=0.625 * 10^{-6} \mathrm{gm}$ 
Overall balance:

Amount in feed $=$ Amount Leached + Amount remaining in Leached Coal Sample

$$
\begin{array}{ll}
8.85^{*} 10^{-6} \mathrm{gm} & =8.15^{*} 10^{-6} \mathrm{gm}+0.625^{*} 10^{-6} \mathrm{gm} \\
8.85 * 10^{-6} \mathrm{gm} & \sim 8.775^{*} 10^{-6} \mathrm{gm}
\end{array}
$$

Material balance for Illinois No.6 Coal was also calculated in similar method as above to verify the amount of mercury during the leaching process. It can be shown as:

Amount of mercury in the reactor (before leaching) $\quad=50 * 0.216 / 10^{6}=10.8^{*} 10^{-6} \mathrm{gm}$

Cumulative amount leached by the end of the leaching process $=97.58 \%$

$$
\begin{aligned}
& =0.9758 * 10.8 * 10^{-6} \mathrm{gm} \\
& =10.54 * 10^{-6} \mathrm{gm}
\end{aligned}
$$

Leached coal was dried thoroughly and was sent to commercial analyzer (standard laboratories Inc.) for mercury analysis. The mercury content in the leached coal sample was found to be $\underline{0.0048 p p m}$.

Mercury content in the leached coal

$$
=50 * 0.0048 / 10^{6}=0.24 * 10^{-6} \mathrm{gm}
$$

Overall balance:

Amount in feed $=$ Amount Leached + Amount remaining in Leached Coal Sample

$$
\begin{array}{ll}
10.8 * 10^{-6} \mathrm{gm} & =10.54 * 10^{-6} \mathrm{gm}+0.24 * 10^{-6} \mathrm{gm} \\
10.8 * 10^{-6} \mathrm{gm} & \sim 10.78 * 10^{-6} \mathrm{gm}
\end{array}
$$




\subsection{Problems Faced:}

The largest problem with the analysis of mercury came from the contamination of glassware through experiments and analysis procedures because of the extremely low range of mercury concentration. Thus, after each experiment, the reactor and condenser were thoroughly washed with $10 \%$ nitric acid solution, followed by washing with de-ionized water. Also, the pipettes and filter assembly were thoroughly washed the same way between uses. The plastic tips of the automatic pipette used for preparing mercury stock solutions were discarded after one-time use. The $10 \mathrm{ml}$ pipettes used for the mercury hydride system were immersed in 10\% hydrochloric acid overnight and washed with deionized water the next day. 


\section{CHAPTER 6}

\section{RESULTS AND DISCUSSION}

This chapter deals with the results obtained from various experimental conditions and conclusions drawn from these results.

Pittsburgh No.8 Coal Results:

\subsection{Temperature Effect for Pittsburgh No.8 Coal:}

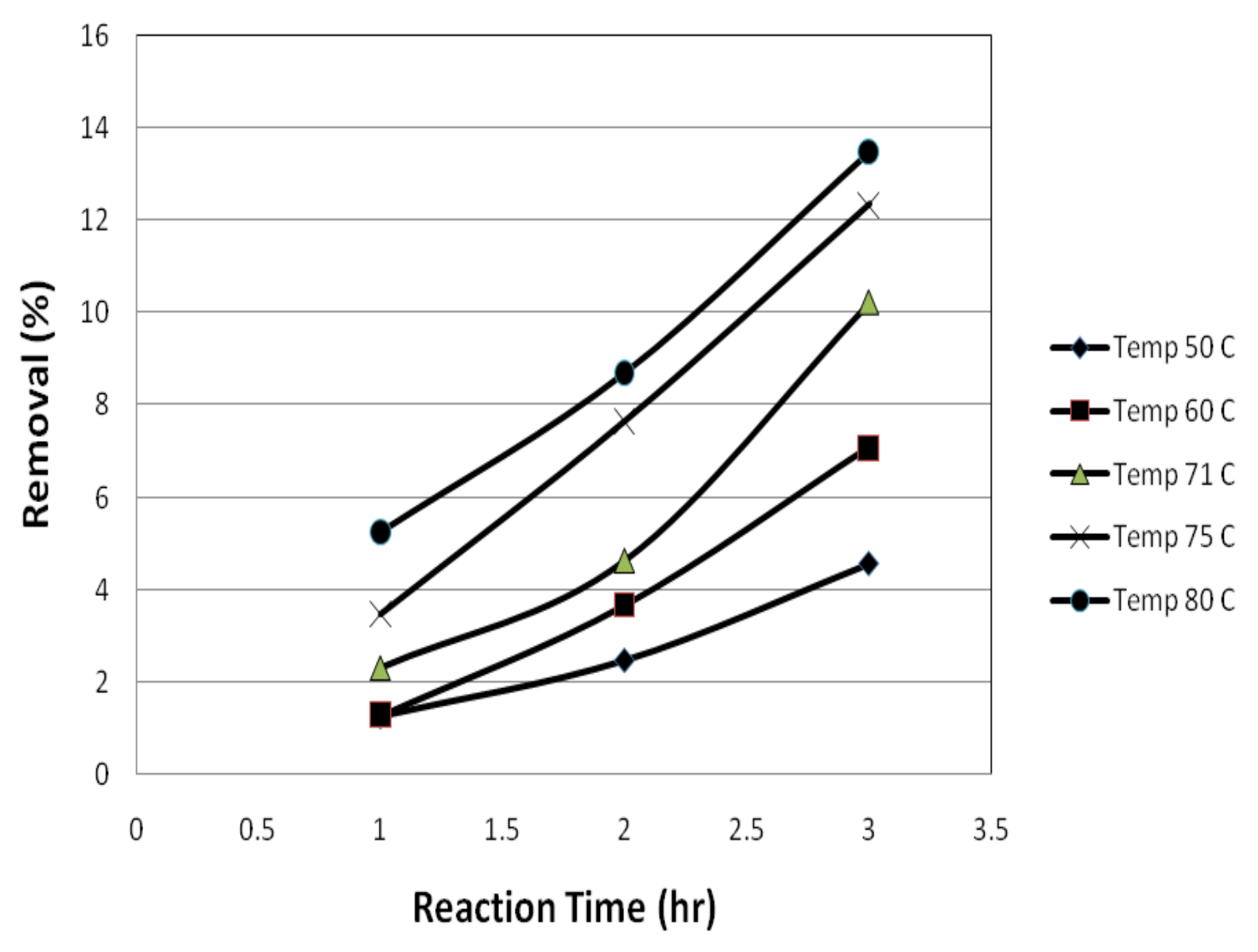

Figure 6-1 Percentage removals of pyrite at $\mathrm{pH} 5.7$ and varying temperatures for Pittsburgh No.8 Coal (1000 $\mathrm{ppm} \mathrm{SO}_{2}$ and $10 \% \mathrm{O}_{2}$ ) 
Figures 6-1 and 6-2 show the effect of temperature on the pyrite and mercury removal respectively. The temperatures are varied from 50 to $80^{\circ} \mathrm{C}$. It is clear that the mercury removal percentages are much higher than those of pyrite. The leaching conversions of pyrite were calculated over the combined amount of pyritic and non-pyritic iron. This was because the soluble iron in the solution could not be distinguished from the source of pyritic iron or non-pyritic iron. Also, it is seen that the removals of both species of pyrite and mercury increase as temperature increases. The total mercury removal percentage increases from $44.2 \%$ at $50^{\circ} \mathrm{C}$ to $88.6 \%$ at $75^{\circ} \mathrm{C}$ in three hours, but it slightly decreases to $85.1 \%$ at $80^{\circ} \mathrm{C}$. The decrease in conversion when the temperature increased from 75 to $80^{\circ} \mathrm{C}$ is due to the decrease in solubility of $\mathrm{SO}_{2}$ as shown in Figure 2-3.

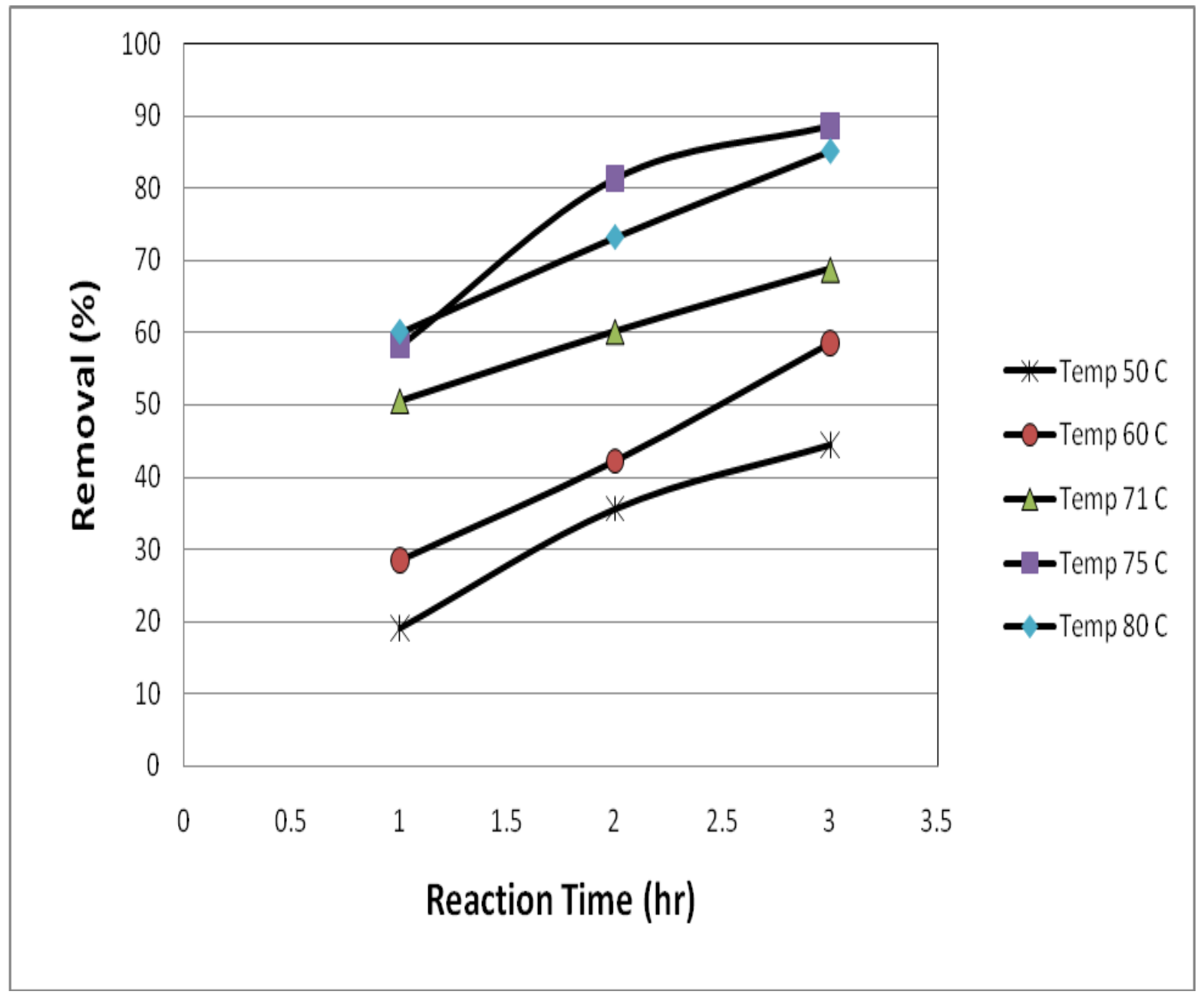

Figure 6-2 Percentage removals of Mercury at $\mathrm{pH} 5.7$ and varying temperatures for Pittsburgh No.8 Coal (1000 $\mathrm{ppm} \mathrm{SO}_{2}$ and $\left.10 \% \mathrm{O}_{2}\right)$ 


\section{$6.2 \mathrm{pH}$ Effect on Pittsburgh No.8 Coal:}

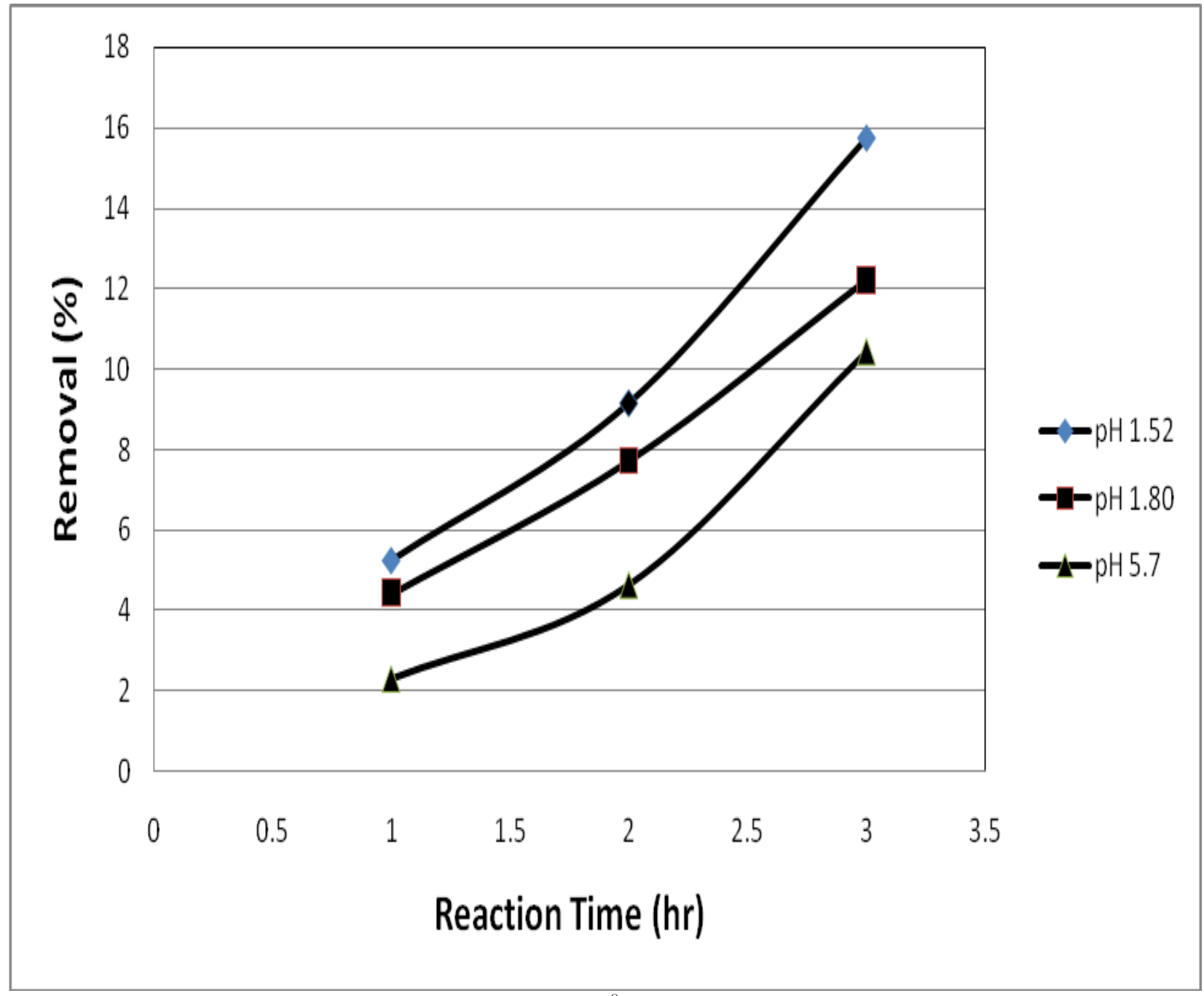

Figure 6-3 Percentage removals of Pyrite at $70.5^{\circ} \mathrm{C}$ and at varying $\mathrm{pH}$ values for Pittsburgh No.8 Coal (1000 $\mathrm{ppm} \mathrm{SO}_{2}$ and $10 \% \mathrm{O}_{2}$ ).

From Figures 6-3 and 6-4, it can be noticed that removal percentages of Pyrite and Mercury increase with the decreasing initial $\mathrm{pH}$, which is due to the more $\mathrm{H}_{2} \mathrm{SO}_{3}$ availability at lower $\mathrm{pH}$ value. This suggests that the solubility if sulfur-dioxide and oxygen gases increases with decrease in $\mathrm{pH}$. 


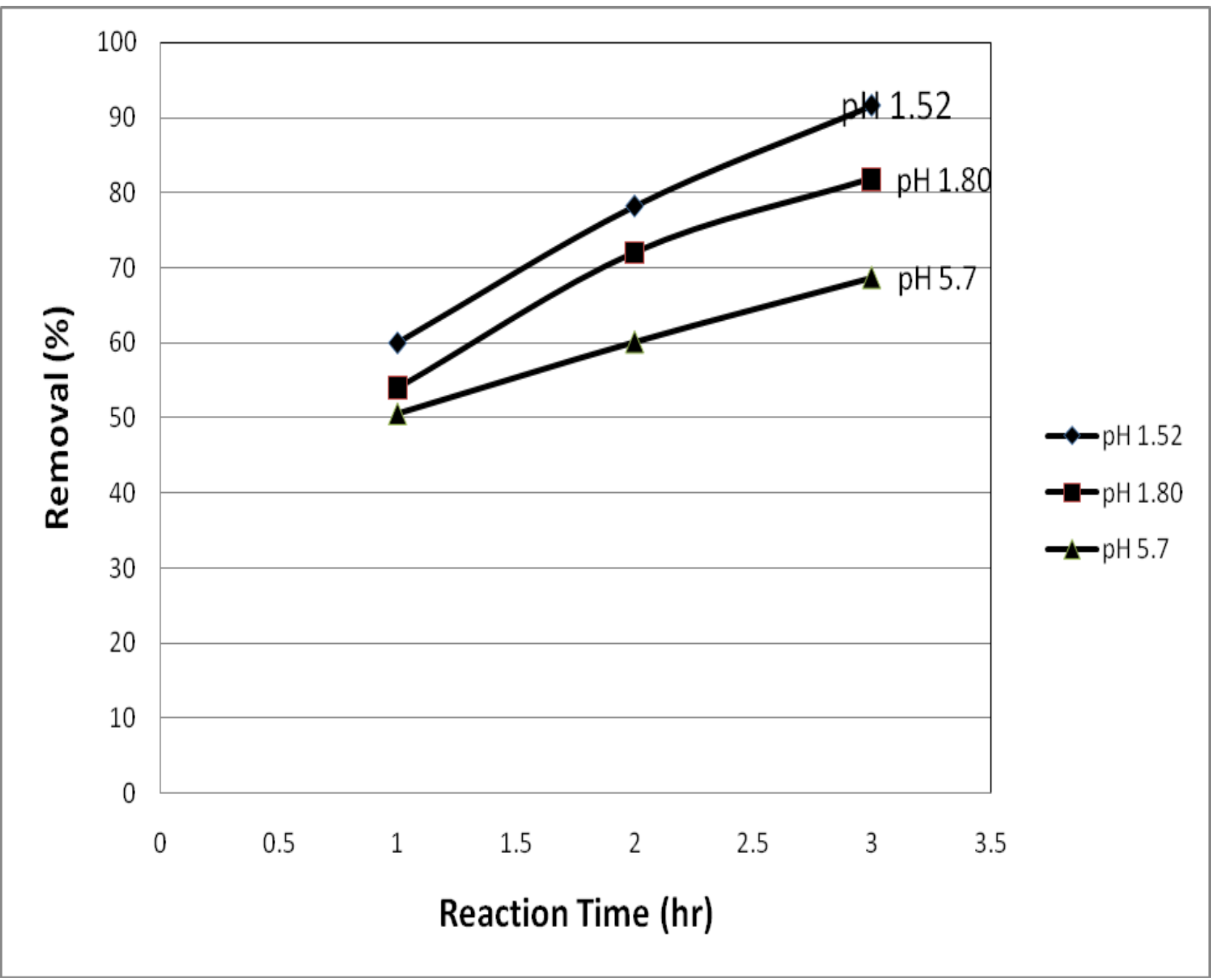

Figure 6-4 Percentage removals of Mercury at $70.5^{\circ} \mathrm{C}$ and at varying $\mathrm{pH}$ values for Pittsburgh No.8 Coal (1000 ppm SO 2 and 10\% $\mathrm{O}_{2}$ )

From the Figure 6-4, it can be seen that mercury removal reached about $91 \%$ in three hours at initial $\mathrm{pH}$ of 1.52. This high value strongly suggests that the present leaching scheme has the potential for mercury removal in a commercial process.

Figures 6-3 and 6-4 show the pyrite and mercury removal percentages as a function of initial $\mathrm{pH}$. 


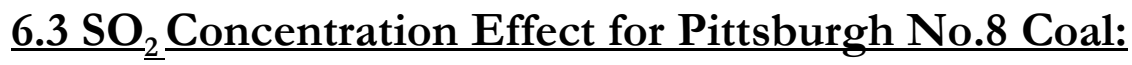

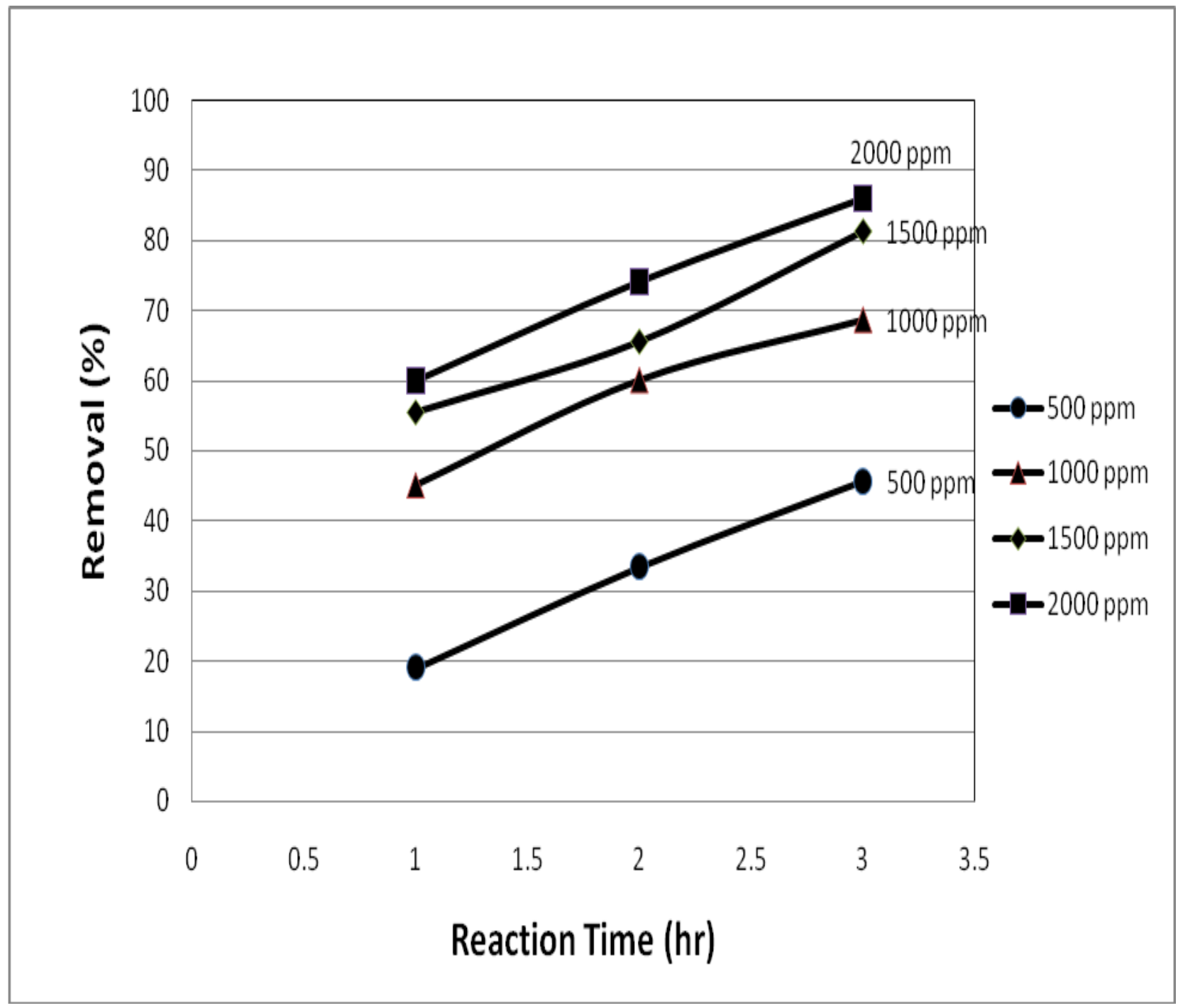

Figure 6-5 Percentage removals of Mercury at $70.5^{\circ} \mathrm{C}, \mathrm{pH} 5.7$ and varying concentrations of $\mathrm{SO}_{2}$ gas. $\left(10 \% \mathrm{O}_{2}\right)$

The $\mathrm{SO}_{2}$ concentration in the gas stream is varied from 500 to $2000 \mathrm{ppm}$ while the $\mathrm{O}_{2}$ concentration is held constant at 10\%. It can be seen from the Figure 6-5 that the removal percentage increases significantly as the $\mathrm{SO}_{2}$ concentration increases from 500 to $1000 \mathrm{ppm}$. Mercury removal percentage reaches $86 \%$ at $2000 \mathrm{ppm}$ of $\mathrm{SO}_{2}$ after three hours of reaction time. At $1000 \mathrm{ppm}$, which is about the average concentration in the flue gas stream from coal fired power plants, the mercury removal percentage is $69 \%$ after three hours of reaction time, verifying the feasibility of this technology. 


\section{${\underline{6.4 O_{2}}}_{2}$ Effect Results for Pittsburgh No.8 Coal:}

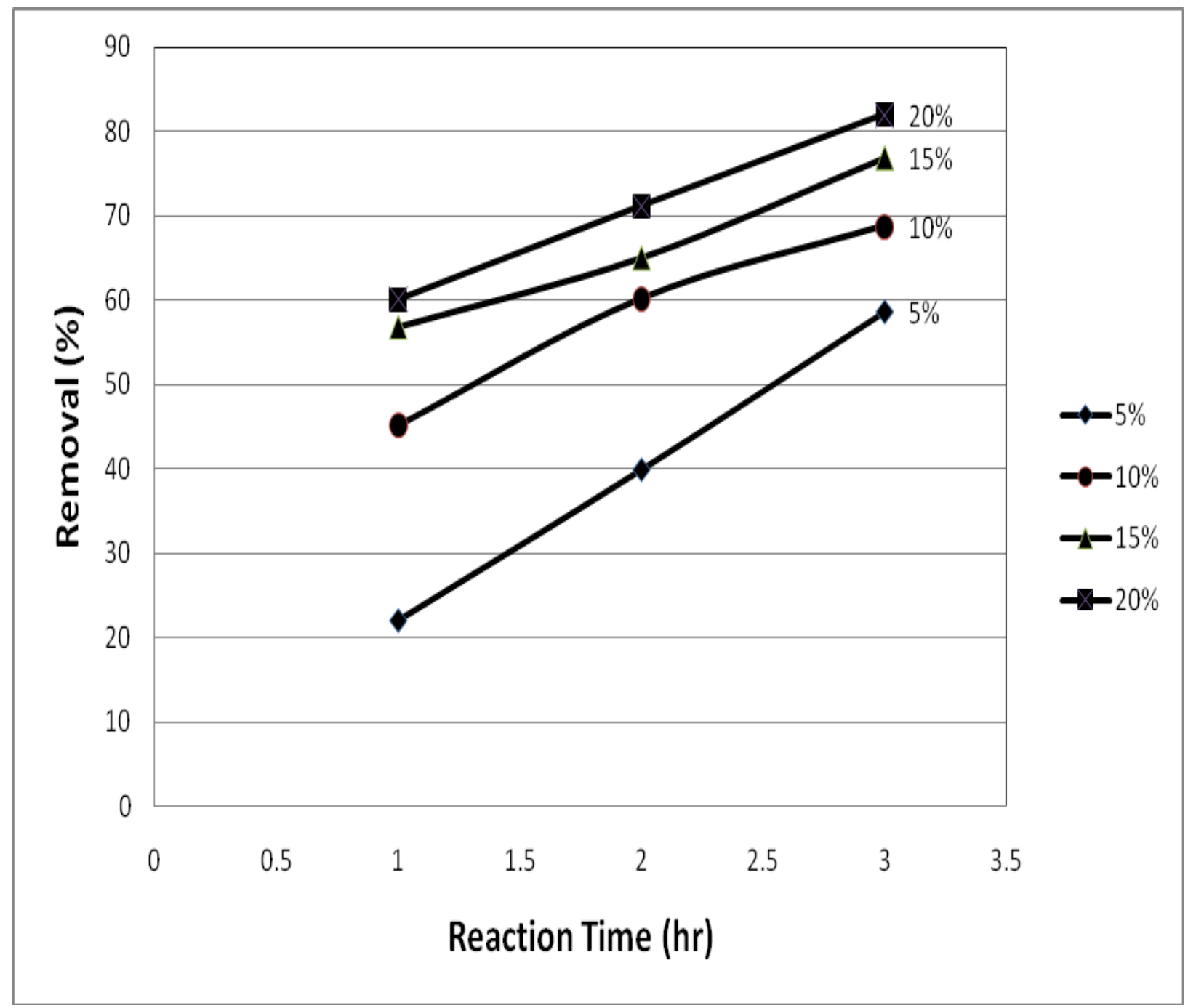

Figure 6-6 Percentage removals of Mercury at $70.5^{\circ} \mathrm{C}, \mathrm{pH} 5.7$ and varying concentrations of $\mathrm{O}_{2}$ gas.(1000 $\left.\mathrm{ppm} \mathrm{SO}_{2}\right)$

The $\mathrm{O}_{2}$ concentration in the gas stream is varied from 5 to $20 \%$ while keeping the $\mathrm{SO}_{2}$ concentration constant at $1000 \mathrm{ppm}$. It can be seen from the Figure 6-6 that the removal percentage increases significantly as the $\mathrm{O}_{2}$ concentration increases from 5 to $10 \%$. Mercury removal percentage reaches $82 \%$ at $20 \% \mathrm{O}_{2}$ after three hours of reaction time. At $10 \% \mathrm{O}_{2}$, which is about the average concentration in flue gas stream from coal fired power plants, the mercury removal percentage is $69 \%$ after three hours of reaction time, verifying the feasibility of this technology. Tthe solubility of $\mathrm{O}_{2}$ in water decreases with increase in temperature. 


\subsection{Leaching without Gas for Pittsburgh No.8 Coal:}

Coal sample was leached in a separate experiment to determine the mercury fraction that can be leached by sulfuric acid only. $500 \mathrm{ml}$ of $1 \mathrm{~N}$ sulfuric acid solution was used to leach $50 \mathrm{gm}$ of 35 x 65 mesh coal. The temperature is maintained at $80^{\circ} \mathrm{C}, \mathrm{pH}$ of about 1.01 and the reaction time was 3 hours. It is found that the fraction of acid-soluble mercury was $40 \%$. Much of this amount may be $\mathrm{HgO}$. There are other species, such as $\mathrm{HgS}$ and organic mercury and these are leached. At this moment, because there is no information available on the rate of each, further analysis is not possible. So this experiment confirms that the $\mathrm{SO}_{3}^{-}$from the sulfuric acid can also leach by itself without the aid of flue gas.

\section{Illinois No.6 Coal Results:}

\subsection{Temperature Effect for Illinois No.6 Coal :}

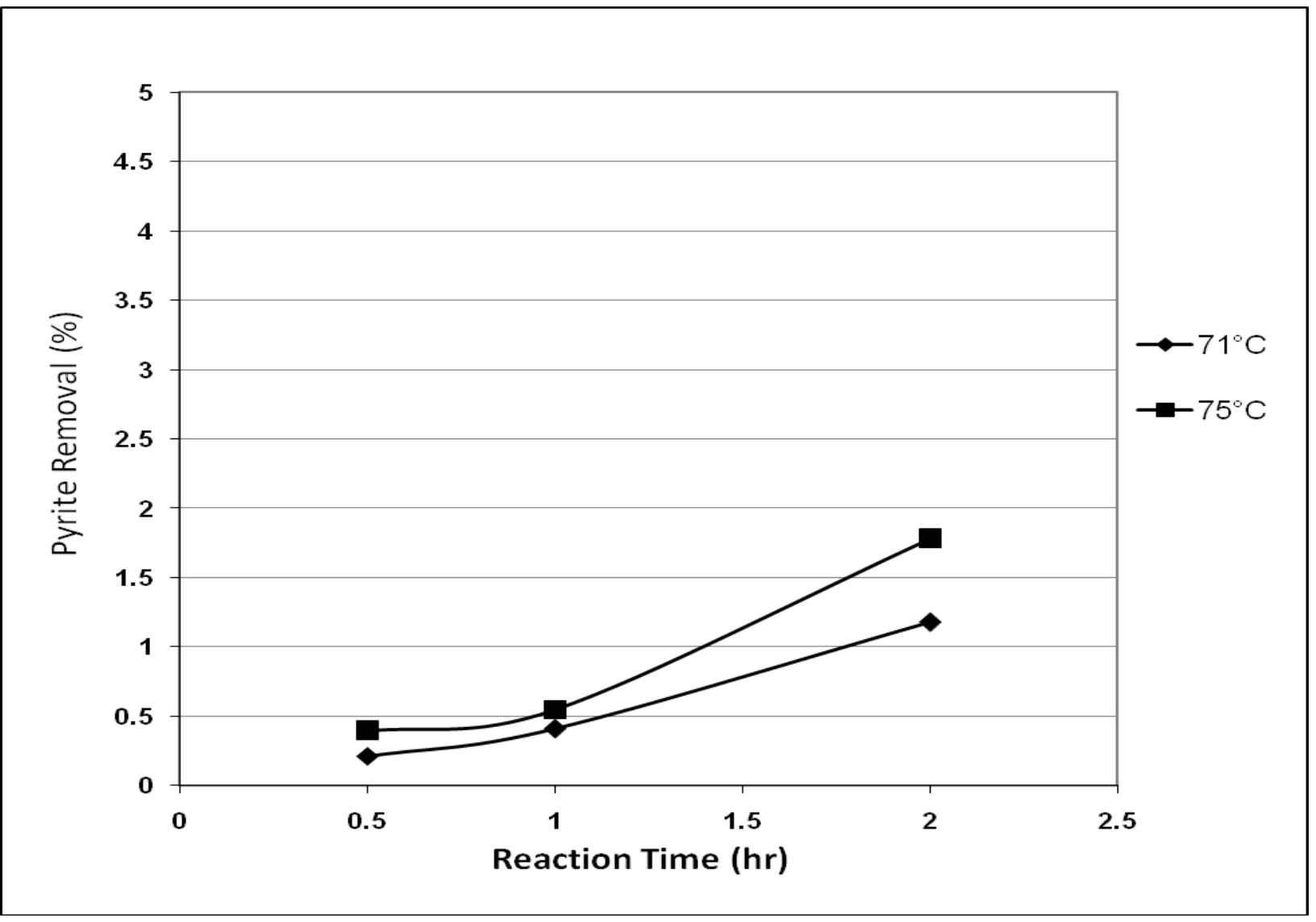

Figure 6-7 Percentage removals of Pyrite at $\mathrm{pH} 5.7$ and varying temperatures for Illinois No.6 Coal (1000 ppm $\mathrm{SO}_{2}$ and $10 \% \mathrm{O}_{2}$ ) 
Figure 6-7 shows the pyrite removal percentages at 71 and $75^{\circ} \mathrm{C}$ and $\mathrm{pH}$ 5.7. The leaching percentages were calculated over the combined amount of pyritic and non-pyritic irons. This was because the soluble iron in the solution could not be distinguished from the source of pyritic iron or non-pyritic iron. However, this calculation method and the method using the pyritic iron as the basis may not be much different because the non-pyritic iron content is only $11.6 \%$ of the pyritic iron. It is seen from Figure 6-7 that the pyrite removal percentages are very low. They are $1.2 \%$ at $71^{\circ} \mathrm{C}$ and $1.8 \%$ at $75^{\circ} \mathrm{C}$ after 2 hours of reaction time, which are much lower than those of Pittsburgh No. 8 coal $^{6}$. The values were 4.2 and $6.9 \%$, respectively with the Pittsburgh No. 8 coal. Because of the relatively low values of pyrite removal percentages, this study was not further experimented at lower temperatures.

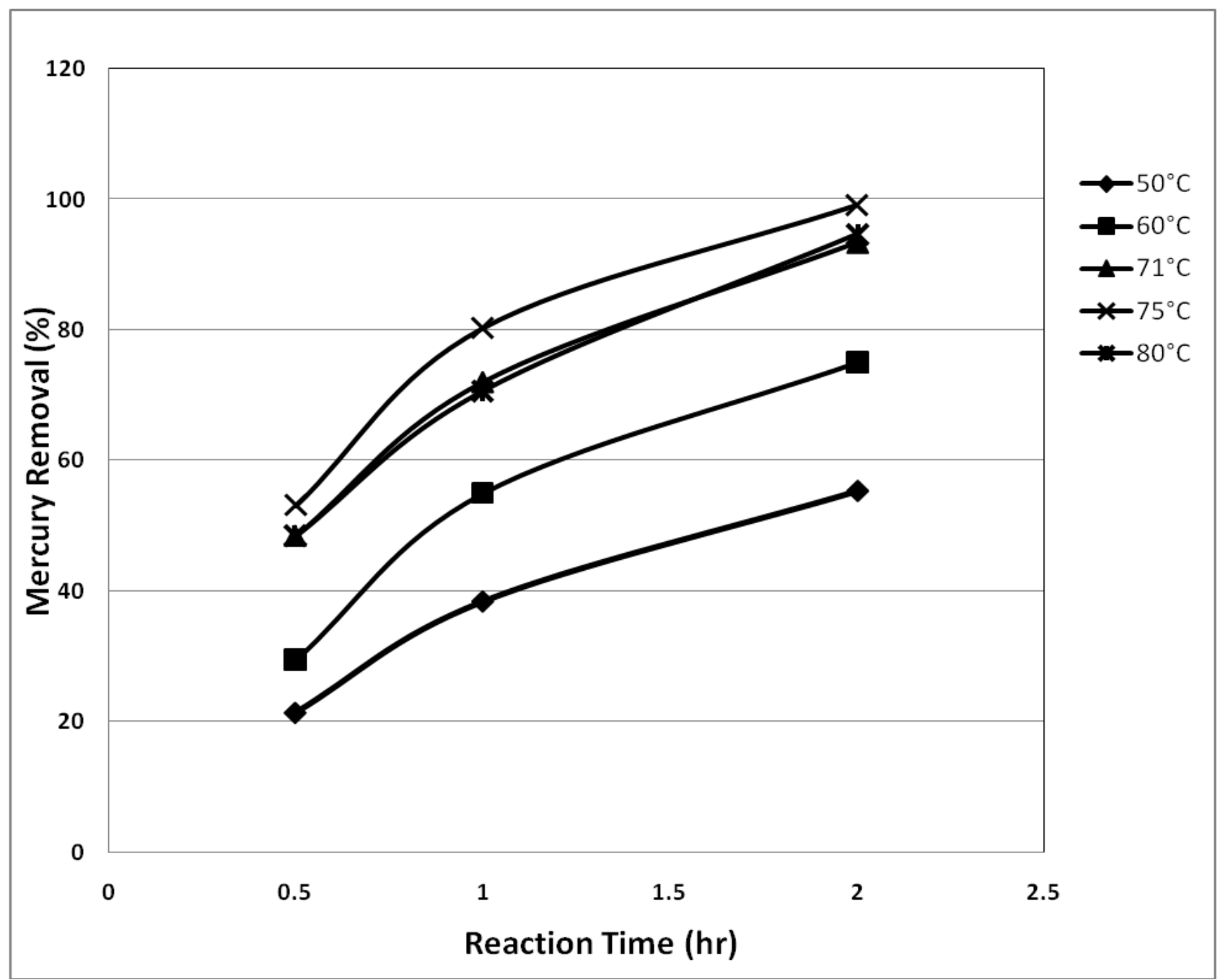

Figure 6-8 Percentage removals of Mercury at $\mathrm{pH} 5.7$ and varying temperatures for Illinois No.6 Coal (1000 ppm $\mathrm{SO}_{2}$ and $10 \% \mathrm{O}_{2}$ ). 
Figure 6-8 shows the effect of temperature on the mercury removal from Illinois No.6 Coal. The temperatures are varied from 50 to $80^{\circ} \mathrm{C}$. It is seen that the removal of mercury increases as temperature increases. The total mercury removal percentage increases from $21.38 \%$ at $50^{\circ} \mathrm{C}$ to $99.15 \%$ at $75^{\circ} \mathrm{C}$ in two hours, but it slightly decreases to $94.68 \%$ at $80^{\circ} \mathrm{C}$. The decrease in conversion when the temperature increased from 75 to $80^{\circ} \mathrm{C}$ is due to the decrease in solubility of $\mathrm{SO}_{2}$ and $\mathrm{O}_{2}{ }^{9}$. This phenomenon can be related to the observation by Adams and Mattew ${ }^{10}$ that the leaching rate of sphalerite $(\mathrm{ZnS})$ with $\mathrm{SO}_{2}$ and $\mathrm{O}_{2}$ showed a maximum around $85^{\circ} \mathrm{C}$.

It is also clear from Figures 6-7 and 6-8 that the mercury removal percentages are much higher than those of pyrite. This result suggests that a substantial amount of mercury in Illinois No.6 coal is not associated with coal pyrite. There must then be other forms of mercury which are co-existent such as $\mathrm{HgO}$.

\section{7pH Effect for Illinois No.6 Coal:}

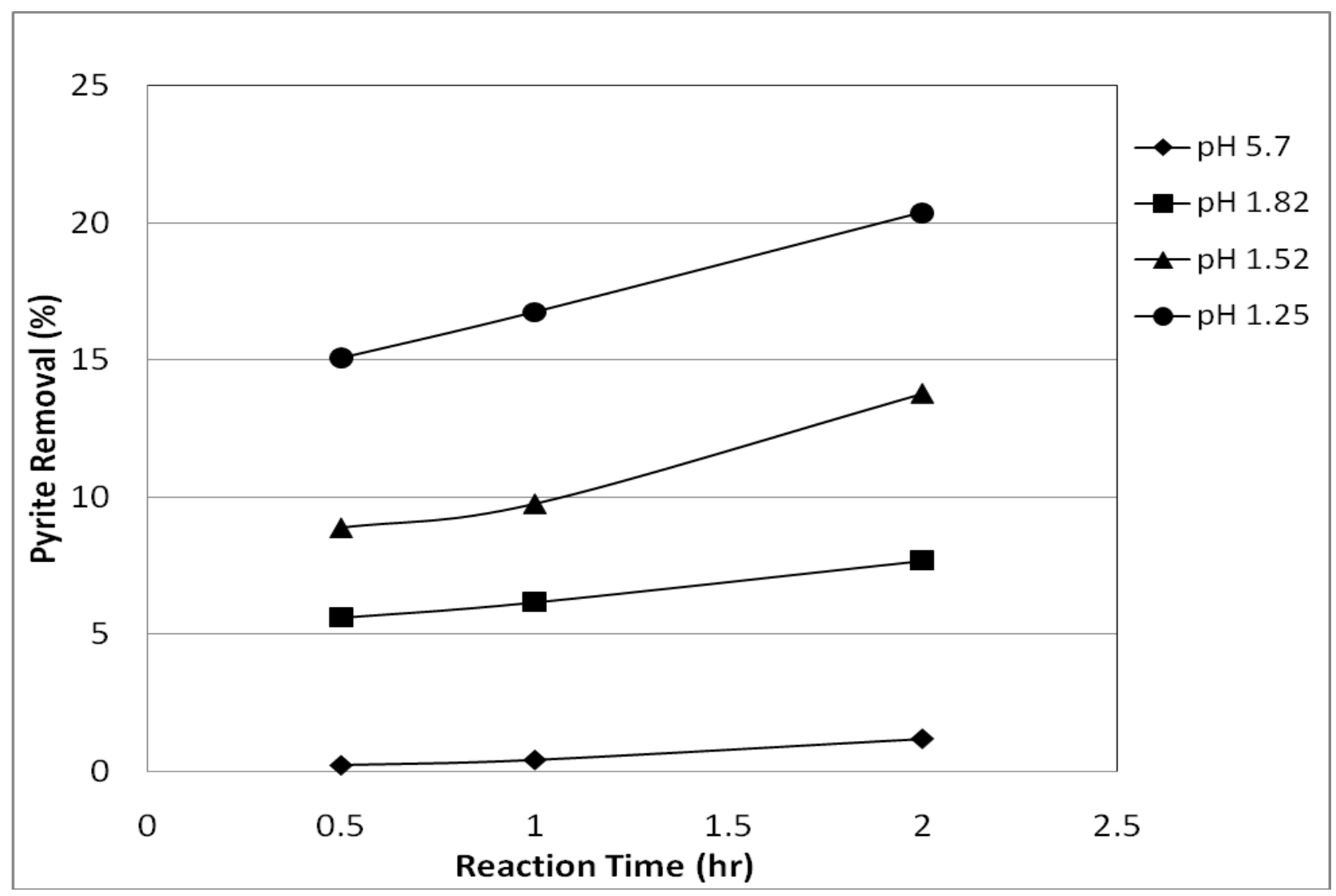

Figure 6-9 Percentage removals of Pyrite at $70.5^{\circ} \mathrm{C}$ and at varying $\mathrm{pH}$ values for Illinois No.6 Coal $\left(1000\right.$ ppm $\mathrm{SO}_{2}$ and $\left.10 \% \mathrm{O}_{2}\right)$ 
Figure 6-9 demonstrates the effect of initial $\mathrm{pH}$ on pyrite removal at $70.5^{\circ} \mathrm{C}$. The initial $\mathrm{pH}$ levels were 5.7, 1.82, 1.52 and 1.25. It is seen from above figure that the pyrite removal percentages increased with decreasing initial $\mathrm{pH}$. It is also seen that the initial $\mathrm{pH}$ effect is large as the pyrite removal percentages increased from $1.2 \%$ at the initial $\mathrm{pH} 5.7$ to $20.4 \%$ at the initial $\mathrm{pH} 1.25$ after 2 hours.

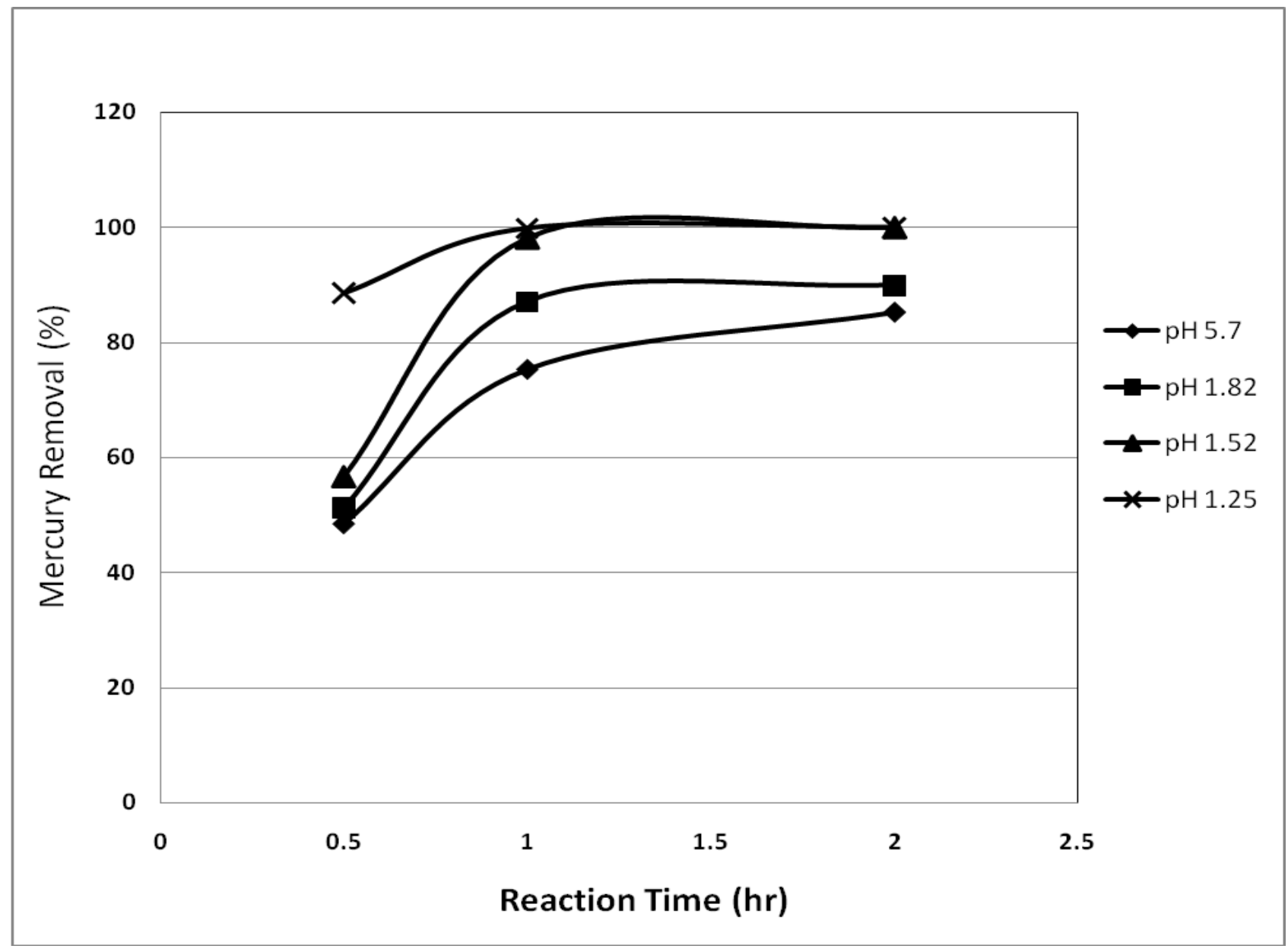

Figure 6-10 Percentage removals of Mercury at $70.5^{\circ} \mathrm{C}$ and at varying $\mathrm{pH}$ values for Illinois No.6 Coal (1000 ppm $\mathrm{SO}_{2}$ and $10 \% \mathrm{O}_{2}$ )

Figure 6-10 demonstrates the effect of $\mathrm{pH}$ on mercury removal at $70.5^{\circ} \mathrm{C}$. The initial $\mathrm{pH}$ levels were 5.7, 1.82, 1.52 and 1.25. As the leaching reactions of both pyrite and mercury (equations 3-5 and 3-6) are acid producing, by the end of three hours the $\mathrm{pH}$ of the final solution in the reactor went down to $1.4,1.28,1.16$ and 1.05 respectively. The decreasing values of the $\mathrm{pH}$ as temperature increases are the results from the increased pyrite leaching conversions. It is seen from above figure that the mercury removal percentages increased with decreasing initial $\mathrm{pH}$. This may be due to the fact that 
more $\mathrm{H}_{2} \mathrm{SO}_{3}$ was available at the lower $\mathrm{pH}$ values as mentioned previously with reactions 3-2 and 33. It is noted that the mercury removal is almost complete at the initial $\mathrm{pH}$ values of 1.52 and 1.25 at 2 hours. It can also be seen that mercury removal reached as much as $100 \%$ in two hours at initial $\mathrm{pH}$ of 1.25. This high value strongly suggests that this leaching scheme has the potential for mercury removal in a commercial process.

\subsection{No Gas Leaching for Illinois No.6 Coal}

Two series of experiments were conducted to remove the mercury with only sulfuric acid: One is at the various temperatures and the other is at the various $\mathrm{pH}$ values. These series were initiated because it had been speculated that a significant fraction of the original mercury is non-pyrite associated like $\mathrm{HgO}^{6}$.

\subsubsection{No Gas Temperature Effect for Illinois No.6 Coal :}

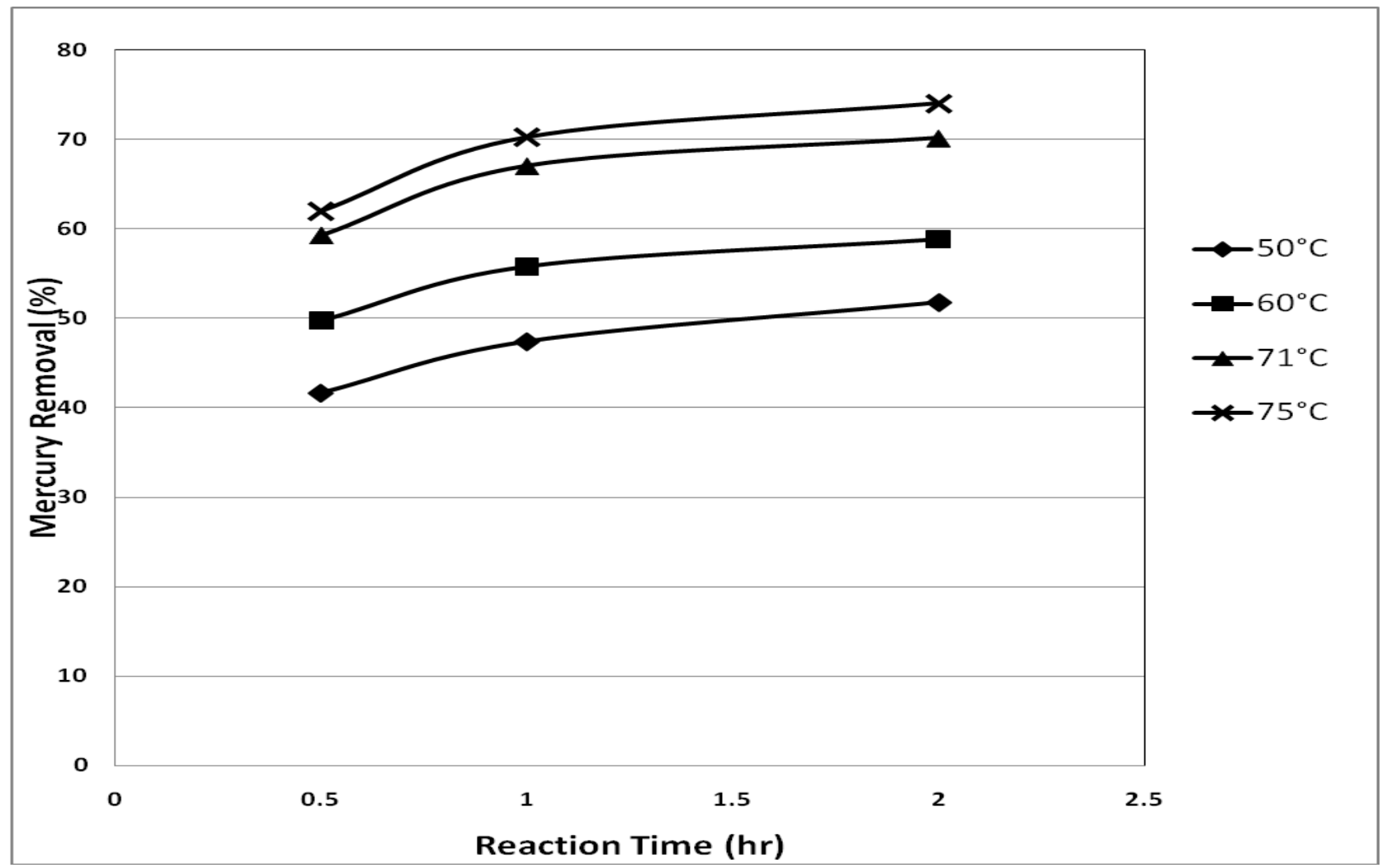

Figure 6-11 Percentage removals of Mercury at $\mathrm{pH} 1.25$ and at varying temperatures and no gas for Illinois No.6 Coal 
Figure 6-11 shows the effect of temperature on mercury removal at 50,60, 71 and $75^{\circ} \mathrm{C}$ and initial $\mathrm{pH} 1.25$ with no $\mathrm{SO}_{2}$ or $\mathrm{O}_{2}$ gas bubbled through the reactor. It is seen that a significant amount of mercury is removed with sulfuric acid alone without any gas. It reaches $74 \%$ at $75^{\circ} \mathrm{C}$ after 2 hours of reaction time. From this it can be said that much of the mercury in Illinois No.6 coal may be acid soluble $\mathrm{HgO}$. However the fraction of $\mathrm{HgO}$ in the Pittsburgh No.8 coal seems to be much lower as the leaching reaction under same conditions yielded only $40 \%$ mercury removal. It can be suspected that the gas $\left(\mathrm{SO}_{2}\right)$ acts as a medium used to increase the concentration of $\mathrm{H}_{2} \mathrm{SO}_{3}$ and to decrease the $\mathrm{pH}$ so as to facilitate the leaching reaction and does not necessarily take part in the leaching reaction.

\subsubsection{No Gas pH Effect for Illinois No.6 Coal:}

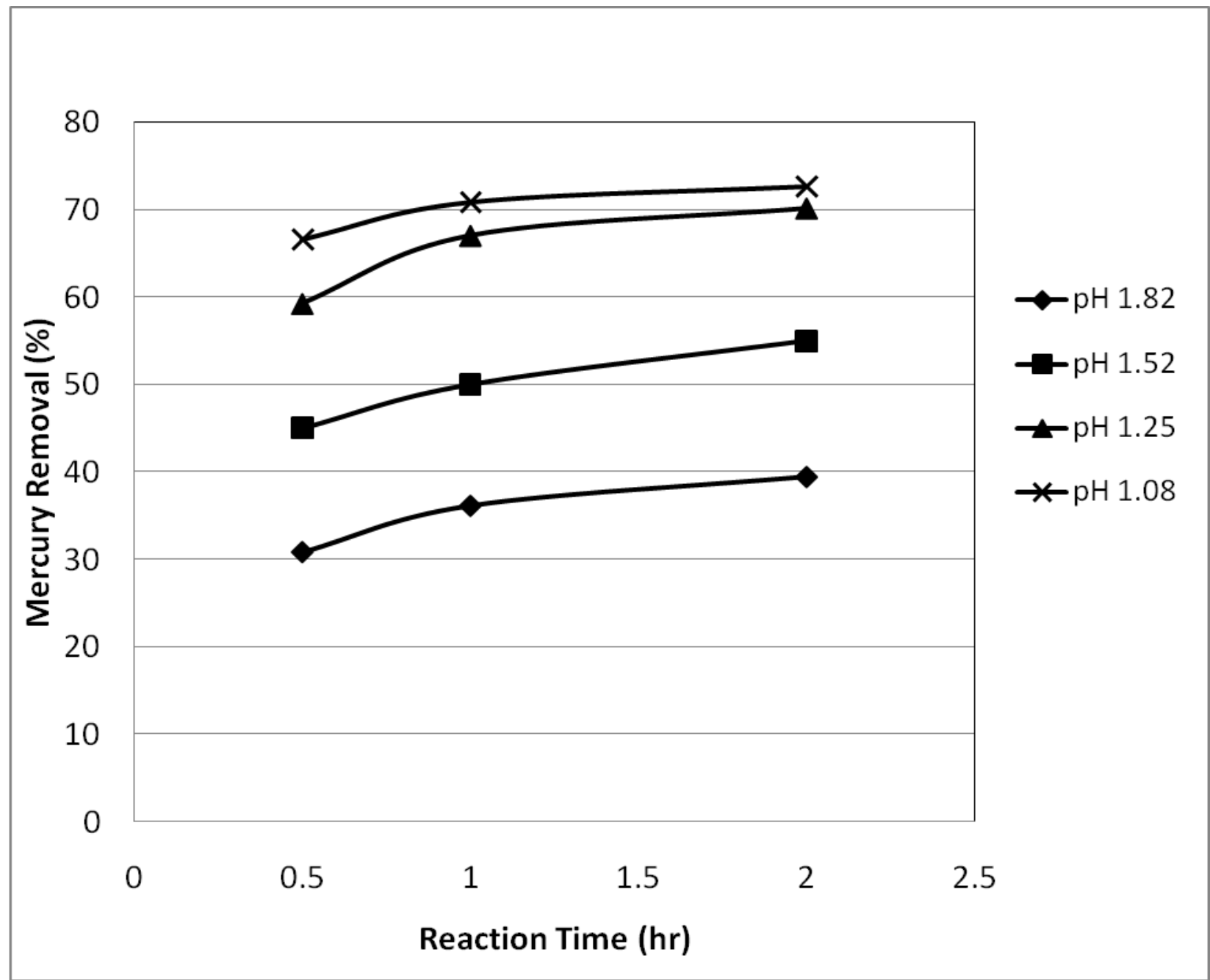

Figure 6-12 Percentage removals of Mercury at $70.5^{\circ} \mathrm{C}$ and at different $\mathrm{pH}$ values and no gas for Illinois No.6 Coal 
Figure 6-12 shows the effect of initial $\mathrm{pH}$ on mercury removal at $70.5^{\circ} \mathrm{C}$ and no gas. The initial $\mathrm{pH}$ was varied from 1.82 to 1.08. Again, it is seen that a significant fraction of mercury is removed. It reaches $73 \%$ at the initial $\mathrm{pH}$ of 1.08 and a temperature of $71^{\circ} \mathrm{C}$. The mercury removal percentages at $\mathrm{pH} 5.7$ were little or none. It is obvious that approximately $75 \%$ of the original mercury is acid soluble. Much of it could be $\mathrm{HgO}$. 


\section{CHAPTER 7}

\section{DISCUSSION}

This chapter deals with the discussion of the results obtained from the experiments and the proposed model for the leaching reaction.

\subsection{Discussion:}

In this study, the leaching rate of pyrite is analyzed by the reaction zone model. This model is based on a shrinking core model in which the reaction zone at the reaction interface moves inward ${ }^{7,13}$. The reaction zone may be viewed as a region in which disseminated pyrite grains are in all stages of reaction. Figure 7-1 represents an idealized coal particle showing the reacted shell, un-reacted core, and reaction zone.

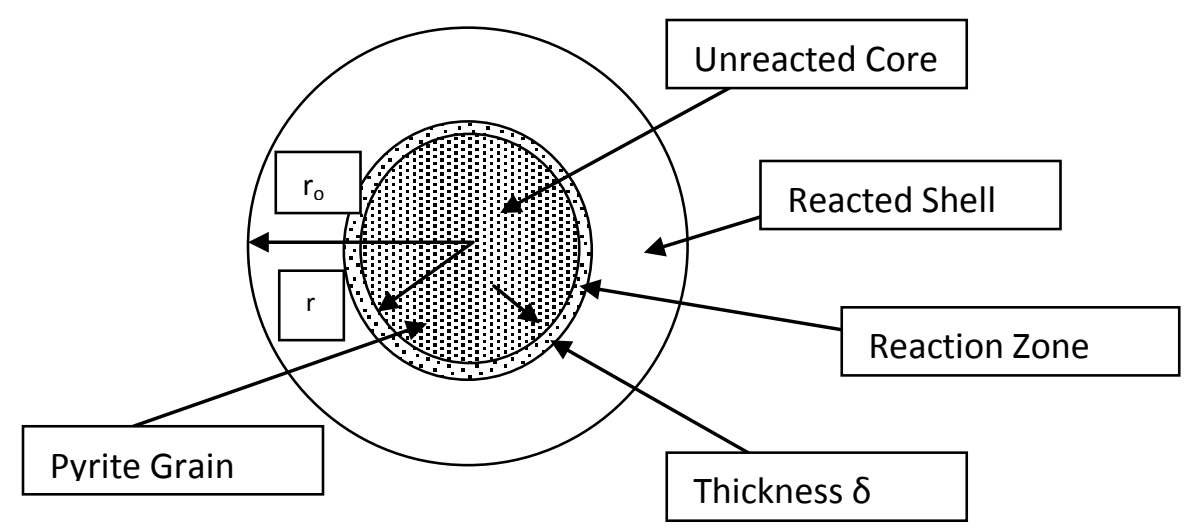

Figure 7-1 Coal particle of radius $r_{0}$ showing Reaction Zone ${ }^{14}$

As the zone moves to smaller values of $\mathrm{r}$ (radius of un-reacted core), un-reacted pyrite grains are included in the zone. At the outer edge of the zone, the last vestige of un-reacted pyrite disappears. The leaching rate based on chemical reactions within the zone may be given as

$$
\frac{d n}{d t}=-\frac{4 \pi r^{2}}{\Phi} \delta * n_{g} * A_{g} *\left[S O_{2}\right]^{p}\left[O_{2}\right]^{q} * k
$$


where,

$\mathrm{n}=$ number of moles of un-leached pyrite in a coal particle at time $\mathrm{t},(\mathrm{mol})$

$\mathrm{p}=$ reaction order with respect to $\left[\mathrm{SO}_{2}\right]$

$\mathrm{q}=$ reaction order with respect to $\left[\mathrm{O}_{2}\right]$

$\delta=$ reaction zone thickness, $(\mathrm{cm})$

$\mathrm{n}_{\mathrm{g}}=$ number of pyrite grains per unit volume of coal in the reaction zone, (moles- $\mathrm{cm}^{-3}$ )

$\mathrm{Ag}=$ average surface area of a pyrite grain, $\left(\mathrm{cm}^{2}\right)$

$\mathrm{k}=$ intrinsic rate constant

$\left[\mathrm{SO}_{2}\right]$ and $\left[\mathrm{O}_{2}\right]=$ concentrations of $\mathrm{SO}_{2}$ and $\mathrm{O}_{2}$ in the reaction zone, respectively, (mol/lit)

$\Phi=$ sphericity of coal particle

Integrating and simplifying this equation under the assumption that the concentration of $\mathrm{SO}_{2}$ and $\mathrm{O}_{2}$ are constant during the reaction and there is no internal or external mass transfer, yields:

$$
1-(1-F)^{1 / 3}=k_{1} t \quad 7-2
$$

In equation $7-2, \mathrm{~F}$ represents the fraction of iron minerals reacted or the conversion that was calculated by the amount of iron in the solution divided by the total iron content of both pyritic and non-pyritic iron contained in the coal sample.

Where,

$$
k_{1}=\frac{3 M \delta}{r_{g} r_{o} \rho_{g}}\left[S O_{2}\right]^{p}\left[O_{2}\right]^{q} k
$$

Where,

$\mathrm{M}=$ molecular weight of pyrite (grams $/ \mathrm{mol})$,

$\mathrm{r}_{\mathrm{g}}=$ average pyrite grain radius $(\mathrm{cm})$,

$\mathrm{r}_{\mathrm{o}}=$ coal particle radius $(\mathrm{cm})$,

$\varrho_{g}=$ density of pyrite $\left(\mathrm{gram} / \mathrm{cm}^{3}\right)$,

$\mathrm{F}=$ fraction of pyrite reacted. 
$\mathrm{k}_{1}=$ apparent rate constant

$\mathrm{k}=$ intrinsic rate constant

The unit of $\mathrm{k}$, the rate constant, depends on the reaction orders of $\mathrm{p}$ and $\mathrm{q}$. For example, if $\mathrm{p}$ and $\mathrm{q}$ are both $1 / 2$, the unit of $\mathrm{k}$ will be liter $/ \mathrm{cm}^{2}-\mathrm{hr}$.

The leaching rate of mercury may be analyzed similarly to that of pyrite using the reaction zone model. If this is the case, the integrated equation may be written as

$$
1-(1-F)^{1 / 3}=k_{2} t
$$

Where $\mathrm{k}_{2}$ is defined by

$$
k_{2}=\frac{3 M_{H g} \delta}{r_{g} r_{o} \rho_{H g}}\left[S O_{2}\right]^{p}\left[O_{2}\right]^{q} k
$$

Where,

$\mathrm{M}=$ molecular weight of mercury species (grams/mol),

$Q_{\mathrm{Hg}}=$ density of mercury (grams $\left./ \mathrm{cm}^{3}\right)$,

$\mathrm{F}=$ fraction of mercury leached.

$\mathrm{k}_{2}=$ apparent rate constant

$\mathrm{k}=$ intrinsic rate constant

The unit of $\mathrm{k}$, the rate constant, depends on the reaction orders of $\mathrm{p}$ and $\mathrm{q}$. For example, if each $\mathrm{p}$ and $\mathrm{q}$ are both $1 / 2$, the unit of $\mathrm{k}$ will be liter $/ \mathrm{cm}^{2}-\mathrm{hr}$. 


\subsection{Pittsburgh No.8 Coal}

Figure 7-2 represents plots according to Equation 7.2 for leaching data of pyrite which are given in Figure 6-1. It is clear that each plot is linear. The slope of each line will be $k_{1}$, the apparent rate constant.

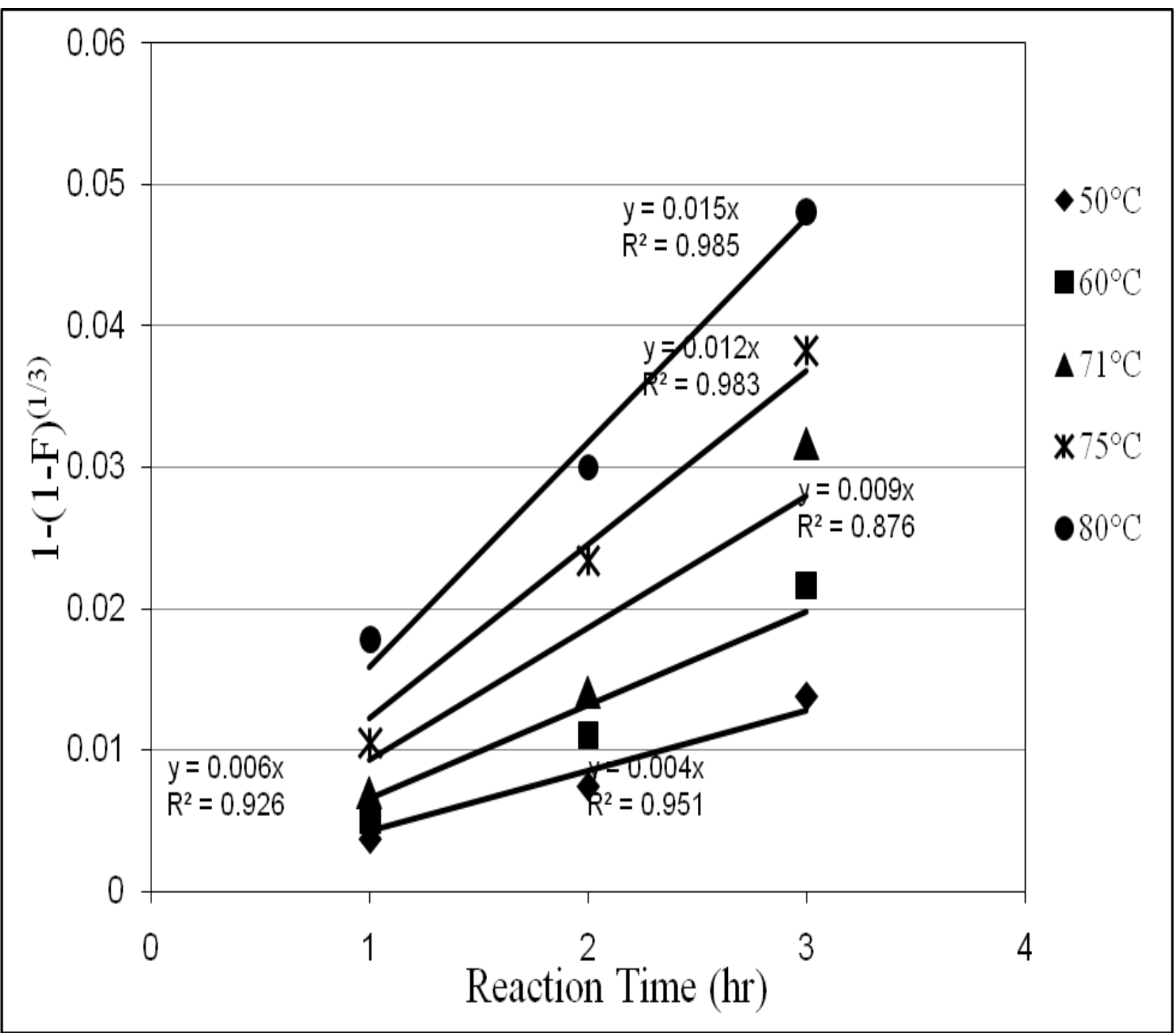

Figure 7-2 Plot of [1-(1-F) 1/3] VS time at various temperatures for pyrite removal for Pittsburgh No.8 Coal at pH 5.7 (1000 $\mathrm{ppm} \mathrm{SO}_{2}$ and $10 \% \mathrm{O}_{2}$ ) 
The values of the apparent rate constants obtained from above plot are tabulated below in the Table 7-1.

Table 7-1 Rate Constant Values for Pyrite Leaching

\begin{tabular}{|c|c|c|}
\hline Serial No. & Temperature $\left({ }^{\circ} \mathrm{C}\right)$ & Rate Constant $\left(\mathrm{k}_{1}\right)(1 / \mathrm{hr})$ \\
\hline 1. & 50 & $4 \times 10^{-3}$ \\
\hline 2. & 60 & $6 \times 10^{-3}$ \\
\hline 3. & 70.5 & $9 \times 10^{-3}$ \\
\hline 4. & 75 & $12 \times 10^{-3}$ \\
\hline 5. & 80 & $15 \times 10^{-3}$ \\
\hline
\end{tabular}

An Arrhenius plot is made with the $\mathrm{k}_{1}$ values and shown in Figure 7-3.

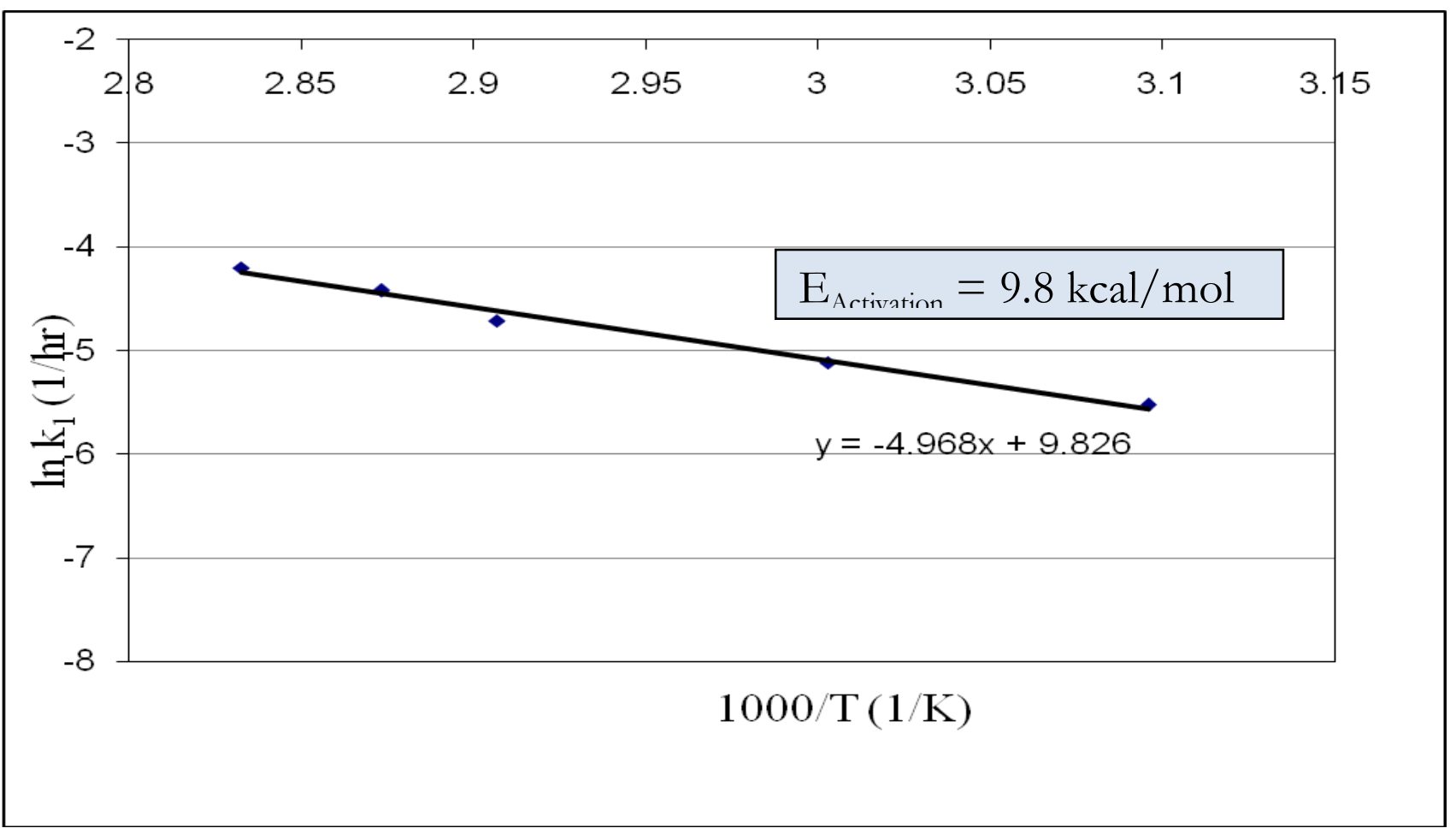

Figure 7-3 Arrhenius Plot for Leaching of Pyrite for Pittsburgh No.8 Coal at pH 5.7 (1000 ppm SO 2 , $\left.10 \% \mathrm{O}_{2}\right)$ 
From the slope, the apparent activation energy was calculated and found to be $9.8 \mathrm{kcal} / \mathrm{mol}$ or $41.3 \mathrm{~kJ} / \mathrm{mol}$. This value is different from the value observed in previous study by Cho in " $\mathrm{SO}_{2}$ removal by leaching Coal Pyrite" ${ }^{7}$, which was found to be $11.6 \mathrm{kcal} / \mathrm{mol}$. The difference of about 10 $\%$ (not too bad) may be due to the different Pittsburgh No.8 coal samples. It is also important to note that the true activation energy may be higher than the apparent activation energy of 9.8 $\mathrm{kcal} /$ mole determined in the present study. This may be because the solubility values of $\mathrm{SO}_{2}$ and $\mathrm{O}_{2}$ decrease with the increase in temperature ${ }^{12}$. It may be then speculated that the true activation energy may be higher than $10 \mathrm{kcal} / \mathrm{mol}$ which validates the chemical reaction controlled mechanism assumed in writing Equation 7-1.

The leaching data for mercury which are given in Figure 6-2 are plotted according to Equation 7-4 and shown in Figure 7-4. It is seen that the plots produce good straight lines.

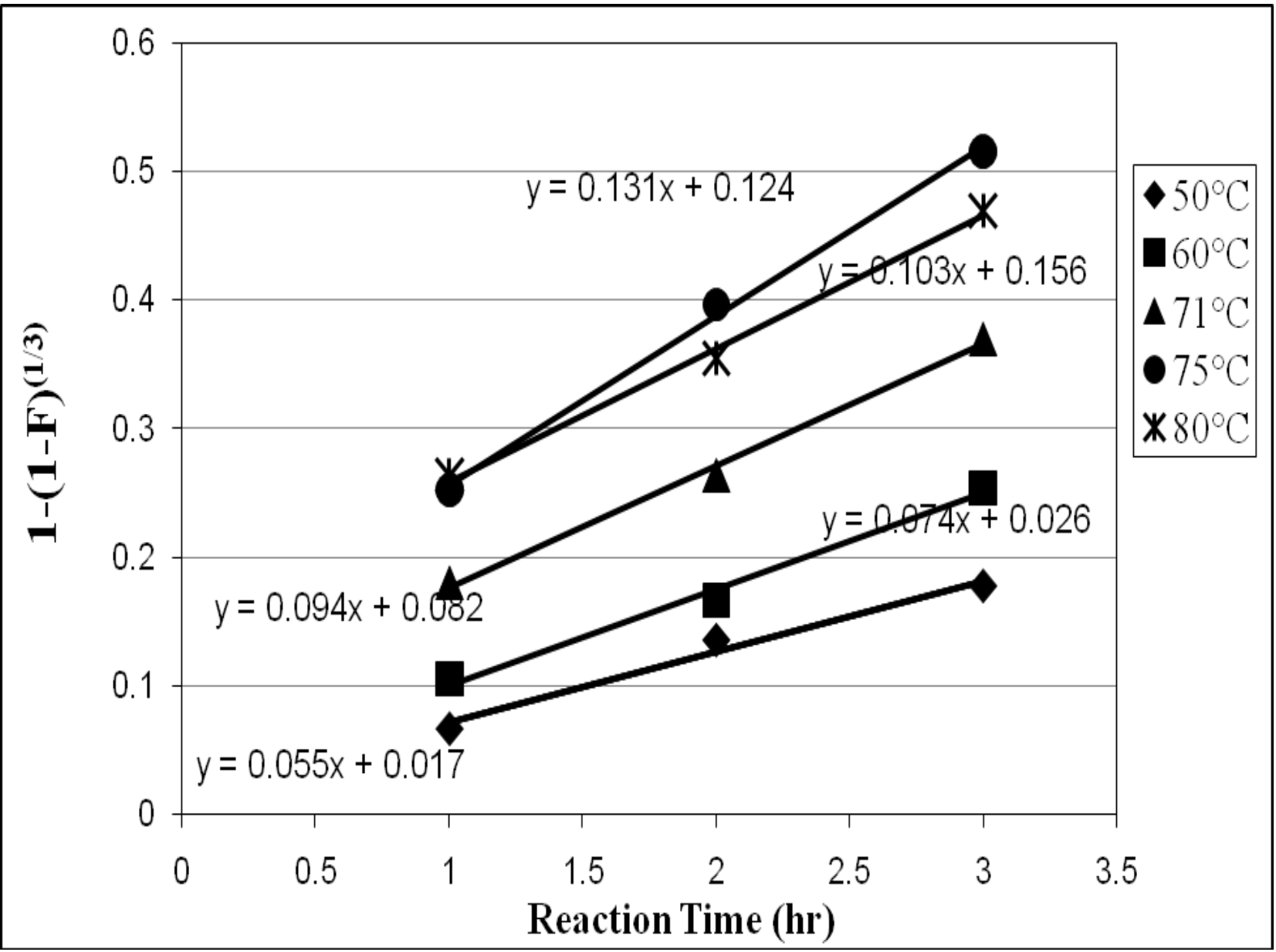

Figure 7-4 Plot of [1-(1-F) 1/3] versus time at various temperatures, $\mathrm{pH} 5.7$ for mercury removal for Pittsburgh No.8 Coal (1000 ppm SO, $10 \% \mathrm{O}_{2}$ ) 
The slope of each line will be $k_{2}$ and the values of the apparent rate constants obtained from above plot are tabulated in the Table 7-2. It can be seen that the above lines do not pass through the origin which is due to the different forms of mercury like $\mathrm{HgO}, \mathrm{HgS}$ and organic mercury in the coal. Since the leaching rate of each of these species is unknown, further discussion is not possible.

Table 7-2 Rate Constant Values for Mercury Leaching

\begin{tabular}{|c|c|c|}
\hline Serial No. & Temperature $\left({ }^{\circ} \mathrm{C}\right)$ & Rate Constant $\left(\mathrm{k}_{1}\right)(1 / \mathrm{hr})$ \\
\hline 1. & 50 & $5.5 \times 10^{-2}$ \\
\hline 2. & 60 & $7.4 \times 10^{-2}$ \\
\hline 3. & 70.5 & $9.4 \times 10^{-2}$ \\
\hline 4. & 75 & $10.3 \times 10^{-2}$ \\
\hline 5. & 80 & $13.1 \times 10^{-2}$ \\
\hline
\end{tabular}

The Arrhenius plot was made using $\mathrm{k}_{2}$ values and shown in Figure 7-5. The apparent activation energy was $7.1 \mathrm{kcal} / \mathrm{mol}$ or $59.2 \mathrm{~kJ} / \mathrm{mol}$. This energy represents the temperature effect for leaching rates of all the mercury species. However, the true activation energy should be higher than this value because the solubility of $\mathrm{SO}_{2}$ and $\mathrm{O}_{2}$ decreases as temperature increases. Again, it can be speculated that the true activation energy becomes higher than $10 \mathrm{kcal} / \mathrm{mol}$, which may validate the chemical reaction controlled mechanism assumed in writing equation 7-1. So for $k_{1}$ and $k_{2}$, these are the temperature effects not only from the intrinsic rate constant but also from the temperature dependence of the solubilities of the $\mathrm{SO}_{2}$ an $\mathrm{O}_{2}$ in solution. These can't be separated in this study. 


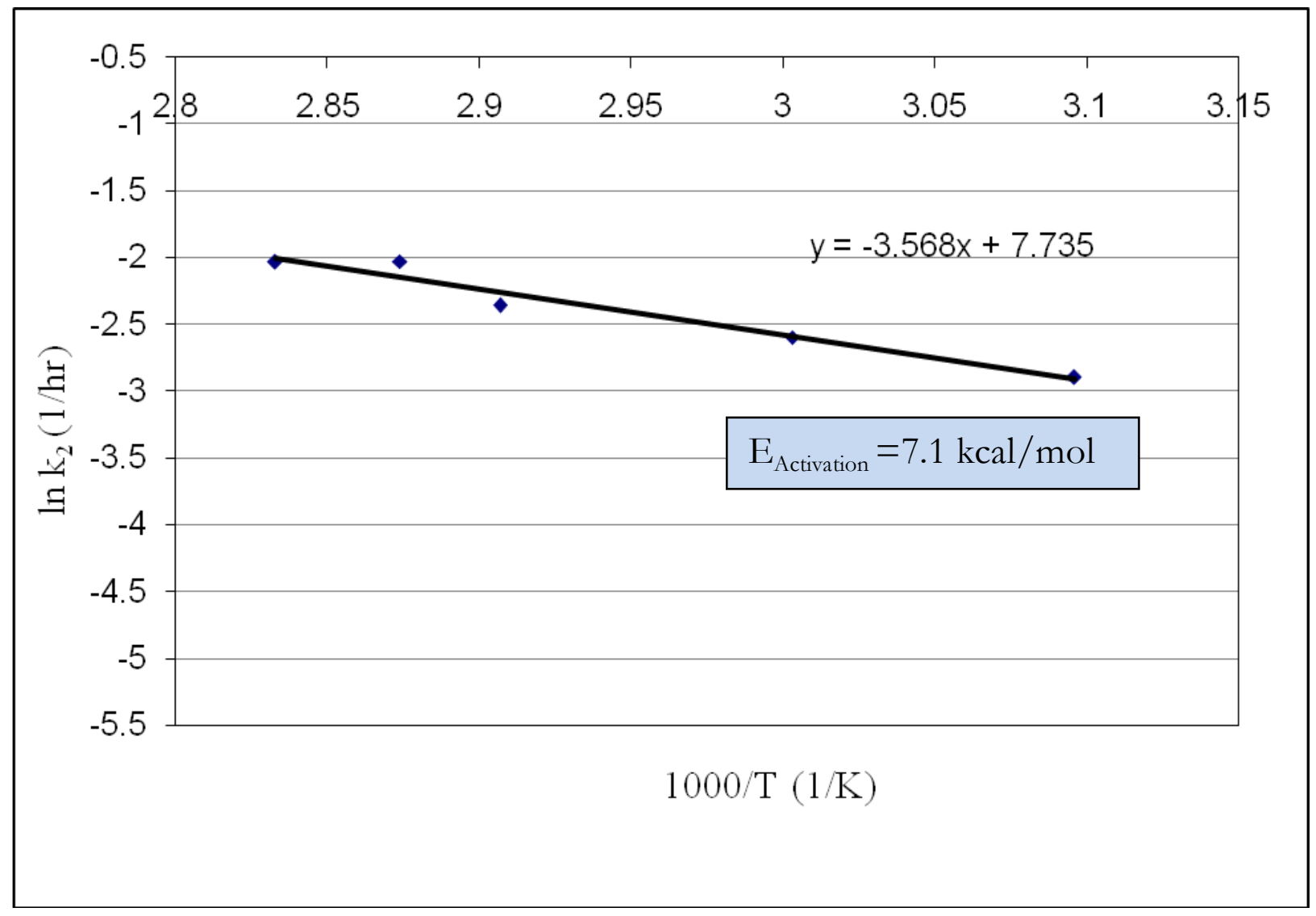

Figure 7-5 Arrhenius Plot for leaching of Mercury for Pittsburgh No.8 Coal at pH 5.7 (1000 ppm $\mathrm{SO}_{2}, 10 \% \mathrm{O}_{2}$ ) 


\subsection{Illinois No.6 Coal}

Figure 7-6 presents plots according to Equation 7.4 for leaching data of mercury which are given in Figure 6-8. It is clear that each plot is linear.

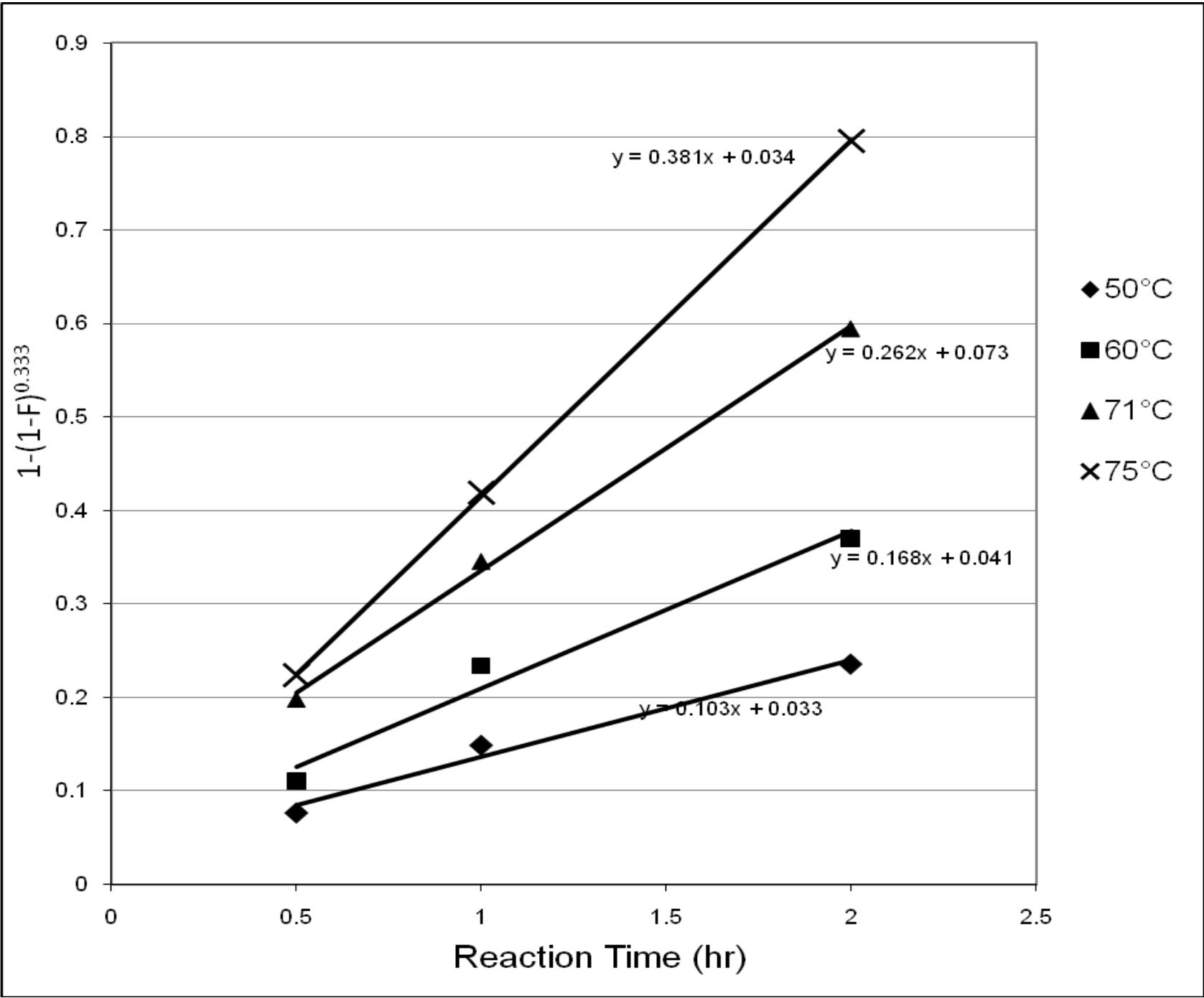

Figure 7-6 Plot of [1-(1-F) 1/3] VS time at various temperatures for Mercury removal for Illinoi No.6 Coal at pH 5.7 (1000 ppm SO, $10 \% \mathrm{O}_{2}$ )

The slope of each line will be $\mathrm{k}_{2}$ and the values of rate constants obtained from above plot are tabulated in the Table 7-3. 
Table 7-3 Rate Constant Values for Mercury Leaching

\begin{tabular}{|c|c|c|}
\hline Serial No. & Temperature $\left({ }^{\circ} \mathrm{C}\right)$ & Rate Constant $\left(\mathrm{k}_{2}\right)(1 / \mathrm{hr})$ \\
\hline 1. & 50 & $10.3 \times 10^{-2}$ \\
\hline 2. & 60 & $26.8 \times 10^{-2}$ \\
\hline 3. & 70.5 & $38.1 \times 10^{-2}$ \\
\hline 4. & 75 & \\
\hline
\end{tabular}

An Arrhenius plot is made with the $\mathrm{k}_{2}$ values and shown in Figure 7-7.

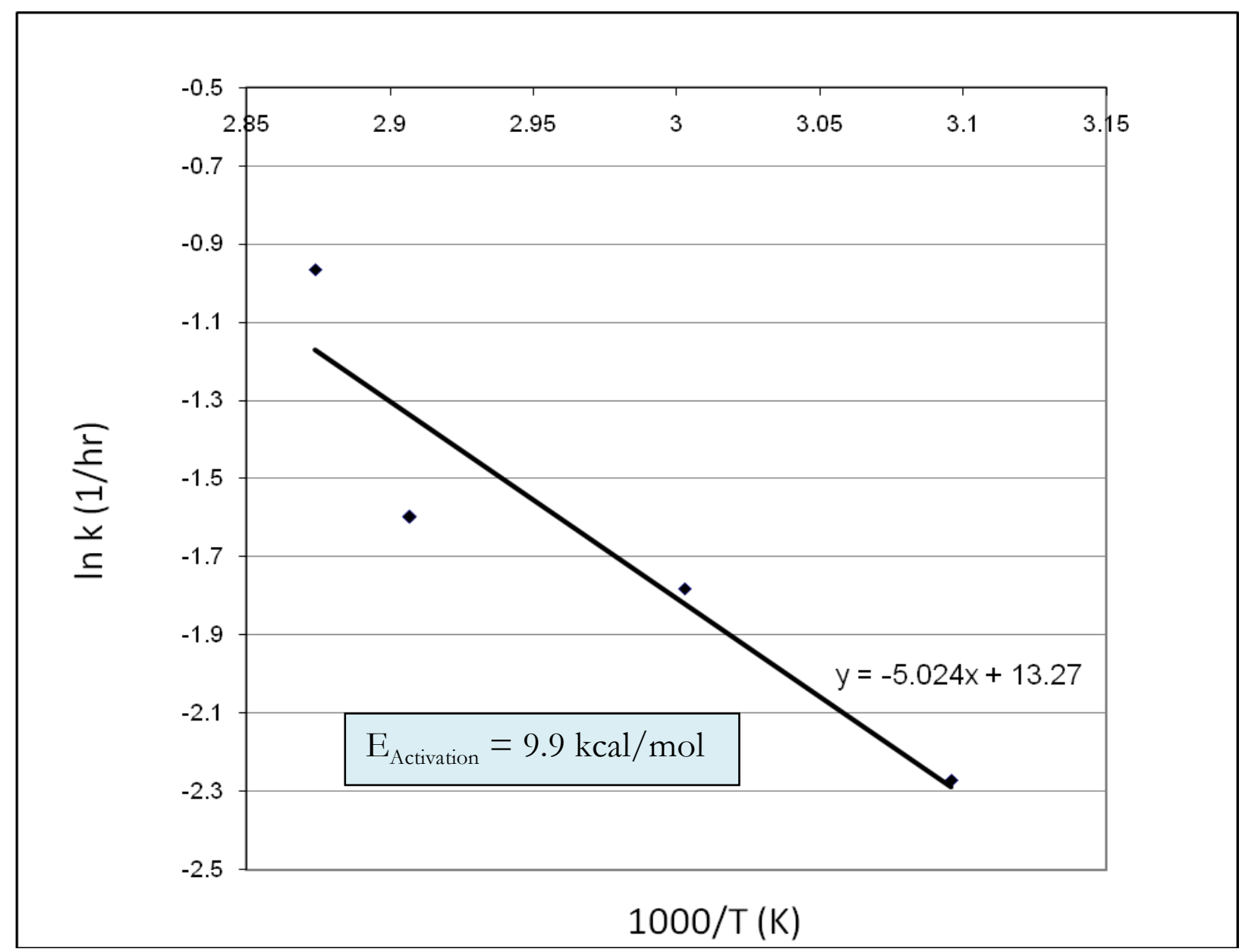

Figure 7-7 Arrhenius Plot for Leaching of Mercury for Illinois No.6 Coal at pH $5.7(1000$ ppm SO , $\left.10 \% \mathrm{O}_{2}\right)$ 
From the slope, the apparent activation energy was calculated and this was found to be $9.9 \mathrm{kcal} / \mathrm{mole}$ or $41.7 \mathrm{~kJ} / \mathrm{mol}$. It is important to note that the true activation energy may be higher than the apparent activation energy of $9.9 \mathrm{kcal} /$ mole determined in this study. This may be because the solubility values of $\mathrm{SO}_{2}$ and $\mathrm{O}_{2}$ decrease with increasing temperatures ${ }^{9}$ as shown in Figure 2-3. So for this reason, the high temperature points are off the line in above plot. Nonetheless the magnitude of this activation energy validates the chemical reaction controlled mechanism assumed in writing Equation 7-2.

\subsection{Cost Estimation:}

A rough cost analysis for this process was done in order to verify its technical feasibility for the commercial applications. One ton of coal has $0.0004 \mathrm{lb}$ of mercury if it contains $0.2 \mathrm{ppm}$. If the cost of coal leaching is estimated at $\$ 4 /$ ton (from enhanced conventional technologies) at $85 \%$ mercury removal, the cost of mercury removal would be $\$ 11,764 / \mathrm{lb}$ of mercury removed. This figure is significantly lower than the activated carbon injection technology cost which is around $\$ 33,000 / \mathrm{lb}$

of mercury removed. Also the present study removes $\mathrm{SO}_{2}$ from flue gas, by using it as a reducing agent in combination with $\mathrm{O}_{2}$ to leach mercury from coal.

If a process is developed using this technology, it might as well function as stack gas desulfurization. In other words, the process will serve double purposes of removal of mercury from coal and $\mathrm{SO}_{2}$ from flue gas. Hence from the results here, the technique looks promising \& requires further research and study. 


\section{SUMMARY:}

1. The oxidizing power of the combination of $\mathrm{SO}_{2}$ and $\mathrm{O}_{2}$ is strong enough to leach much of the mercury content from the coal. The mercury removal increased from $44.2 \%$ at $50^{\circ} \mathrm{C}$ to $88.6 \%$ at $75^{\circ} \mathrm{C}$ at $\mathrm{pH}$ of 5.7 and after 3 hours of reaction time for Pittsburgh No.8 Coal. In the case of Illinois No.6 Coal, the removal percentages increased from $55.5 \%$ at $50^{\circ} \mathrm{C}$ to $99.2^{\circ}$ at $75^{\circ} \mathrm{C}$, pH 5.7 and 2 hours of reaction time under the conditions of $1000 \mathrm{ppm} \mathrm{SO}_{2}$ and $10 \% \mathrm{O}_{2}$.

2. The pyrite removal percentages were much lower than that of mercury removal percentages.

3. Both the mercury and pyrite removals increased as the $\mathrm{pH}$ decreased at $71^{\circ} \mathrm{C}$.

4. The pyrite removal percentages were only $1.2 \%$ at $\mathrm{pH} 5.7$ and increased much to $20.4 \%$ at $\mathrm{pH} 1.25$ at 2 hours and $71^{\circ} \mathrm{C}$ with the gas stream of $2000 \mathrm{ppm} \mathrm{SO}_{2}$ and $10 \% \mathrm{O}_{2}$ in the case of Illinois No.6 coal.

5. A significant amount, as much as $75 \%$ of the original mercury, is acid soluble.

6. The k units of both the pyrite and mercury removals were modeled successfully by means of a simple shrinking core model.

7. In Pittsburgh No.8 Coal, the apparent activation energy for pyrite removal was $9.8 \mathrm{kcal} / \mathrm{mole}$ and that for mercury removal was $7.1 \mathrm{kcal} / \mathrm{mole}$. In Illinois No.6 Coal, the apparent activation energy for mercury removal was $9.9 \mathrm{kcal} / \mathrm{mole}$. The pyrite removal percentages were very low for Illinois No.6 Coal.

8. The optimum conditions for maximum mercury removal were high temperature and low $\mathrm{pH}$ i.e., at $75^{\circ} \mathrm{C}$ and at $\mathrm{pH}$ of around 1.25 with $1000 \mathrm{ppm} \mathrm{SO}_{2}$ and $10 \% \mathrm{O}_{2}$.

9. This leaching scheme is feasible to be used in a commercial process because high removal percentages of mercury can be achieved under moderate conditions. Some flue gas desulfurization can also be achieved with this process. 


\section{SAFETY CONSIDERATIONS}

- Always wear well protective equipments for eyes, hands and body. For eye-protection, the safety glasses, tightly sealed goggles, should be used. For hands suitable gloves and the body should be covered by lab coat.

- The selection of suitable gloves not only depends on the type of material but also on quantity. Depending on the type of chemical materials, different types of gloves are used such as leather palm gloves, support vinyl gloves, latex exam gloves.

- Open toe shoes and shorts should not be worn as they leave a person too vulnerable if there is a spill. Always use proper lab coat and shoes.

- Always avoid inhalation of chemicals or contact of chemicals with skin or clothing. Operation should be always carried out in an efficient fume hood or equivalent system.

- Chemicals should be always stored in proper conditions.

- Always use fire fighting measures which the suit environment and take into account other materials which may be involved. In general water based extinguishers should not be used for fire involving organic materials. Always use carbon dioxide.

- Cylinders must be kept away from sources of heat.

- Keep valve protective caps in place when the cylinder is not in use.

- Compressed gas cylinders should be secured firmly at all times. A clamp and belt or chain, securing the cylinder between "waist" and "shoulder" to a wall, are generally suitable for this purpose.

- Sulfur dioxide $\left(\mathrm{SO}_{2}\right)$ is a colorless gas with a characteristic, irritating, pungent odor that is also liquid when below $14^{0} \mathrm{~F}$ for many industrial applications. It reacts with water to form sulfurous acid and is highly dangerous in this state. Accidental exposure to sulfur dioxide in the workplace can have severe and life-threatening consequences. So $\mathrm{SO}_{2}$ cylinders should be tightly secured and checked regularly for leaks. 
- Sulfur dioxide is an allergen to which some consumers are sensitive. $\mathrm{SO}_{2}$ is associated with increased respiratory symptoms and disease, difficulty in breathing, and premature death. 


\section{FUTURE WORK}

The present work studied all the possible effects of temperature, $\mathrm{pH}$, concentrations of $\mathrm{SO}_{2}$ and $\mathrm{O}_{2}$ on removing mercury from Pittsburgh No.8 and Illinoi No.6 Coals. This study can further be extended to study these effects on various other types of coal. Also this research can be extended to study the leaching rates of other forms of mercury like $\mathrm{HgO}, \mathrm{HgS}$ etc. 


\section{REFERENCES}

\section{1. http://www.epa.gov/camr/basic.htm}

2. U.S. Environmental Protection Agency, 1999 National Emissions Inventory for Hazardous Air Pollutants.

\section{3. http://people.uwec.edu/piercech/Hg/mercury water/cycling.htm}

4. Hoffman, J.; and Brown, J. R. Preliminary Cost Estimate of Activated Carbon Injection for Controlling Mercury Emissions from an Un-Scrubbed 500 MW Coal-Fired Power Plant. Final Report to US DOE/NETL (Innovations for Existing Plants Programs) by Science Applications International Corporation. November 2003.

5. Luttrell, G. H.; Yoon, R. H.; and Adel, G. T. Precombustion Removal of Hazardous Air Pollutant

Precursors. 1997 Coal Liquefaction and Solid Fuels Contractors Review Conference - Hazardous Air Pollutant Precursor Control; Pittsburgh, FETC/DOE.

6. Rosandale, L. W.; Devito, M. S.; Conrad, V. B.; and Meenan, G. F. The Effect of Coal Cleaning on Trace Element Concentrations. 1993, an internal document, CONSOL Inc., Research and Development, 4000 Brownsville Road, Library, PA 15129.

7. Sundaram, H. P.; and Cho, E. H.; and Miller, A.. SO2 Removal by Leaching Coal Pyrite. Energy \& Fuels, 2001, 15(2); 470-476.

8. http://www.tva.gov/environment/air/ontheair/images/mercury

9. http://oceanworld.tamu.edu/resources/oceanography-book/Images/exposurea.gif

10. Lange's Handbook of Chemistry, Eleventh ed.; Dean J. A.., ed.; McGraw-Hill: New York, 1973, $5-53$.

11. Lange's Handbook of Chemistry, Eleventh ed.; Dean J. A.., ed.; McGraw-Hill: New York, 1973, 10-7.,

12. Adams,R. W.; Mattew, I.G. Leaching of sulfide concentrates at atmospheric pressure using $\mathrm{SO}_{2}$ and $\mathrm{O}_{2}$ mixture. Proc. Aust. Inst. Min. Metall. 1981, 280, 41-52. 
13. Cho, E.H.; chang, K.H.; Rollins R.R. A kinetic study of leaching of coal pyrite with nitric acid. Metall. Mater. Trans. B 1983, 14, 317-324.

14. http://www.osti.gov/bridge/servlets/purl/834570-Co4rvJ/native/834570.PDF

15http://www.netl.doe.gov/technologies/coalpower/ewr/pubs/DOENETL_HgR\&D_WhitePape r_Final.pdf

16. Energy Futures and Urban Air Pollution: Challenges for China and the United States. 2007, 195.

17. http://epa.gov/mercury/pdfs/OAR-2002-0056-0043.pdf

18. http://en.wikipedia.org/wiki/Flue gas

19. http://www.habmigern2003.info/4 what-is-flue-gas.html

20.

http://www.anl.gov/PCS/acsfuel/preprint $\% 20$ archive/Files/45 3 WASHINGTON\%20DC 08$\underline{00 \text { 0431.pdf }}$

21. Keating, M.H., et al. Mercury Study Repor7 to Congress, Volume 1: Executive Summary, EPA452!R-97-003, December 1997.

22. Stein, E.D., Cohen, Y., and Winer, A.M. Critical Rev. Environ. Sci.TechnoL, 1996.26, 1-43.

23. Pai, P., Karamchandani, P., and Seigneur, C. "Uncertainties in Modeling Long-Range Transport and Fate of Mercury Emissions in North America," presented at EPRI Managing Hazardous Air Pollutants, Fourth International Conference, Washington, DC, November 12-14, 1997.

24. Meij, R. (1994), Fuel Processing Technology 391994

25.http://www.atsdr.cdc.gov/mhmi/mmg116.html. 
26.http://en.wikipedia.org/wiki/Sulfur dioxide.

27.http://www.epa.gov/apti/bces/module4/absorption/pp answer/p answer.htm

28.http://www.lenntech.com/periodic/water/oxygen/oxygen-and-water.htm\#ixzz11XbCo9GP

29. Pradyot Patnaik, "Handbook of Inorganic Chemistry",7782-44-7,674-679. 